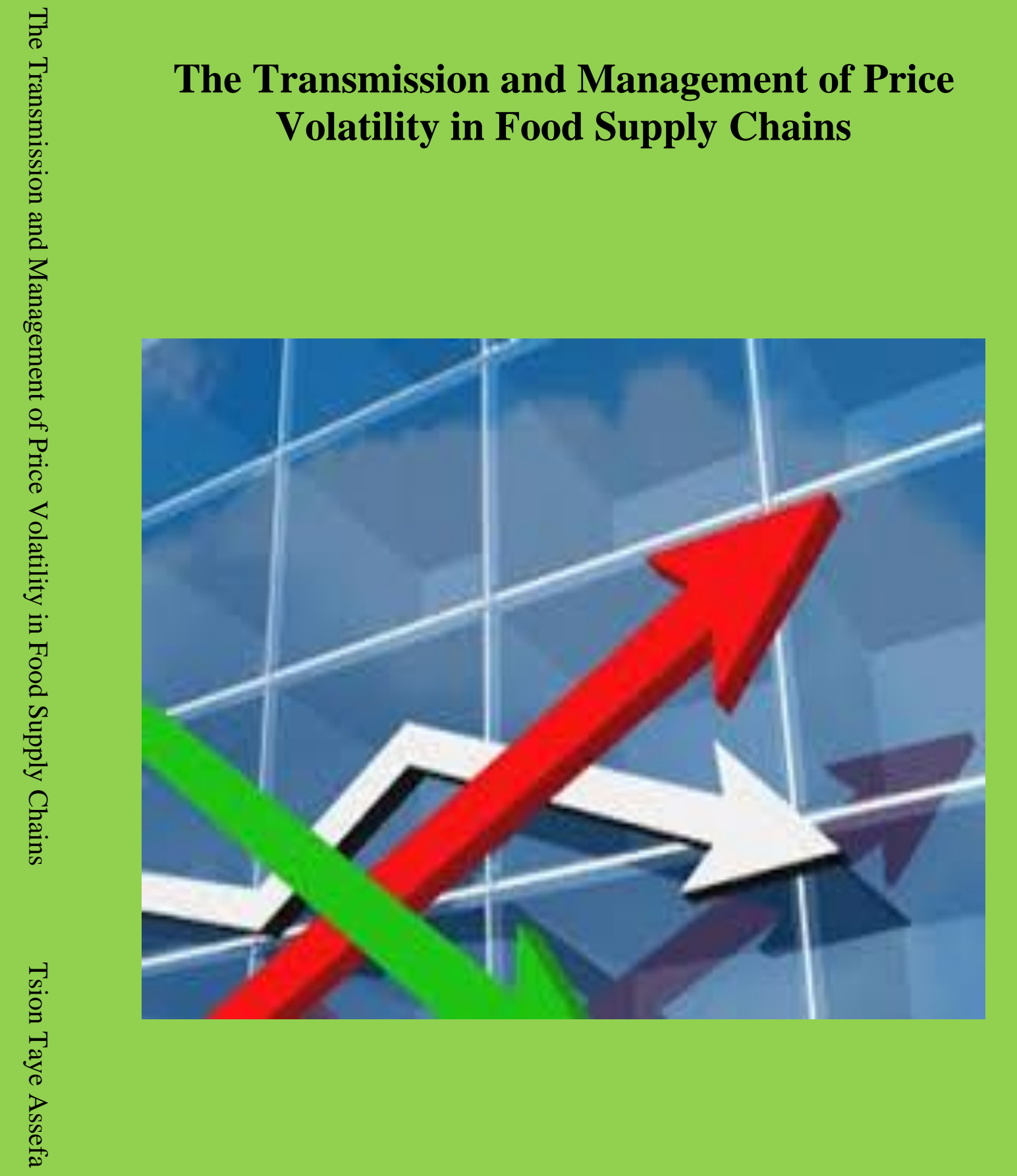

Tsion Taye Assefa

$\stackrel{\circ}{a}$ 
The Transmission and Management of Price Volatility in Food Supply Chains

Tsion Taye Assefa 


\section{Thesis committee}

\section{Promotor}

Prof. Dr Alfons G.J.M Oude Lansink

Professor of Business Economics

Wageningen University

\section{Co-promotor}

Dr Miranda P.M. Meuwissen

Associate professor, Business Economics

Wageningen University

\section{Other members}

Prof. Dr J.M.E Pennings - Wageningen University

Dr D. Drabik - Wageningen University

Dr M.A.P.M van Asseldonk - Wageningen Economic Research

Prof. S. McCorriston - University of Exeter

This research was conducted under the auspices of the Graduate School of Wageningen School of Social Sciences (WASS) 


\title{
The Transmission and Management of Price Volatility in Food Supply Chains
}

\author{
Tsion Taye Assefa
}

\section{Thesis}

Submitted in fulfilment of the requirements for the degree of doctor at Wageningen University by the authority of the Rector Magnificus

Prof. dr.ir. Arthur P.J. Mol, in the presence of the Thesis Committee appointed by the Academic Board to be defended in public on Wednesday December $21^{\text {st }} 2016$ at 4 p.m. in the Aula 
Tsion Taye Assefa

The Transmission and Management of Price Volatility in Food Supply Chains

$\mathrm{PhD}$ thesis, Wageningen University, Wageningen, NL (2016)

With references, with summary in English

ISBN: 978-94-6257-983-5

DOI: http://dx.doi.org/10.18174/393612 


\begin{abstract}
The 2006-2011 period has been marked by increased volatility in food an agricultural commodity prices at a global level. In the EU, the continuous liberalization of agricultural markets under the Common Agricultural Policy has led to the exposure of EU agricultural to increasing market price volatility. This thesis has investigated the transmission and management of price volatility in EU food supply chains. The transmission of price volatility in various food supply chains is first investigated through a literature review followed by an empirical analysis of price volatility transmission in the case of the German fresh pork supply chain. The effect of market power was also taken into account in the latter empirical analysis. Next, the management of price volatility was investigated through interviews conducted with actors of selected EU food supply chains. This was followed by the analysis of the effectiveness of selected price volatility management strategies. Lastly, in light of the policy support for agricultural insurance within the Common agricultural policy, premium rates of an agricultural revenue insurance contract were calculated for the Dutch ware potato sector.

One of the gaps identified in the reviewed literature is the lack of attention given to the effects of contextual factors on price volatility transmissions in food supply chains. Contextual factors include market power in the chain and pricing strategies (e.g. contracts) by chain actors. Results of the price volatility transmission analysis conducted in this thesis in the case of the German pork chain show that retail market power limited both the transmission of price levels and price volatility. This thesis shows that price volatility is perceived as risky by all actors in the food supply chain. Deviations of prices by more than 10 to $15 \%$ from expected levels were perceived as price volatility by a majority of the chain actors. Results further show that price volatility management strategies in EU food chains are diverse and well beyond traditional instruments such as futures and forward contracts. Contrary to expectations, price fixing contracts were not found to be desirable by interviewed chain actors. This thesis also found that the effectiveness of contracts in reducing price volatility depended on how the contract price was set.
\end{abstract}

Results of this thesis further show that premium rates of a revenue insurance contract for the Dutch ware potato sector across categories of farms. The average premium rates calculated were $32.1 \%$, $22.2 \%, 33.1 \%$ and $24.0 \%$ on guaranteed revenue per hectare for the high expected yield, low expected yield, high yield variance to expected yield ratio and low yield variance to expected yield ratio categories of farm, respectively. The difference in premium rates across categories of farms implies that charging the same average premium rate to all Dutch ware potato farms can lead to adverse selection.

Keywords: Price volatility, management strategies, price volatility transmission, EU food chains, market power, agricultural revenue insurance 



\section{Table of Contents}

Chapter 1 - General introduction ..................................................................................................... 1

Chapter 2 - Price volatility transmission in food supply chains: A literature review .................... 11

Chapter 3 - Price volatility transmissions and market power in the German fresh pork supply

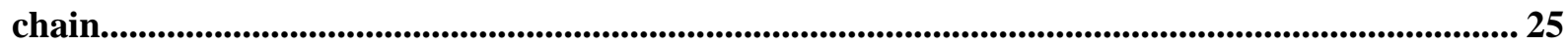

Chapter 4 - Price risk perceptions and management strategies in selected European food supply chains: An exploratory approach................................................................................................................ 46

Chapter 5 - The effectiveness of price volatility management strategies in food supply chains .. 71

Chapter 6 - Revenue insurance premium rates accounting for farm heterogeneity: The case of the Dutch ware potato sector........................................................................................................................... 87

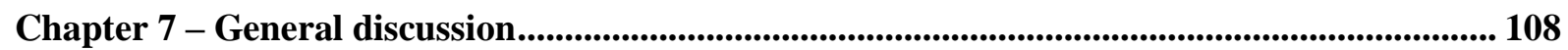

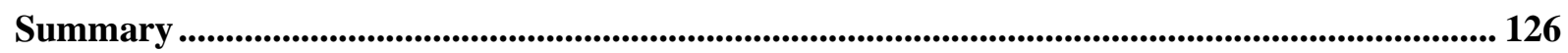

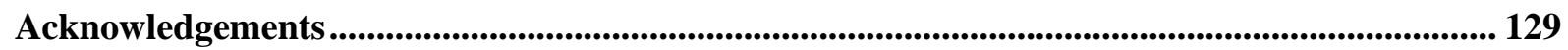

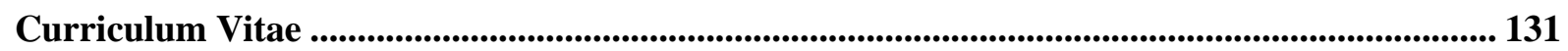

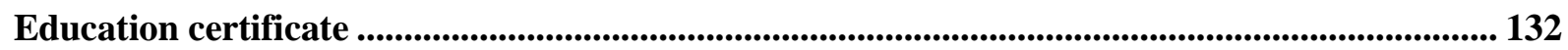



Chapter 1

General introduction 


\subsection{Background}

In the last decade, price volatility increased at a global level due to demand booming and supply slowing factors (Rabobank, 2011). In the EU, the recent rise of volatility in international agricultural commodity prices has intensified the debate about risk related agricultural policies. Such debate was already underway in response to increasing volatility of agricultural prices as a result of successive reforms of the CAP, since the early 1990s, which have led to the exposure of EU domestic prices to international price signals (Tangermann, 2011). Market measures under the CAP such as border protection through import barriers, export subsidies, production quotas and intervention buying have traditionally kept EU agricultural prices at high and stable levels (Bardaji et al., 2011; Tangermann, 2011). The mounting pressure of such market interventions on the EU budget and the increasing tensions with the EU's trading partners have led to the CAP reforms in 1992 and 2003 which gradually shifted the policy from market interventions to decoupled single farm payments and opened up the EU to international markets (Sckokai and Moro, 2009; Tangermann, 2011). However, the Single Farm Payment Scheme, even though proven to be a powerful income stabilization tool (Bardaji et al., 2011), does not reduce the price risk faced by farmers (Tangermann, 2011). Yield volatility has also increased in the EU as a result of recurrent extreme weather events and more regulated uses of herbicides, medicines and vaccines (Meuwissen et al., 2011; Severeni and Cortignani, 2011) thereby subjecting EU farmers to income volatility.

\subsection{Problem statement}

Price volatility has undesirable consequences at all stages in the food supply chain. Farmers may react to price volatility by reducing output supply and investments in productive inputs (Seal and Shonkwiler, 1987; Rezitis and Stavropoulos, 2009; Sckokai and Moro, 2009; Piot-Lepetit, 2011; Tangermann, 2011; Taya, 2012). Furthermore, agricultural input price volatility exposes the downstream sector of food supply chains to sourcing uncertainties, forcing food and agricultural companies to alter their sourcing strategies as a coping mechanism (Rabobank, 2011). Unexpected price increases also pose food security risks, particularly to consumers who spend a large share of their income on food items (Hernandez et al., 2013). All this implies that managing the risk from price volatility is necessary for the smooth functioning of food supply chains.

Managing the risk from price volatility requires an understanding of the extent to which price volatility transmits in the chain. This is because the level of price volatility faced by a chain actor may not only depend on the price volatility that originated in his/her own market but also on the price volatility that is transmitted from other stages of the chain. Knowledge of price volatility transmission in chains can, among others, improve price volatility forecasts in own market (Apergis and Regitis, 2003; Buguk et al., 2003), allow cross-hedging in futures markets (Buguk et al., 2003) and support policy makers in identifying the chain stages that are major sources of price volatility in the chain. Currently, the literature concerned about price linkages in the chain focuses mainly on price (level) transmission with limited attention given to price volatility transmission in the chain. While the former type of transmission refers to the transmission of predictable price changes, the latter type refers to the transmission of unpredictable price changes in the chain. The limited interest of researchers in price volatility transmission may be due to an implicit assumption that the transmission of price levels implies the transmission of price volatility, and vice versa. Research has however shown that that may not be the case. For instance, Natcher and Weaver (1999) detected volatility transmission from the feeder and live cattle market to the beef wholesale market, while no-short run causality in price levels 
could be detected for the same markets. Another example is Serra (2011) who found no short-run causality between farm and retail beef price levels, while she found volatilities in these two prices to co-vary although the covariance was regime dependent.

In the price (level) transmission literature, several factors were shown both empirically and theoretically to affect the degree of price transmission. The factors include the degree of market power in the chain, menu costs in changing prices, and inventory strategies of firms (e.g. First-in-first out, First-in-first out) (see the review by Meyer and Von Cramon Taubadel, 2004). The most prominent factor is however the degree of market power in the chain (Meyer and Von Cramon Taubadel, 2004). Firms are shown to use market power to asymmetrically transmit output and input price changes or to keep output prices rigid in response to input price changes (Meyer and Von Cramon Taubadel, 2004; Weber and Anders, 2007). The effect of market power on price transmission has often raised concerns among policy makers due to its negative implication on the distribution of welfare among actors in the chain (Griffith and Piggott, 1994). For instance, price related measures designed to decrease the cost of production of farms through subsidies may not benefit consumers if retailers use market power to keep consumer prices irresponsive to decreases in producer prices (Girapunthong, 2003). Although it is argued in the price volatility transmission literature that market power also reduces the transmission of price volatility in the chain (for example, in Serra (2011) and Rezitis (2012)), such an effect remains unexplored both theoretically and empirically. Exploring the effects of market power on price volatility transmission is also of policy interest. For instance, a negative effect of retail market power on the transmission of farm price shocks to consumers may imply a squeeze in the margin of the processor who is unable to transmit farm price shocks to the retailer. Such an effect in turn provides support for a more competitive retail market.

Although price volatility may transmit in the chain and therefore may expose all actors in the chain to price risk, the price volatility management strategies of actors beyond the farm stage are not covered in the current literature. The current literature focuses on the farm sector (see for instance Meuwissen et al. (2001), Hall et al. (2003), Greinier et al. (2009), and Bergfjord (2009) for studies investigating price volatility perceptions and adoption of management strategies, and Neyhard et al. (2013), Manfredo et al. (2003) and Bielza et al. (2007) for studies investigating the effectiveness of price volatility management strategies). The focus on the farm sector may be reasonable given the fact that the farm sector has limited control over prices due to its atomic structure, the time lags in farm production and the undifferentiated nature of farm products which prevents farmers from influencing the level and degree of variability of price. These factors combined may make farmers the most vulnerable actors to price volatility. Nevertheless, given that price volatility can affect not only farmers but also other chain actors, exploration of strategies from the farm stage to the rest of the chain is necessary. Another limitation of the current agricultural risk management literature is that it focuses on few farm instruments that include forward contracts, derivative markets (i.e. futures and options), insurance and income diversification (for instance in Martin 1995, Meuwissen et al. 2001, Hall et al. 2003, Bergfjord 2009). The structured types of questionnaires used in large scale surveys, which prespecify a list of traditional strategies, may have contributed to the focus on a limited number of strategies. In this regard, exploring chain actors' price volatility management strategies through openended in-depth interviews is necessary. Such an approach is not only useful in identifying a wider set of strategies, but also to have a deeper understanding of actors' perception of price risk. Knowledge of actors' price risk perceptions can in turn explain the choice of actors' management strategies.

In an era of an increasingly liberalized EU agricultural market, new instruments supporting chain actors to better manage the risk from price volatility may be needed. An area of policy support worth considering is the launching of revenue insurance schemes for EU farmers. Unlike chain stages 
beyond the farm stage (i.e. wholesalers, processors, retailers) with better control over supply, farmers are not only exposed to price volatility but also to yield volatility. Given the European Commission's recognition of the need to subsidize EU farmers' income insurance (Severeni and Cortignani, 2011; Perez Blanco et al., 2014), exploring practical issues related to the launching of revenue insurance schemes is of interest. The problem of adverse selection is one of the most important issues that need to be addressed when considering the implementation of any insurance scheme. Adverse selection arises when farms with higher risk levels constitute a major share of the insurance pool because farms have more detailed information about their risks of loss than the insurer (Bielza et al., 2007). In such a situation, assessing farms' risk levels and charging premium rates commensurate with risk levels can be a solution to deal with adverse selection.

\subsection{Research objectives}

The general objective of this thesis is to examine the transmission and management of food price volatility in food supply chains. The sub-objectives are the following:

1. To review the existing price volatility transmission literature in food supply chains and identify the research gaps.

2. To investigate the effect of market power on price volatility transmission in the food supply chain.

3. To explore the price risk perceptions and management strategies of actors in food supply chains.

4. To design a method for evaluating the effectiveness of price volatility management strategies in reducing the price volatility faced by food supply chain actors

5. To calculate premium rates of agricultural revenue insurance by taking into account the risk heterogeneity of farms.

The above research objectives are applied to selected food supply chains. Table 1.1 shows the agricultural products, the chain stages and the countries investigated per specific research objective. The chains are selected in such a way that different classes of food products are represented, i.e. meat, dairy, cereals, and vegetables. Both storable and non-storable products are also represented in this thesis. The country-food product combinations assure that the countries for which the selected products have the most economic significance are selected. The Chapters dealing with the whole food supply chain (Chapter 3, 4 and 5) represent the chain stages that handle significant shares of the volume of product flowing through the chains. 
Table 1.1 - Agricultural products, chain stages and countries investigated

\begin{tabular}{|c|c|c|c|}
\hline Chapters & Agricultural product(s) & Country & Chain stage(s) \\
\hline $\begin{array}{l}\text { 2- } \text { Market power } \\
\text { and price } \\
\text { volatility } \\
\text { transmission }\end{array}$ & Fresh pork & Germany & $\begin{array}{l}\text { Farm, slaughterhouse, } \\
\text { retail }\end{array}$ \\
\hline \multirow{6}{*}{$\begin{array}{ll}\text { 3- } & \text { Price risk } \\
\text { perceptions and } \\
\text { management }\end{array}$} & Wheat grain, wheat flour & Bulgaria & $\begin{array}{l}\text { Farm, } \\
\text { processing }\end{array}$ \\
\hline & Wheat grain, wheat flour & France & $\begin{array}{l}\text { Farm, } \\
\text { processing }\end{array}$ \\
\hline & Fresh pork & Germany & Farm, wholesale \\
\hline & Milk, cheese & Netherlands & $\begin{array}{l}\text { Farm, wholesale, } \\
\text { processing, retail }\end{array}$ \\
\hline & Fresh tomatoes & Netherlands & Farm, wholesale \\
\hline & Fresh tomatoes & Spain & Farm, wholesale, retail \\
\hline 4- $\begin{array}{l}\text { Effectiveness of } \\
\text { strategies }\end{array}$ & $\begin{array}{l}\text { Fresh tomatoes } \\
\text { Fresh pork }\end{array}$ & $\begin{array}{l}\text { Spain } \\
\text { Germany }\end{array}$ & $\begin{array}{l}\text { Farm, wholesale } \\
\text { Farm, wholesale }\end{array}$ \\
\hline $\begin{array}{l}\text { 5- } \begin{array}{l}\text { Revenue } \\
\text { insurance }\end{array}\end{array}$ & Ware potatoes & $\begin{array}{l}\text { The } \\
\text { Netherlands }\end{array}$ & Farm \\
\hline
\end{tabular}

${ }^{1}$ Not applicable.

Figure 1.1 illustrates the thesis framework. The chapters address two key issues. These are price volatility transmission in the chain and price volatility management strategies. While price volatility transmission is addressed in two chapters (Chapter 2 and 3), price volatility management strategies are addressed in three chapters (Chapter 4, 5 and 6). The latter three chapters deal with three aspects of price volatility management strategies. Chapter 4 identifies the strategies, Chapter 5 evaluates the effectiveness of strategies and Chapter 6 focuses on the pricing of one management strategy (i.e. revenue insurance) for which premium rates are calculated. While Chapter 2 and 4 address the whole chain, Chapter 3 and 5 focus on the farm and intermediate stages of the chain. Chapter 6 focuses on the farm stage. 


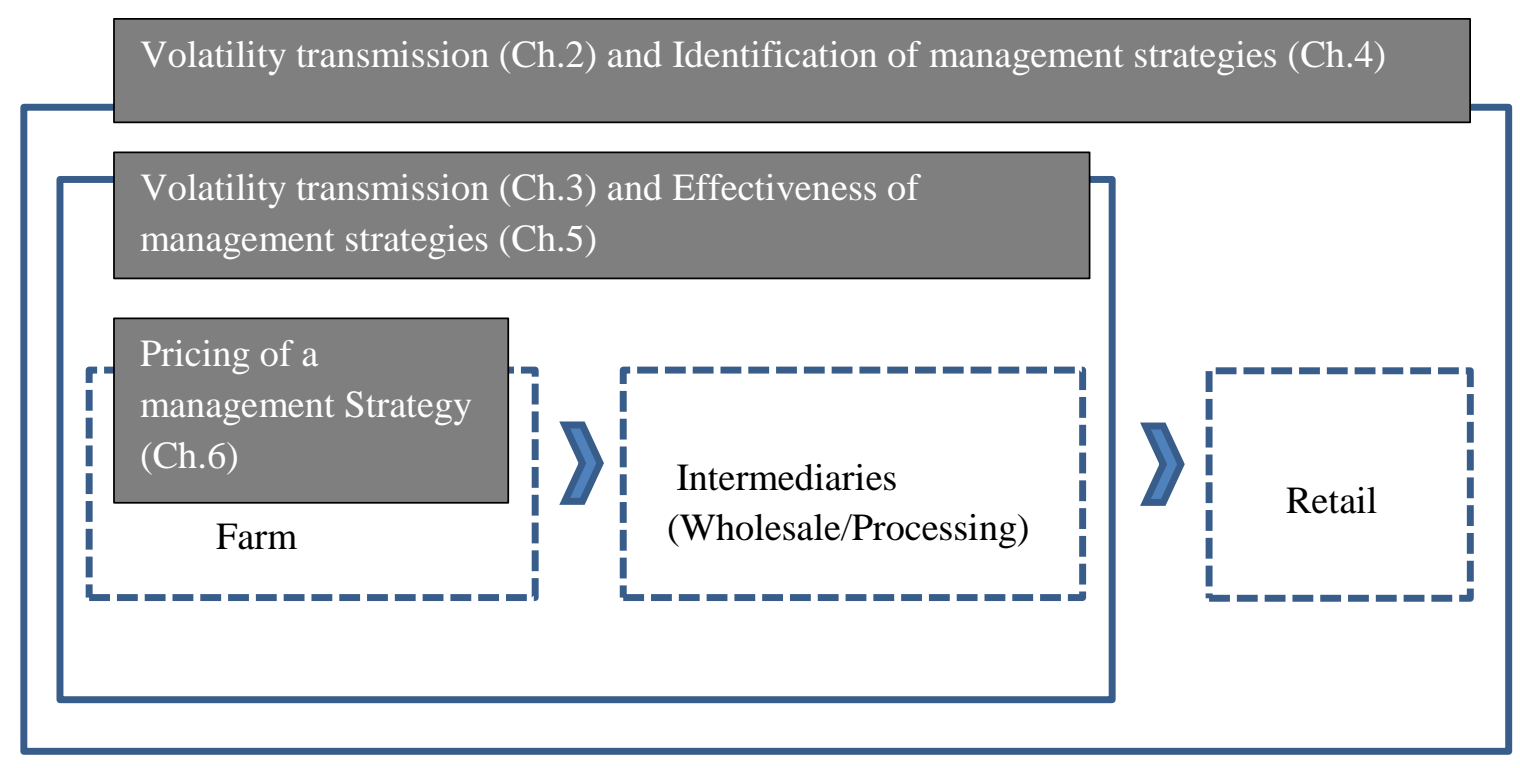

Figure 1.1 - Thesis framework

\subsection{Thesis outline}

This thesis is composed of a general introduction (Chapter 1), five research chapters with each chapter aimed at achieving each of the five research objectives (Chapters 2-6) and a general discussion and main conclusions (Chapter 7).

Chapter 2 reviews the previous literature on price volatility transmission in food supply chains. The review first illustrates the definitional and methodological differences between price transmission and price volatility transmission in food chains. The review then explores methods adopted to investigate price volatility transmission and the data used. It then identifies the research gaps in previous literature and suggests improvements for further research.

Chapter 3 provides evidence of the effects of market power on price volatility transmission in the food supply chain by taking the case of the German fresh pork supply chain. Theoretical models of price transmission and price volatility transmission are first developed to theoretically link both types of transmission with market power. These models are then used to empirically estimate price transmission and price volatility transmission in the German fresh pork chain. A vector error correction model and least square regressions are used for the empirical estimations.

Chapter 4 explores the price risk perceptions and management strategies of food chain actors by conducting interviews with forty-two actors in six EU food supply chains. Price risk perceptions are explored by asking chain actors on percentage price deviations from expected levels which they perceived as price volatility. Actors are then asked about the strategies they use to deal with price risk.

Chapter 5 designs a method for evaluating the effectiveness of strategies in food supply chains. The presented method proposes a way to remove the effects of market power in the chain when attempting to evaluate the effectiveness of strategies in food supply chains. The method uses the percentage price 
deviations defined in Chapter 4 to define triggers of strategy implementation of food chain actors. Strategies identified in Chapter 4 for the Spanish tomato and French wheat farmers and wholesalers are used to illustrate the presented method.

Chapter 6 calculates premium rates of a hypothetical revenue insurance contract for Dutch ware potato farmers. Premium rates are calculated by categorizing farms based on their expected yields and yield variances. These two measures are used because they affect farmers' likelihood of losses and therefore determine farmers' risk levels. Farmers' categorization can in turn help to reduce the problem of adverse selection. Expected yields and yield variances are predicted by estimating a JustPope production function. In premium rate simulations, the dependence between prices and yields is modelled using copulas. 


\section{References}

Apergis, N., and Rezitis, A. (2003). Agricultural price volatility spillover effects: The case of Greece. European Review of Agricultural Economics, 30(3), 389-406.

Bardaji, M., Garrido, A., Iglesias, E., Blanco, M. and Bielza, M. (2011). What market measures in the future CAP after 2013? Retrieved from www.europarl.europa.eu/studies.

Buguk, C., Hudson, D., and Hanson, D. (2003). Price volatility in agricultural markets: An examination of U.S. catfish markets. Journal of Agricultural and Resource Economics, 28(1), 86-99.

Bergfjord, O.J. 2009. Risk perception and risk management in Norwegian aquaculture. Journal of Risk Research, 12 (1), 91-104.

Bielza, M., Stroblmair, J. and Gallego, J. (2007). Agricultural risk management in Europe. Paper prepared for presentation at the $101^{\text {st }}$ EAAE seminar on management of climate risks in agriculture, Berlin, Germany.

FAO, IFAD, IMF, OECD, UNCTAD, WFP, the World Bank, the WTO, IFPRI and the UN HLTF (2011). Price volatility in food and agricultural markets: policy responses. Retrieved from http://www.oecd.org/dataoecd/40/34/48152638.pdf.

Girapunthong, N., Van Sickle, J.J. and Renwick A.W. (2003). Price Asymmetry in the United States Fresh Tomato Market. Journal of Food Distribution Research, 34(3), 51-59.

Greinier, R., Patterson, R., and O. Miller. (2009). Motivations, risk perceptions, and adoption of conservation practices by farmers. Agricultural systems, 99 (2), 86-104.

Griffith, G.R. and Piggott, N.E. (1994). Asymmetry in beef, lamb and pork farm-retail price transmission in Australia, Agricultural Economics, 10 (3), 307-316.

Hall, D.C., Knight, T.O., Coble, K.H., Baquet, A.E., and G.F. Patrick (2003). Analysis of beef producers' risk management perceptions and desire for further risk management education. Review of Agricultural Economics, 25(2), 430-448.

Hernandez, M.A., Ibarra, R., and Trupkin, D.R. (2013). How far do shocks move across borders? Examining volatility transmission in major agricultural futures markets. European Review of Agricultural Economics, 41(2), 1-25.

Manfredo, M., Richards and McDermott (2003). Risk Management Techniques for Agricultural Cooperatives: An Empirical Evaluation. Paper presented at the NCR-134 conference on applied commodity price analysis, forecasting, and market risk management, St. Louis, Missouri.

Martin, S. (1996). Risk management strategies in New Zealand agriculture and horticulture. Review of Marketing and Agricultural Economics, 64(1), 31-44.

Meuwissen, M.P.M, Huirne, R.B.M., and J.B. Hardaker (2001). Risk and risk management: An empirical analysis of Dutch livestock farmers. Livestock Production Science, 69 (1), 43-53.

Meuwissen, M.P.M., Van Asseldonk, M., Peitola, K., Hardaker, B. and Huirne, R. (2011). Income insurance as a risk management tool after 2013 CAP reforms? Paper prepared for presentation at the 
EAAE 2011 Congress on change and uncertainty, challenges for agriculture, food and natural ressouorces, Zurich, Switzerland.

Meyer, J., and von Cramon-Taubadel, S. (2004). Asymmetric price transmission: A survey. Journal of Agricultural Economics, 55(3), 581-611.

Natcher, W.C., and Weaver, R. (1999). The transmission of price volatility in the beef market: A multivariate approach. Paper selected for presentation at the American Agricultural Economics Association annual meeting, Nashville, Tennessee.

Neyhard, J., Tauer, L. and Gloy, B. (2013). Analysis of price risk management strategies in dairy farming using whole-farm simulations. Journal of Agricultural and Applied economics, 42 (2), 313 327.

Perez-Blanco, D., Mysiak, J., Gutiérrez-Martín, C. and de Salvo, M. (2014). What role for income stabilisation insurance in EU agriculture? (Report No. RP0242). The case of the Regione Emilia Romagna in Italy. Retrieved from CMCC website: http://www.cmcc.it/publications/rp0242-whatrole-for-income-stabilisation-insurance-in-eu-agriculture-the-case-of-the-regione-emilia-romagna-initaly.

Piot-Lepetit, I. (2011). Price volatility and price leadership in the EU beef and pork meat market. In Piot-Lepetit, I. and M'Barek, R. (Eds.), Methods to Analyse Agricultural Commodity Price Volatility (pp. 85-106). N.Y., Springer Science and Business Media.

Rabobank (2011). Rethinking the food and agribusiness supply chain; impact of agricultural price volatility on sourcing strategies. Retrieved from http://hugin.info/133178/R/1549493/476482.pdf .

Rezitis, A. and Stavropoulos, K. (2009). Modelling pork supply response and price volatility: The case of Greece. Journal of agricultural and applied economics, 41 (1), 145-162.

Rezitis, A.N. (2012). Modelling and decomposing price volatility in the Greek meat market. International Journal of Computational Economics and Econometrics, 2(3-4), 1757-1189.

Sckokai, P. and Moro, D. (2009). Modelling the impact of the CAP single farm payment on farm investment and output. European review of agricultural economics, 36 (3), 395-423.

Seal, J. and Shonkwiler, J. (1987). Rationality, price risk, and response. Southern journal of agricultural economics, 19 (1), 111-118.

Serra, T. (2011). Food scares and price volatility: The case of the BSE in Spain. Food policy, 36(2), $179-185$.

Serra, T., and Zilberman, D. (2013). Biofuel-related price transmission literature: A review. Energy Economics, 37 (1), 141-151.

Severini, S. and Cortignani, R. (2011). Modeling farmer participation to a revenue insurance scheme by means of positive mathematical programming. Paper prepared for presentation at the EAAE 2011 congress on change and uncertainty challenges for agriculture, food and natural resources, Zurich, Switzerland. 
Tangermann, S. (2011). Risk management in agriculture and the future of the EU's Common Agricultural Policy. Retrieved from http://ictsd.org/downloads/2011/12/risk-management-inagriculture-and-the-future-of-the-eus-common-agricultural-policy.pdf .

Taya, S. (2012). Stochastic model development and price volatility analysis ( OECD food, agricultural and fisheries working papers No. 57). OECD publishing.

Weber, S.A. and Anders, S.M. (2007). Price rigidity and market power in German retailing. Managerial and decision economics, 28 (7), 737-749. 


\section{Chapter 2}

\section{Price volatility transmission in food supply chains: A literature review}

Tsion Taye Assefa, Miranda P.M. Meuwissen, Alfons G.J.M. Oude Lansink Published in Agribusiness 31 (1), 3-13 


\begin{abstract}
:
This paper reviews the literature on price volatility transmission in vertical food markets. The methods and major findings of the literature are discussed and avenues for future research are suggested. The literature review shows that price volatility is analyzed using a class of univariate and multivariate GARCH models. The reviewed studies conclude that price volatility transmits along food supply chains thereby exposing all chain actors to risk and uncertainty. Extension of the limited sample period, country, product, and chain stages coverage of the current literature are suggested as avenues for future research. A largely ignored aspect in the current literature is the identification and empirical testing of the role of contextual factors on the degree of price volatility transmission.
\end{abstract}

Keywords: Literature review, price volatility transmission, food supply chains.

\title{
2.1. Introduction
}

Global agricultural prices have experienced an increasing degree of volatility in the last decade (FAO et al., 2011). Prices rose sharply in 2006 and 2007 reaching peak levels in the second half of 2007 for some products and in the second half of 2008 for others, and then plummeted sharply in the second half of the same year to sharply rise back in 2011 (FAO et al., 2011). Demand booming factors such as economic growth, shifting dietary patterns in developing countries and growth of the biofuel industry, and supply slowing factors (such as the weak transfer of market price signals to farmers) are attributed to the recent rise in food price volatility (Rabobank, 2011). While there is no generally accepted definition of price volatility (Serra and Zilberman, 2013), it is commonly acknowledged that price volatility is characterized by price changes that are unpredictable and unanticipated in nature (PiotLepetit, 2011; FAO et al., 2011; Serra and Zilberman, 2013; Rabobank, 2011). Price changes along a well-established trend reflecting market fundamentals and with known cyclical patterns are less a matter of concern (FAO et al., 2011) and may not be defined as price volatility.

The impacts of price volatility extend to all food supply chain actors. Price volatility implies risk to farmers who may react by reducing output supply and investments in productive inputs (Seal and Shonkwiler, 1987; Rezitis and Stavropoulos, 2009; Sckokai and Moro, 2009; Piot-Lepetit, 2011; Tangermann, 2011; and Taya, 2012). Furthermore, agricultural input price volatility exposes the downstream sector of food supply chains to sourcing uncertainties, forcing food and agricultural companies to alter their sourcing strategies as a coping mechanism (Rabobank, 2011). On the other end of food supply chains, an unexpected price increase poses food security risks, particularly to consumers who spend a large share of their income on food items (Hernandez, 2013). These chain wide implications of food price volatility stress the importance of investigating the degree to which each chain actor is exposed to price volatility and the mechanism by which price volatility transmits along the chain.

Investigating the magnitude and direction of price volatility transmission in food supply chains is particularly informative to policy makers and risk managers. As put by Buguk et al. (2003), policy changes in primary input markets that alter price volatility will have impacts on price volatility through the vertical chain. And where it is found that volatility is not being transmitted across chain stages, one cannot expect that stabilizing one market will lead to stability in other related markets (Serra, 2011). This informs policy makers of the need for different types of interventions for different levels of the supply chain (Serra, 2011). The transmission of volatility from one stage to another also 
increases the accuracy of forecasts made by agents about prices in other markets (Apergis and Rezitis, 2003; Buguk et al., 2003). This in turn affects the hedging decisions of chain actors. According to Buguk et al. (2003), volatility spillover could introduce cross-hedge relationships across chain stages. For instance, if price volatility spills over from a chain stage where futures markets exist to a chain stage where such markets do not exist, actors in the latter market stage can use futures market in the former stage to hedge against price volatilities in their own market.

Agricultural economists have traditionally been more interested in the chain-wide transmission of prices in levels than in the transmission of price volatilities. Reviews of the former stream of literature have been made by Meyer and Von CramonTaubadel (2004) and Frey and Manera (2007). And more recently, Serra and Zilberman (2013) reviewed the literature that deals with the transmission of prices (in levels) and price volatilities in energy-agricultural commodity markets. No review has however been made of studies that investigated the transmission of price volatility in food supply chains (farmretail). Increasing concerns about the chain wide implications of the recent rise in food price volatility make the review of the latter stream of literature a timely one. This review serves as guide for future research by discussing the data and modelling approaches used and the major findings of the literature.

This paper proceeds in section 2.2 with general definitions and a discussion of differences in modelling approaches in price transmission and price volatility transmission. This is followed by a review of data, methods and findings of the price volatility transmission literature for food supply chains in section 2.3. Section 2.4 concludes the review and provides suggestions for future research.

\subsection{Price volatility transmission versus price transmission: definition and modelling issues}

Price transmission and price volatility transmission are similar in that they both deal with price linkages along the chain. However, whereas price transmission refers to the linkages between the conditional mean prices, price volatility transmission refers to the linkages between the conditional variance of prices (Natcher and Weaver, 1999). Price transmission deals more generally with the relationship between the predictable 'portions' of prices whereas price volatility transmission deals with the relationship between the unpredictable 'portions' of prices. Price volatility transmission is also defined as the degree to which price uncertainty in one market affects price uncertainty in other markets (Apergis and Rezitis, 2003).

If prices volatilities are fully and instantaneously transmitted along the chain, one would expect a near to unity correlation between price volatilities at different market levels (Serra, 2011). It can be the case that the predictable portion of prices is perfectly transmitted whereas the unpredictable portions are not. Figure 2.1 illustrates a situation that implies a perfect price transmission in levels and an imperfect price volatility transmission for a chain consisting of a farm and retail sector of an unprocessed agricultural food product (to allow direct comparison of the degree of price transmission). Farm and retail price predictions can be made based on market fundamentals such as past prices, the degree of market competition, and demand and supply conditions. 


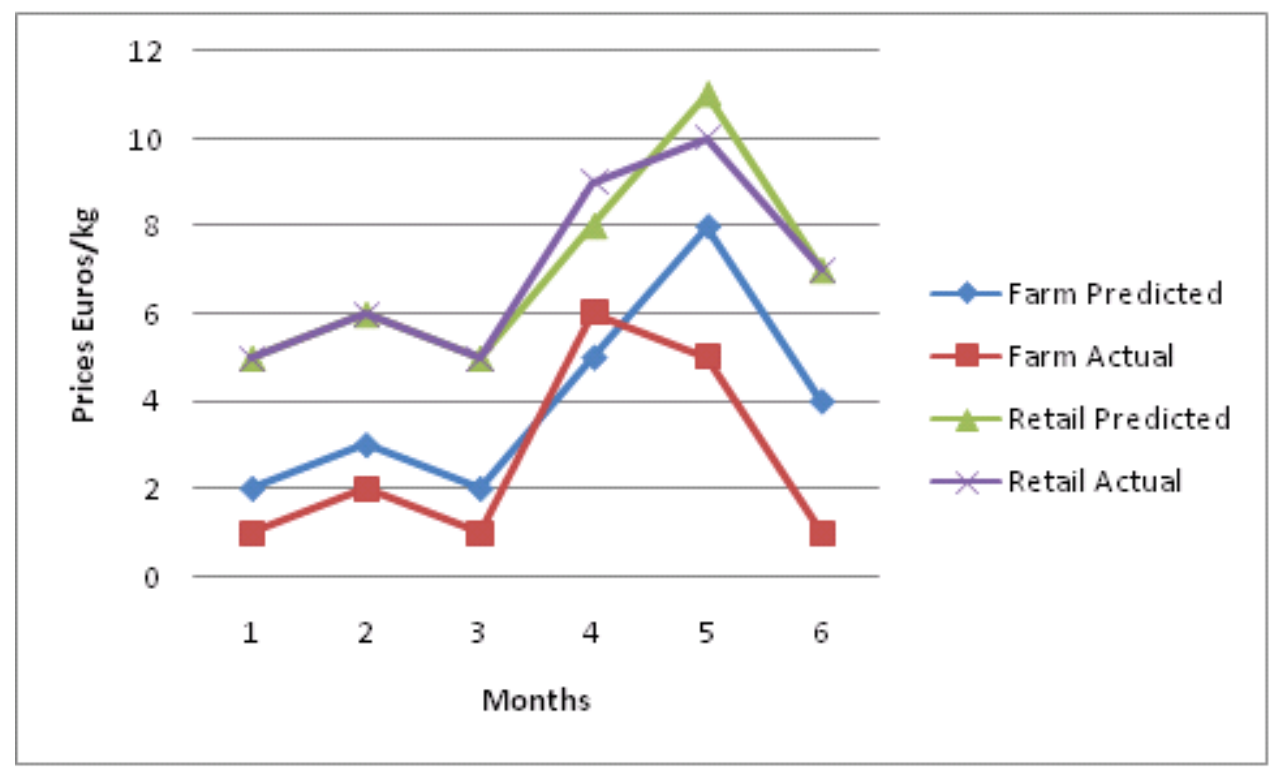

Figure 2.1 - Price transmission and price volatility transmission

Figure 2.1 shows that the predictable portions or the conditional means of farm and retail prices follow each other both in the short and long run. This indicates that price transmission in levels is perfect. However, the graph on actual prices shows that farm prices deviate more often from the mean values than the retail prices do. This implies that farm prices are less predictable than retail prices, and that this farm price unpredictability is not translated into unpredictable retail prices. This implies imperfect price volatility transmission from farm to retail even though causality cannot be directly inferred from the Figure.

Price transmission models (in levels) can take several specifications depending on their intended use. The most commonly used econometric model applied in recent papers is the vector error correction model (see for instance Lloyd et al., 2006; Falkowski, 2010; Kuiper and Oude Lansink, 2013) where the error correction mechanism was first suggested by Von-cramonTaubadel (1997). Variations of this model can be used to test for asymmetric price transmission (see Meyer and Von CramonTaubadel (2004) and Frey and Manera (2007) for a survey of asymmetric price transmission models), and to test for non-linearity in price dynamics (e.g. threshold vector error correction model). For applications of the threshold vector error correction model see for instance Goodwin and Holt (1999) and Rezitis and Stavropoulos (2011), as well as Brummer et al. (2009) for application of the Markov switching vector error correction model. A basic vector error correction model (VECM) is specified as follows for a hypotheticalchain consisting of two stages:

$$
\begin{aligned}
& \Delta p_{1, t}=\alpha_{1}+\sum_{i=0}^{r} \beta_{i}^{\prime} \Delta p_{2, t-i}+\sum_{i=1}^{s} \beta_{i}^{\prime \prime} \Delta p_{1, t-i}-\beta_{1}\left(p_{1, t-1}-\beta p_{2, t-1}\right)+u_{1, t} \\
& \Delta p_{2, t}=\alpha_{2}+\sum_{i=1}^{r} \beta_{i} \Delta p_{2, t-i}+\sum_{i=0}^{s} \beta_{i}^{\prime \prime \prime} \Delta p_{1, t-i}-\beta_{2}\left(p_{1, t-1}-\beta p_{2, t-1}\right)+u_{2, t}
\end{aligned}
$$

Equation (1) and (2) form the VECM and are solved simultaneously to determine the degree of price transmission between the two stages. In these equations, $p_{1 t}$ is the retail price at time $\mathrm{t}$ and $p_{2 t}$ is the farm price at time t. The coefficients $\beta_{i}^{\prime}$ show the short term effects of farm price changes on current retail price changes, while the coefficients $\beta_{i}^{\prime \prime \prime}$ show the short-term effects of retail price changes on current farm price changes. The degree to which retail prices and farm prices adjust to the long-term 
equilibrium relation are given by coefficients $\beta_{1}$ and $\beta_{2}$ respectively. The term in parenthesis represents the long-run equilibrium relation. This vector error correction model shows how the predictable portions of farm (past) price changes transmit to retail price changes and vice versa.

The price volatility transmission literature commonly uses Multivariate Generalized Autoregressive Heteroskedasticity models (MGARCH) to model volatility transmission effects (see Table 2.1). A family of MGARCH models exist which, similar to price transmission models, can have different specifications depending on the intended use and estimation efficiencies. For the purpose of illustration of the difference of price transmission and price volatility transmission models, a common specification of an MGARCH model called the BEKK model (Baba, Engle, Kraft, Kroner, 1991) for two price series is provided below.

$u_{t} \mid I_{t-1} \sim N\left(0, H_{t}\right)$

$H_{t}=C C^{\prime}+A^{\prime} u_{t-1} u_{t-1}^{\prime} A+B^{\prime} H_{t-1} B$

where $H_{t}$ is a $2 \times 2$ variance- covariance matrix, $C$ is a lower triangular matrix of constants, $A$ is a $2 \times 2$ matrix of ARCH term coefficients and $B$ is a $2 \times 2$ matrix of GARCH term coefficients. The $A$ matrix is a coefficient matrix for own and cross recent shock transmission effects, while the $B$ matrix contains coefficients for own and cross past volatility transmission effects. The $u_{t}$ are the residuals of the (conditional) mean equations, which can be specified in a VECM form (Eq. 1 and 2) or other forms. It can be seen that the residuals $u_{t}$ from the (conditional) mean equations form the basis for volatility modelling as they represent the price changes not predicted by the (conditional) mean equations. To clearly see the matrix elements of the variance equation, it can be written as:

$\left[\begin{array}{ll}h_{11, t} & h_{12, t} \\ h_{21, t} & h_{22, t}\end{array}\right]=\left[\begin{array}{cc}c_{11} & 0 \\ c_{21} & c_{22}\end{array}\right]\left[\begin{array}{cc}c_{11} & c_{21} \\ 0 & c_{22}\end{array}\right]+\left[\begin{array}{ll}a_{11} & a_{21} \\ a_{12} & a_{22}\end{array}\right]\left[\begin{array}{cc}u_{1, t-1}^{2} & u_{1, t-1} u_{2, t-1} \\ u_{2, t-1} u_{1, t-1} & u_{2, t-1}^{2}\end{array}\right]\left[\begin{array}{ll}a_{11} & a_{12} \\ a_{21} & a_{22}\end{array}\right]+$

$\left[\begin{array}{ll}b_{11} & b_{21} \\ b_{12} & b_{22}\end{array}\right]\left[\begin{array}{ll}h_{11, t-1} & h_{12, t-1} \\ h_{21, t-1} & h_{22, t-1}\end{array}\right]\left[\begin{array}{ll}b_{11} & b_{12} \\ b_{21} & b_{22}\end{array}\right]$

The transmission of prices in levels along the chain is necessary for a market to operate efficiently (Chavas and Mehta, 2004), for maximising producers and consumers welfare, and for an effective transmission of policy induced price measures (Meyer and von Cramon-Taubadel, 2004; Vavra and Goodwin, 2005; Ben-Kaabia and Gil, 2007). However, price volatility transmission entails the transmission of risks from unpredictable price changes from one market to another (Apergis and Rezitis, 2003) and this transmission should rationally be minimized. Hence, awareness of these conflicting objectives is necessary in designing policy measures and risk management options. That is, the policy measures and risk management options have to be designed such that they improve the transmission of predictable price changes and reduce the transmission of unpredictable price changes along the chain.

\subsection{Price volatility transmission in food supply chains}

The reviewed studies (summarized in Table 2.1) can be classified as those that explicitly investigate the transmission of price volatility across chain stages, and those that only indirectly infer about it. Those studies that only indirectly infer about the degree of price volatility transmission either make a comparison between price volatilities in different stages of the chain or investigate the correlation of volatilities in different stages of the chain. Direct causal effects of price volatilities across chain stages 
are not investigated in this latter stream of literature. The stream of literature that explicitly investigates the degree of price volatility transmission in food chains consists of eight papers and includes the papers by Khan and Helmers (1997), Natcher and Weaver (1999), Buguk et al. (2003), Apergis and Rezitis (2003), Rezitis (2010), Uchezuba et al. (2010), Rezitis and Stavropoulos (2011) and Khiyavi et al. (2012). 
Table 2.1- Summary of reviewed literature

\begin{tabular}{|c|c|c|c|c|c|c|c|c|}
\hline \multirow[b]{2}{*}{ Authors (date) } & \multirow[b]{2}{*}{ Countries } & \multirow[b]{2}{*}{ Products } & \multirow[b]{2}{*}{ Chain stages } & \multirow{2}{*}{$\begin{array}{l}\text { Sample } \\
\text { period }\end{array}$} & \multicolumn{2}{|c|}{ Model } & \multirow{2}{*}{$\begin{array}{c}\text { Transmission of } \\
\text { volatility } \\
\text { detected }\end{array}$} & \multirow{2}{*}{$\begin{array}{c}\text { Direction of } \\
\text { detected volatility } \\
\text { transmission }\end{array}$} \\
\hline & & & & & $\begin{array}{c}\text { Mean } \\
\text { equations }\end{array}$ & $\begin{array}{l}\text { Variance } \\
\text { equations }\end{array}$ & & \\
\hline $\begin{array}{l}\text { Khan and } \\
\text { Helmers (1997) }\end{array}$ & $\overline{\mathrm{USS}}$ & $\begin{array}{l}\text { Feed (corn), } \\
\text { beef, poultry, } \\
\text { pork }\end{array}$ & $\begin{array}{l}\text { Feed-farm- } \\
\text { wholesale-retail }\end{array}$ & "1970-1981 & ב... & "VAR & "Yes & From feed to farm \\
\hline $\begin{array}{l}\text { Natcher and } \\
\text { Weaver (1999) }\end{array}$ & US & Beef & $\begin{array}{l}\text { Feeder cattle- } \\
\text { live cattle- } \\
\text { wholesale-retail }\end{array}$ & $1970-1983$ & $\ldots$ & $\begin{array}{l}\text { VAR } \\
\text { specification of } \\
\text { univariate } \\
\text { GARCH }\end{array}$ & Yes & $\begin{array}{l}\text { Bidirectional across } \\
\text { all chain stages }\end{array}$ \\
\hline $\begin{array}{l}\text { Buguk et al. } \\
\text { (2003) }\end{array}$ & US & Catfish & $\begin{array}{l}\text { Feed-farm- } \\
\text { wholesale-retail }\end{array}$ & $1980-2000$ & VAR & $\begin{array}{l}\text { Univariate } \\
\text { EGARCH }\end{array}$ & Yes & $\begin{array}{l}\text { From feed to farm; } \\
\text { From wholesale to } \\
\text { farm; From farm to } \\
\text { wholesale }\end{array}$ \\
\hline $\begin{array}{l}\text { Apergis and } \\
\text { Rezitis (2003) }\end{array}$ & Greece & $\begin{array}{l}\text { Agricultural } \\
\text { products }\end{array}$ & $\begin{array}{l}\text { Agricultural } \\
\text { input- } \\
\text { agricultural } \\
\text { output-retail }\end{array}$ & 1985-1999 & VECM & $\begin{array}{l}\text { Variation of } \\
\text { VECH model }\end{array}$ & Yes & $\begin{array}{l}\text { From feed to farm; } \\
\text { From consumer to } \\
\text { farm }\end{array}$ \\
\hline $\begin{array}{l}\text { Chavas and } \\
\text { Mehta (2004) }\end{array}$ & US & Butter & $\begin{array}{l}\text { Wholesale- } \\
\text { retail }\end{array}$ & $1980-2011$ & VECM & $\begin{array}{l}\text { Cholesky } \\
\text { decomposition** }\end{array}$ & Yes & N/A*** \\
\hline $\begin{array}{l}\text { Zheng et al. } \\
\text { (2008) }\end{array}$ & US & $\begin{array}{l}45 \text { retail food } \\
\text { items }\end{array}$ & Retail & $1980-2004$ & $\mathrm{AR}$ & $\begin{array}{l}\text { EGARCH } \\
\text { (univariate) }\end{array}$ & Yes & From farm to retail \\
\hline $\begin{array}{l}\text { Mehta and } \\
\text { Chavas (2008) }\end{array}$ & Brazil-US & Coffee & $\begin{array}{l}\text { Farm (Brazil)- } \\
\text { wholesale (US)- } \\
\text { retail (US) }\end{array}$ & $1975-2002$ & VAR & $\begin{array}{l}\text { Cholesky } \\
\text { decomposition** }\end{array}$ & Yes & N/A*** \\
\hline
\end{tabular}


Table 2.1- Summary of reviewed literature (continued)

\begin{tabular}{|c|c|c|c|c|c|c|c|c|}
\hline \multirow[b]{2}{*}{$\begin{array}{l}\text { Authors } \\
\text { (date) }\end{array}$} & \multirow[b]{2}{*}{ Countries } & \multirow[b]{2}{*}{ Products } & \multirow[b]{2}{*}{ Chain stages } & \multirow[b]{2}{*}{$\begin{array}{l}\text { Sample } \\
\text { period }\end{array}$} & \multicolumn{2}{|c|}{ Model } & \multirow[b]{2}{*}{$\begin{array}{l}\text { Transmission } \\
\text { of volatility } \\
\text { detected }\end{array}$} & \multirow[b]{2}{*}{$\begin{array}{l}\text { Direction of } \\
\text { detected } \\
\text { volatility } \\
\text { transmission }\end{array}$} \\
\hline & & & & & $\begin{array}{l}\text { Mean } \\
\text { equations }\end{array}$ & $\begin{array}{l}\text { Variance } \\
\text { equations }\end{array}$ & & \\
\hline $\begin{array}{l}\text { Uchezuba et } \\
\text { al. (2010) }\end{array}$ & South Africa & Boiler & Farm-retail & $2000-2008$ & AR & $\begin{array}{l}\text { EGARCH } \\
\text { with spillover } \\
\text { effect }\end{array}$ & Yes & $\begin{array}{l}\text { From farm to } \\
\text { retail }\end{array}$ \\
\hline Serra (2011) & Spain & Beef & Farm-retail & $1996-2005$ & VECM & $\begin{array}{l}\text { Univariate } \\
\text { STCC- } \\
\text { GARCH }\end{array}$ & Mixed**** & N/A \\
\hline $\begin{array}{l}\text { Alexandri } \\
\text { (2011) }\end{array}$ & Romania & $\begin{array}{l}\text { Agricultural } \\
\text { price indices }\end{array}$ & Farm-retail & $2006-2010$ & $\ldots$ & $\begin{array}{l}\text { Comparison } \\
\text { of coefficient } \\
\text { of variance of } \\
\text { prices }\end{array}$ & Yes & N/A \\
\hline $\begin{array}{l}\text { Rezitis and } \\
\text { Stravapoulaus } \\
\text { (2011) }\end{array}$ & Greece & Broiler & Farm-retail & $1993-2009$ & TVECM & BEKK & No & N/A \\
\hline $\begin{array}{l}\text { Rezitis } \\
(2012)\end{array}$ & Greece & $\begin{array}{l}\text { Beef, lamb, } \\
\text { pork and } \\
\text { poultry }\end{array}$ & Farm-retail & $1993-2008$ & $\begin{array}{l}\text { AR and } \\
\text { ARMA }\end{array}$ & $\begin{array}{l}\text { Diagonal } \\
\text { VECH }\end{array}$ & Yes**** & N/A \\
\hline $\begin{array}{l}\text { Khiyavi et al. } \\
\text { (2012) }\end{array}$ & Iran & Poultry & $\begin{array}{l}\text { Feed-farm- } \\
\text { retail }\end{array}$ & $1997-2010$ & VECM & $\begin{array}{l}\text { Variant of } \\
\text { VECH }\end{array}$ & Yes & $\begin{array}{l}\text { From feed to } \\
\text { farm; From } \\
\text { retail to farm }\end{array}$ \\
\hline
\end{tabular}

*all data frequency are monthly

**based on effect of prices on covariance of price volatilities

***not applicable

$* * * *$ based on correlation of price volatilities 
These papers differ in their methodological approaches. The earliest study by Khan and Helmers (1997) applies a Vector Autoregressive model (VAR) on moving variances of farm, wholesale and retail monthly prices for US beef and pork products. Natcher and Weaver (1999) also use a VAR model, but apply it to the predicted conditional variances of univariate GARCH models estimated for the US cattle sector. They investigate volatility spillover effects for the feeder cattle-live cattlewholesale beef-retail beef supply chain. Buguk et al. (2003) take a different approach by estimating univariate exponential GARCH (EGARCH) models for three stages of the US wholesale catfish supply chain (Feed, farm and wholesale). In the univariate EGARCH model of each market (which allows testing for asymmetry in transmissions), the most recent innovations from other markets are included as exogenous variables that potentially cause volatility spillover. A similar approach is used by Uchezuba et al. (2010) who also applies univariate EGARCH models to investigate spillover effects in the South African farm-retail broiler chain.

Apergis and Rezitis (2003), Rezitis (2010), Rezitis and Stavropoulos (2011a) and Khiyavi et al. (2012) share some methodology wise similarities in that they all apply standard multivariate GARCH models with BEKK and VECH specifications. While the BEKK specification is more parsimonious and assures the positive definiteness of the covariance matrix, both approaches are advantageous in the identification of cross-market volatility effects. The studies discussed above indicate that GARCH models are standard volatility modelling approaches. The reviewed literature applies these models to a 10 to 20 years monthly time series price data. The specifications of mean equations take, in most cases, vector error correction and vector autoregressive forms. The use of mean equations that allow for non-linear price transmission is rather limited, with the paper by Rezitis and Stavropoulos (2011) being an exception with its application of the threshold vector error correction model (TVECM). A striking feature of the papers discussed above is their limited coverage in terms of country, products and periods of study. Six out of the eight papers are for the US and Greek markets, with the papers for the Greek market authored by the same individual(s). Seven out of the eight papers cover the meat sector (broiler, beef, pork and fish). Only three papers have been published after the year 2000 .

A commonality of the papers that directly investigate the transmission of price volatility is that they all detect transmission of volatility across all or some of the chain stages (except for Rezitis and Stavropoulos, 2011). The transmission of feed price volatility to farm output price volatilities is detected by Khan and Helmers (1997),Buguk et al. (2003), Apergis and Rezitis (2003), and Khiyavi et al. (2012). Farm output price volatilities are also shown to respond to retail (wholesale) price volatilities by Natcher and Weaver (1999), Buguk et al. (2003), Apergis and Rezitis (2003), Rezitis (2010), and Khiyavi et al (2012). The wholesale market is considered in the transmission analysis in only three of the studies (Khan and Helmers, 1997; Natcher and Weaver, 1999; Buguk et al., 2003). It is shown in Natcher and Weaver (1999) and Buguk et al. (2003) that wholesale price volatilities are affected by farm price volatilities. Only the study by Natcher and Weaver (1999) and Khan and Helmers (1997) investigated the wholesale-retail price volatility dynamics. Significant bidirectional transmission of wholesale-retail price volatility is, however detected only in Natcher and Weaver (1999).

The second category of the reviewed literature includes those papers that indirectly infer about the transmission of price volatility across chain stages. This category is represented by the papers of Chavas and Mehta (2004), Zheng et al. (2008), Mehta and Chavas (2008), Serra (2011), Alexandri (2011) and Rezitis (2012). This category is also dominated by studies for the US and Greek markets, but shows some variations in the products studied. Serra (2011) analyses the Spanish producer- 
consumer beef chain using a univariate STCC-GARCH model that allows conditional correlations of price volatilities to vary with the economic regime that prevails at each point in time. A similar modelling approach is the one applied by Rezitis (2012) and consists of estimating a diagonal VECH approach to study producer-consumer price volatility interactions in four meat markets in Greece. The similarity in the approaches of Serra (2011) and Rezitis (2012) is that they both use conditional correlations (covariances) in volatilities to infer about price volatility transmission. However, correlation or covariances might not imply causality. While Serra (2011) finds that the correlation between producer and consumer price volatilities is negative in the periods of the BSE crisis, Rezitis (2012) finds that the average conditional correlations between producer and consumer price volatility is positive for all meat markets (except the lamb market).Zheng et al (2008) estimate a univariate exponential GARCH using only prices of retail food items and make inference on how retail price volatilities respond to negative and positive price shocks (possibly coming from upstream farm price shocks). They find that retail prices respond more to positive price shocks than to negative price shocks. Alexandri (2011) compares farm and retail price volatilities, and concludes that both prices are volatile with farm price volatility being higher. Chavas and Mehta (2004) and Mehta and Chavas (2008) investigate the effect of changes in prices (in levels) on the covariance of price volatilities in two chain stages. Both studies conclude that price levels in one market determine how price volatilities co-vary in two markets.

The above discussed literature challenges the common perception that farmers are the main actors in chain that are affected by price volatility. Typical manifestations of such perception are the numerous studies that investigate the effects of farm price volatility on farm supply response. The papers by Seal and Shonkwiler (1987), Rezitis and Stavropoulos (2009a), Rezitis and Stavropoulos (2009b), Sckokai and Moro (2009), Rezitis and Stavropoulos (2010a), Rezitis and Stavropoulos (2010b), Piot-Lepetit (2011), Tangermann (2011), Taya (2012), Rezitis and Stavropoulos (2011b), Rezitis and Stavropoulos (2012) are some of the studies that explored this issue. Some insights can be drawn from these papers on volatility transmissions from the farm stage to the downstream stage of the chain, but these insights are mere implications ${ }^{1}$. For instance, to make volatility estimates to be incorporated in the broiler farm supply equation, Rezitis and Stavropoulos (2010a) estimate a univariate NAGARCH model that accounts for asymmetric price shocks at the farm stage, and find that farm price volatilities respond mainly to past positive price shocks than negative ones. This implies that the wholesale or retail stage faces higher farm price volatilities in times of increasing farm prices, but does not necessarily mean that the higher farm price volatilities are translated into higher wholesale or retail price volatilities.

A largely ignored aspect in the reviewed literature is the empirical investigation of the role of contextual factors on the degree of price volatility transmission. Some of the studies suggest, without empirically testing for it, that certain factors do affect the degree of transmission. For instance, Khan and Helmers (1997), Apergis and Rezitis (2003) and Khiyavi et al (2012) argue that the lack of contract production is responsible for the transmission of consumer price volatilities to the farm sector. A commonly attributed factor to the low transmission of farm price volatilities to the consumer stage is the degree of market power exercised by retailers (wholesalers) (Zheng et al., 2008; Uchezuba et al., 2010; Serra, 2011; Alexandri, 2011; and Rezitis, 2012). The authors argue that the downstream sector uses its market power to keep consumer prices stable. Such a marketing strategy is argued by some to be a consequence of the sensitivity of consumers to frequent price changes (Alexandri, 2011).Factors such as the biological nature of agricultural production (time lag in production response) and the lower price elasticity of farm-level demand than that of retail demand are attributed to the higher farm price

\footnotetext{
${ }^{1}$ We thank an anonymous referee for pointing out this issue.
} 
volatility relative to consumer price volatility (Apergis and Rezitis, 2003; Alexandri, 2011; and Khiyavi et al., 2012). Further identification and empirical testing of the role of these and other factors can be an interesting area for future research. The use of theory and the price transmission literature (on price levels) can serve as a guide for the identification of potential contextual factors.

\subsection{Conclusions and suggestions for future research}

The literature on price linkages in vertical markets has mostly dealt with the transmission of prices in levels instead of price volatilities. The recent rise of price volatility of food and agricultural commodities, in particular since the mid-2000s, has raised concerns about the negative implications for food chain actors. Even though few studies have explicitly explored the degree of price volatility transmission along food supply chains, the number of studies covering the last decade is very limited.

The studies reviewed in this paper show that price volatility transmits along food supply chains, both from upstream to downstream and vice versa. All studies that investigated the feed-farm linkages show that farm output price volatility responds to feed price volatility. The farm sector was also shown to be vulnerable to price volatility sourced from the (wholesale) retail sector. Even though it was shown that wholesale price volatilities respond to farm output price volatilities, the wholesale-retail price volatility linkage was practically not explored. The findings imply that price stabilization measures that target the chain stage that are the major source of price volatility can help stabilize prices for the other stages of the chain. The studies that were reviewed in this paper used a family of both univariate and multivariate GARCH models to model price volatility transmission. While some studies attempted to indirectly infer about the degree of price volatility transmission by using conditional correlations of price volatilities, those studies that directly investigated the degree of volatility transmission mostly used BEKK and VECH specifications of multivariate GARCH models.

Given the timeliness of the topic of the analysis of volatility transmission literature, extending the period being investigated to the last decade is an avenue of future research. Extending the product and country coverage of the current literature can further help to identify the impact of product and country specific characteristics on the degree of volatility transmission. Current studies tend to focus mainly on US markets and on the meat sector. The chain stages being investigated should also be extended to cover the wholesale-retail price volatility linkage because the wholesale sector can play a major role in either dampening or stimulating the transmission of volatility between the farm and retail stages. Moreover, the use of higher frequency data, such as weekly data, can improve results and help detect short-term cross-market price volatility dynamics in vertical markets. Another highly important aspect that is currently not yet explored in the literature is the identification and empirical testing of the impact of contextual factors (such as market power, contracts in vertical markets and marketing strategies of the downstream sector) on the degree of price volatility transmission. While detecting transmission of price volatility is important, examining the role of contextual factors on transmission is more important in designing policy measures and risk management strategies aimed at minimizing the degree of transmission. The vast literature on price transmission in levels and the use of theory can help in the identification, modelling and empirical testing of relevant contextual factors. 


\section{References}

Alexandri, C. (2011). Analysis of price transmission along the agri-food chains in Romania. Agricultural Economics and Rural Development, 8(2), 171-189.

Apergis, N. and Rezitis, A. (2003). Agricultural price volatility spillover effects: the case of Greece. European Review of Agricultural Economics, 30 (3), 389-406.

Baba, Y., Engle, R. F., Kraft, D. F. and Kroner, K. F. (1991). "Multivariate Simultaneous Generalized ARCH"manuscript, Dept. of Economics, UCSD.

Ben-Kabbia, M. and Gil, J.M. (2007). Asymmetric price transmission in the Spanish lamb sector, European Review of Agricultural Economics. 34 (1), 53-80.

Brummer, B., Von Cramon-Taubadel, S. and Zorya, S. (2009). The impact of market and policy instability on price transmission between wheat and flour in Ukraine. European Review of Agricultural Economics, 36 (2), 203-230.

Buguk C., Hudson, D., and Hanson, D. (2003). Price volatility in agricultural markets: An examination of U.S. catfish markets. Journal of Agricultural and Resource Economics, 28(1), 86-99.

Chavas, J.P and Mehta, A. (2004). Price dynamics in a vertical sector. Agricultural and Applied Economics Association, 86 (4), 1078-1093.

Falkowski, J. (2010). Price transmission and market power in a transition context: Evidence from the polish fluid milk sector. Post-Communist Economies, 22(4), 513-529.

FAO, IFAD, IMF, OECD, UNCTAD, WFP, the World Bank, the WTO, IFPRI and the UN HLTF (2011). Price volatility in food and agricultural markets: policy responses. Retrieved from http://www.oecd.org/dataoecd/40/34/48152638.pdf

Frey, G. and Manera, M. (2007). Econometric models of asymmetric price transmission. Journal of Economic Surveys, 2 (21), 349-415.

Goodwin, B.K. and Holt, M.T. (1999). Price transmission and asymmetric adjustment in the U.S. beef sector. American Agricultural Economics Association, 81(3), 630-637.

Hernandez, M.A., Ibarra, R., and Trupkin, D.R. (2013). How far do shocks move across borders? Examining volatility transmission in major agricultural futures markets. European Review of Agricultural Economics, 41(2), 1-25.

Khan, M.A. and Helmers, G.A.(1997). Causality, input price variability and structural changes in the U.S. livestock-meat industry. Paper submitted to Western agricultural economics association meeting, Reno, Nevada.

Khiyavi, P.K., Moghaddasi, R., Eskandarpur, B. and Mousavi, N. (2012). Spillover effects of agricultural products price volatilities in Iran. Journal of Basic and Applied Scientific Research, 2(8), 7906-7914.

Kuiper, W.E. and Oude Lansink, A.G.J.M. (2013). Asymmetric price transmission in food supply chains: Impulse response analysis by local projections applied to U.S. Broiler and Pork prices. Agribusiness, 29(3), 1-19. 
Lloyd, T.T., McCorriston, S.,Morgan, C.W. and Rayner, A.J. (2006). Food scares, market power and price transmission: the UK BSE crisis. European Review of Agricultural Economics, 33(2), 119-147.

Mehta, A. and Chavas, J.P (2008). Responding to the coffee crisis: What can we can we learn from price dynamics? Journal of Development Economics, 85(2), 282-311.

Meyer, J. and von Cramon-Taubadel, S. (2004). Asymmetric price transmission: A survey. Journal of Agricultural Economics, 55 (3), 581-611.

Natcher, W.C. and Weaver, R. (1999). The transmission of price volatility in the beef market: A multivariate approach. Paper selected for presentation at the American Agricultural Economics Association annual meeting, Nashville, TN.

Piot-Lepetit, I. (2011). Price volatility and price leadership in the EU beef and pork meat market. In Methods to Analyse Agricultural Commodity Price Volatility (pp. 85-106). New York, NY: Springer Science and Business Media.

Rabobank (2011). Rethinking the food and agribusiness supply chain; impact of agricultural price volatility on sourcing strategies. Retrieved from http://hugin.info/133178/R/1549493/476482.pdf

Rezitis, A. N. and Stavropoulos, K. S. (2009a). Modelling pork supply response and price volatility: The case of Greece. Journal of Agricultural and Applied Economics, 41 (1), 145-162.

Rezitis, A. N. and Stavropoulos, K.S. (2009b). Modelling Sheep Supply Response under Asymmetric Price Volatility and CAP Reforms. Economics Bulletin, 29 (2), 524-534.

Rezitis, A. N. (2010). Mean and volatility spillover effects in Greek producer-consumer meat prices. Applied Economic Letters, 10(6), 381-384.

Rezitis, K.N. and Stavropoulos, K.S.(2010a). Supply Response and Price Volatility in the Greek Broiler Market. Agribusiness: An International Journal, 26(1), 25-48.

Rezitis, A. and Stavropoulos, K.S. (2010b). Modelling Beef Supply Response and Price Volatility under CAP Reforms: The Case of Greece. Food Policy, 35, 163-174.

Rezitis, A.N. and Stavropoulos, K.S. (2011a). Price transmission and volatility in the Greek broiler sector: A Threshold Cointegration analysis. Journal of Agricultural and Industrial Organization, 9(1), $1-35$.

Rezitis, A. N., Stavropoulos, K.S(2011b). Price Volatility and Rational Expectations in a Sectoral Framework Commodity Model: A Multivariate GARCH Approach. Agricultural Economics, 42, 419435.

Rezitis, A.N. (2012). Modelling and decomposing price volatility in the Greek meat market. International Journal of Computational Economics and Econometrics, 2(3-4), 1757-1189.

Rezitis, A.N. and Stavropoulos, K.S (2012). Greek Meat Supply Response and Price Volatility in a Rational Expectations Framework: A Multivariate GARCH Approach. European Review of Agricultural Economics, 39, 309-333.

Sckokai, P. and Moro, D. (2009). Modelling the impact of the CAP single farm payment on farm investment and output. European Review of Agricultural Economics, 36 (3), 395-423. 
Seal, J. and Shonkwiler, J. (1987). Rationality, price risk, and response. Southern Journal of Agricultural Economics, 19 (1), 111-118.

Serra, T. (2011). Food scares and price volatility: The case of the BSE in Spain. Food policy, 36, 179185.

Serra, T. and Zilberman, D. (2013). Biofuel-related price transmission literature: A review, Energy Economics, 37, 141-151.

Tangermann, S. (2011). Risk management in agriculture and the future of the EU's Common Agricultural Policy. Retrieved from http://ictsd.org/downloads/2011/12/risk-management-inagriculture-and-the-future-of-the-eus-common-agricultural-policy.pdf.

Taya, S. (2012). Stochastic model development and price volatility analysis ( OECD food, agricultural and fisheries working papers No. 57). OECD publishing.

Uchezuba, I.D., Jooste,A. and Willemse, J. (2010). Measuring asymmetric price and volatility spillover in the South African broiler market. Retrieved from http://ageconsearch.umn.edu/bitstream/96434/2/179briol.pdf

Vavra, P. and B. K. Goodwin (2005). Analysis of price transmission along the food chain (OECD Food,Agriculture and Fisheries Working Papers, No. 3). OECD Publishing.

Von Cramon-Taubadel, S. (1997). Estimating asymmetric price transmission with the error correction representation: An application to the German pork market. European Review of Agricultural Economics, 25 (1), 1-18.

Zheng, Y. Kinnucan, H.W. and Thompson, H.(2008). News and volatility of food prices. Applied Economics, 40(13), 1629-1635. 


\section{Chapter 3}

\section{Price volatility transmissions and market power in the German fresh pork supply chain}

Tsion Taye Assefa, Miranda P.M. Meuwissen, Cornelis Gardebroek, Alfons G.J.M. Oude Lansink Revised version submitted 


\begin{abstract}
This paper investigates the relationship between the transmission of price volatility and market power in the German fresh pork supply chain. A theoretical model underpinning this relationship is first provided followed by an empirical application that uses monthly farm, slaughterhouse and retail pork price data for the period 2000-2011. The relationship of market power with price level transmission and price volatility transmission in the chain are both investigated. The empirical applications consist of a vector error correction model and least square regressions estimated to analyse price transmission and price volatility transmissions, respectively. Results show that retail market power limited both types of transmissions. Competition inducing policy measures coupled with measures that support price risk management initiatives of chain actors are encouraged.
\end{abstract}

Key words: price volatility transmission, price transmission, market power, food supply chain, Germany, theory

\title{
3.1. Introduction
}

Since the food crisis of $2006 / 2007$, price volatility has become a major concern of policymakers worldwide (Brummer et al., 2013). Although a decade has passed since the food crisis, world agricultural markets are still susceptible to a rise in price volatility that can be caused by supply and demand shocks. Factors causing supply shocks include the shifting of agricultural production to regions with variable yields (such as the Black sea region), climatic shocks, volatile oil prices, and delayed farm supply response to world demand shocks (FAO, 2011). Sources of demand shocks include animal health related crises (Van Asseldonk et al., 2000; Serra, 2011) and import bans by major importing countries in response to food safety or animal health concerns causing excess supply relative to demand (FAO, 2011). Due to the interconnectedness of the EU market with global agricultural markets as a result of successive reforms of the Common Agricultural Policy, the EU market is likely to be exposed to global market shocks (Tangermann, 2011). A recent example of a market shock is the Russian embargo on fresh produce imports from the EU which was followed by a drop of fresh produce prices within the EU (Kutlina-Dimitrova, 2015).

Demand and supply shocks cause prices to be volatile and therefore unpredictable. The risk and uncertainty associated with volatile prices in turn increase the complexity of managerial and investment decisions (Piot-Lepetit, 2011; Rabobank, 2011). Assefa et al. (2016) showed through interviews with forty-two EU food chain actors that price volatility is a challenge not only for farmers but also for other actors in the chain. Price volatility at different stages of the chain is exacerbated by price volatility that potentially is transmitted from other stages of the chain in addition to the price volatility originating in own markets (Assefa et al., 2015). Price volatility can be defined as the "portion" of price changes that cannot be predicted by market fundamentals. The transmission of predictable price changes, which can also be termed as price transmission, is necessary for the efficient transmission of market signals as a basis for informed economic decisions (Chavas \& Mehta, 2004). The transmission of price volatility, on the other hand, implies the transmission of risk and uncertainty and may have negative impacts on investments in new technologies in other stages of the chain.

A literature review of Assefa et al. (2015) showed that several studies suggest that market structure (or the degree of market power in the chain) is a major determinant of price volatility transmissions. For instance, Alexandri (2011) compared farm and retail price volatility of various Romanian agricultural products and claims that retailers might be exercising market power to keep consumer prices rigid and 
irresponsive to farm price volatility because consumers are sensitive to frequent price changes. Serra (2011) investigated the Spanish beef chain and associates the low correlation between farm and retail price volatility during turbulent times (when BSE cases were detected) with retailers using market power to keep consumer prices irresponsive to farm price volatility. Another example is the study of Buguk et al. (2003) on the US catfish market who assert that farmers organized in cooperatives might be using market power to asymmetrically transmit positive input price shocks to the next stage. That is, farm price volatility responds to positive input price shocks more than to negative ones. Although these studies claim that market power might have an effect on price volatility transmissions in the chain, they test such claims neither theoretically nor empirically.

The aim of this paper is to empirically investigate the effect of market power on price volatility transmission. The analysis focuses on three stages of the German fresh pork supply chain, i.e. farm, slaughterhouse and retail stages. Similar to previous studies that model price volatility transmission within a GARCH (generalized autoregressive conditional heteroscedasticity) framework (see a review in Assefa et al., 2015), this chapter measures price volatility transmission in two steps. First, price transmission is modelled through conditional mean equations. Next, price residuals from the first step are used to model volatility transmissions. Empirical estimations of both types of transmissions are guided by a theoretical framework that relates both types of transmissions with the degree of market power. The classical conjectural variation approach first advanced by Appelbaum (1982) is used to measure market power.

The relationship between market power and price transmission has been modelled in the price transmission literature (see for instance, Acharya et al., 2011; Verreth et al., 2011). However, to our knowledge, this paper is the first to theoretically model the relationship between both types of transmission and market power. Although several empirical studies investigated price volatility transmission in food supply chains (see Assefa et al., 2015), a theoretical underpinning for the empirical estimations is still lacking. The framework of Thille (2006) is extended to relate market power to price volatility transmission for various actors in the pork supply chain. To our knowledge, this paper is the first application of Thille's (2006) framework to investigate price volatility transmissions along food supply chains. Market power has often been blamed to hinder the efficient transmission of price signals needed for informed production and investment decisions and the enhancement of consumers' welfare (Meyer and von Cramon Taubadel, 2004). This paper investigates whether market power also hinders the transmission of price shocks along the chain.

The remainder of this paper is organized as follows. Section 3.2 provides a description of the German pork supply chain, section 3.3 presents the theoretical framework, section 3.4 presents the empirical framework and section 3.5 presents the data. Results are presented and discussed in section 3.6. Section 3.7 concludes the chapter.

\subsection{The German fresh pork supply chain}

Germany is a major pork meat producer in the EU accounting for $23 \%$ of EU production, followed by France, Spain and The Netherlands, with similar shares (around 13 to 14\%) (Sanjuan and Gil, 2010). The German fresh pork supply chain consists of five major stages, i.e. the farm, livestock wholesale, slaughterhouse, meat wholesale, and retail stages (Theuvsen and Franz, 2007; Schulze et al., 2007). German pig farmers sell their pigs directly to slaughterhouses or though livestock wholesalers. The latter are important intermediaries due to the relatively large number of farms and the need to "bundle" 
large quantities of pigs (European Commission, 2010). According to the European Commission (2010), the meat wholesale market also supplies meat to the retail sector. Figure 3.1 shows the main supply linkages in the German fresh pork chain. The Figure is adapted from Theuvsen and Franz (2007) and from the report of the European Commission (2010). The number of chain actors per chain stage is reported in the Figure. The number of pig farms corresponds to the year 2013 and is obtained from Statistiches Bundesamt. The number of pig slaughterhouses, livestock wholesalers (aggregate over all types of animals) and meat wholesalers (aggregate over all types of animals) correspond to the year 2007 and were obtained from a report of the European Commission (2010). The report used data compiled from the Eurostat, FOODCOMM (2006) and Statistiches Bundesamt Deutschland (2007). The number of retailers in 2010 is obtained from a report of the USDA (2010) which used data from Euromonitor International.

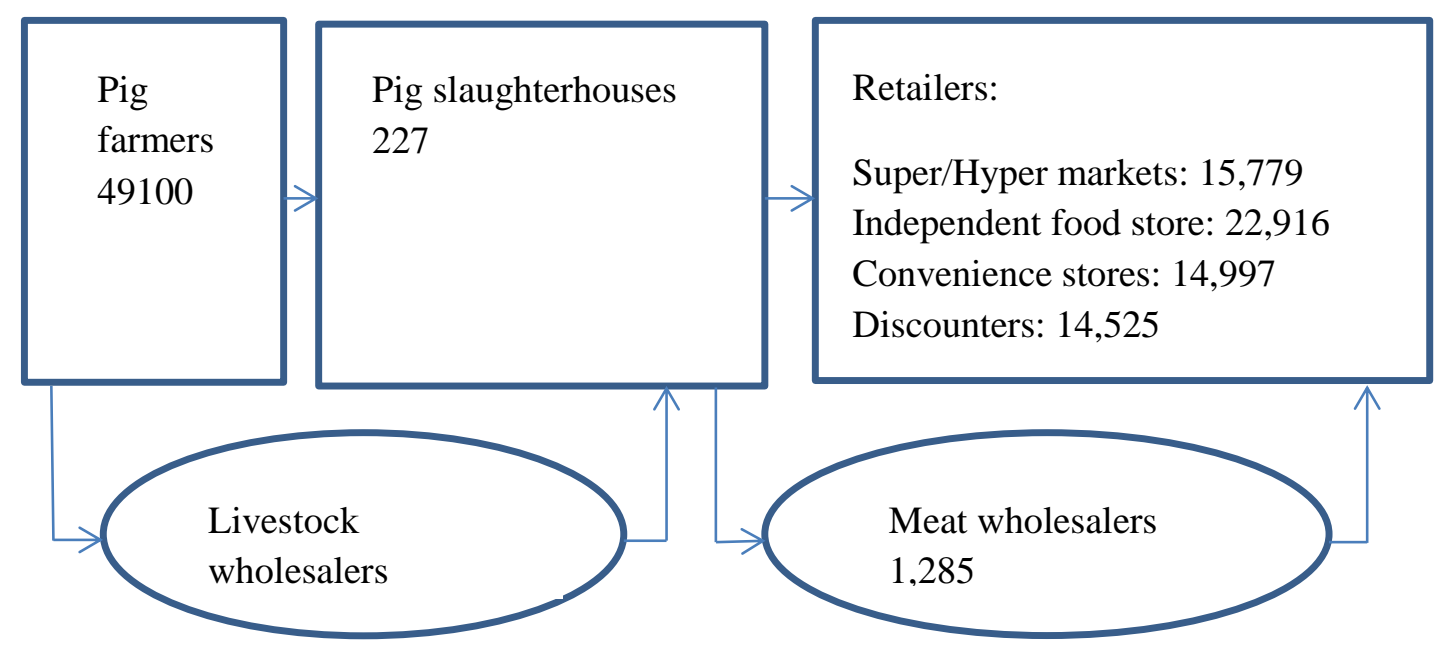

Figure 3.1 - The German fresh pork supply chain and the number of actors per chain stage

Figure 3.1 provides an indication of the relative concentration in each stage of the chain. Although a large number of small and medium retail stores operate in Germany, the German retail sector is highly concentrated. As of 2002, the concentration ratio of the ten largest firms has already reached $86 \%$ (Anders, 2008). Concentration at the retail stage can have implications on price competition and transmission in the chain. Despite the high degree of concentration, the German supermarket industry is characterized by an intense horizontal price competition due to the presence of hard-discounters such as Aldi and Lidl (Anders, 2008; Weber and Anders, 2007). The intense competition limits the opportunity for retailers to transmit cost price increases to consumers. Hence, retailers mark-down the margins of the slaughterhouses and/or processors using oligopsony market power to maintain their own margins (Anders, 2008; Weber and Anders, 2007). The implementation of aggressive "everydaylow-pricing" strategies by discounters also contributes to the rigidity of consumer prices (Weber and Anders, 2007). Weber and Anders (2007) also argue that retailers violate the law of one price, as reflected in the difference in prices for the same product across different retail stores. 
The slaughterhouse stage, although much less concentrated than the retail stage, has a concentration ratio of the ten largest firms equal to $38.7 \%$ as of 2008 (European Commission, 2010). According to Bakucs et al. (2009), the regional market shares of slaughterhouses and institutional restrictions of hog transport can permit slaughterhouses to exercise oligopsony power towards farmers. The German pig farm sector is much less concentrated than the slaughterhouse sector. One indicator is the large number of farms compared to the number of slaughterhouses as reported in Figure 3.1. The farm sector is also loosely horizontally integrated in the form of farmer cooperatives and producer organizations. According to Theuvsen and Franz (2007), there are two types of German livestock wholesalers: Private livestock traders and cooperatively managed livestock trading organizations. The latter type of organizations can further be categorized as producer owned livestock trading cooperatives and as producing and marketing associations. While the former obliges farmers to market all their pigs to the cooperative, the latter allows commercial independence (Theuvsen and Franz, 2007). The distribution of farmers across the three types of wholesalers is comparable (Theuvsen and Franz, 2007).

The German pork supply chain is more vertically integrated downstream (slaughterhouse - retail) than upstream (farm - livestock wholesale - slaughterhouse). German pig farmers generally value their commercial independence and engage in spot market transactions with wholesalers and slaughterhouses (Deimel et al., 2008; Schulze et al., 2006; European Commission, 2010). Nevertheless, there are some large slaughterhouses such as Westfleisch that promote marketing contracts with farmers, and others such as EGO Osnabrück which are owned by farmers (European Commission, 2010). Vertical integration is also observed at the retail stage where retailers such as REWE and EDEKA are integrating into the meat processing industry (European Commission, 2010). Fixed price contracts are common between retailers and meat companies (slaughtering and processing). According to a report by Rabobank (2011), stringent contracts at the retail stage limit the transmission of input cost shocks to the consumers. This is particularly true in times of a sudden rise in input costs as retailers do not frequently renegotiate contracts. As a result, the margins of slaughterhouses sourcing pigs in the spot market are exposed to volatility (Rabobank, 2011).

Prices in the German pork market have generally remained stable over the last decade (as can also be seen from Figure 3.2 in section 3.5. Unlike the beef market, market regulation intensity on the pork (and poultry) market was low and limited to border protections and the occasional use of private storage aid (Assefa et al., 2016; Lence, 2007; Von Ledebur and Schmitz, 2012). A major source of price volatility in the German pig market is a demand shock caused by news of animal scares. Such news can originate within Germany and in other European countries, and from other meat markets (i.e. poultry and beef) (Serra et al., 2006). For instance, the price spike in 2001 in Germany (See Figure 3.2 in section 3.5 ) can be partly associated with the foot and mouth disease in the UK, which caused a switch from beef to pork (Serra et al., 2006; Ledebur and Schmitz, 2012).

\subsection{Theoretical framework}

In this section, first the transmission of prices along the German pork supply chain is described from a theoretical perspective. This is followed by a theoretical framework that describes the transmission of price volatility along the chain. Throughout this section, a chain consisting of a farm, slaughterhouse and retail stage is assumed. The effects of market power in the chain are accounted for in both theoretical models. In line with the structure of the German pork supply chain, it is assumed that retailers may exercise oligopsony and oligopoly power towards slaughterhouses and consumers, 
respectively. Slaughterhouses may exercise oligopsony power towards farmers but behave competitively towards retailers. A competitive farm sector is assumed.

\subsubsection{Price transmission}

The framework of Sexton and Zhang (2001) and Verreth et al. (2015) is followed to describe price transmissions theoretically. The framework starts with an inverse farm supply and an inverse consumer demand function specified as follows, respectively:

$P^{f}=S\left(Q^{f}, Z^{f}\right)$

$P^{r}=D\left(Q^{r}, Z^{r}\right)$

where, $P^{f}$ is the farm price of pork meat, $Q^{f}$ is the aggregate quantity of pork meat supplied by all farmers expressed in kilograms of slaughter weight, $Z^{f}$ represents exogenous supply shifters, $P^{r}$ is the consumer price of pork meat, $Q^{r}$ is the aggregate quantity of pork meat demanded by consumers expressed in kilograms of slaughter weight and $Z^{r}$ represents exogenous demand shifters.

Following Sexton and Zhang (2001) and Verreth et al. (2015), marginal marketing and processing costs of retailers and processors, respectively, are assumed to be constant. The profit function of retailer $i$ is given as follows (omitting exogenous demand and supply shifters for simplification of notations):

$\pi_{i}^{r}=D\left(Q^{r}\right) q_{i}^{r}-S\left(Q^{S}\right) q_{i}^{r}-c_{i}^{r} q_{i}^{r}$

where, $S\left(Q^{S}\right)=P^{S}$ is the inverse supply function of the slaughterhouse and $c_{i}^{r}$ is the unit marketing cost of the retailer. Averaging across retailers (i.e. $q_{i}^{r}=q^{r}$ and $c_{i}^{r}=c^{r}$ ), the profit maximization problem of a representative retailer with respect to quantity yields the following price relationship between the retail and slaughterhouse prices (for detailed derivations, the reader is referred to Sexton and Zhang (2001) and Verreth et al. (2015)):

$P^{r}\left(1-\frac{\theta^{r c}}{\epsilon^{r}}\right)=P^{s}\left(1+\frac{\theta^{r s}}{\gamma^{s}}\right)+c^{r}$

where, $\theta^{r c}=\frac{\partial Q^{r}}{\partial q^{r}} \frac{q^{r}}{Q^{r}}$ is the average conjectural elasticity measuring the retailer's oligopoly vis-a-vis consumers, $\epsilon^{r}=\frac{\partial Q^{r}}{\partial P^{r}} \frac{P^{r}}{Q^{r}}$ is the elasticity of consumer demand, $\theta^{r s}=\frac{\partial Q^{s}}{\partial q^{r}} \frac{q^{r}}{Q^{s}}$ is the conjectural elasticity measuring the retailer's oligopsony power towards the slaughterhouse and $\gamma^{s}=\frac{\partial Q^{s}}{\partial P^{s}} \frac{P^{s}}{Q^{s}}$ is the elasticity of slaughterhouse derived supply. A value of 1 for $\theta^{r c}$ and $\theta^{r s}$ indicates monopoly and monopsony power of the retailer towards consumers and slaughterhouses, respectively. A value of 0 corresponds to competitive behaviour of the retailer. Values between 0 and 1 indicate retailer oligopoly and oligopsony power.

The profit function of the slaughterhouse is given by

$\pi_{i}^{S}=D\left(Q^{S}\right) q_{i}^{S}-S\left(Q^{f}\right) q_{i}^{S}-c_{i}^{S} q_{i}^{S}$

where, $D\left(Q^{S}\right)=P^{s}$ is the inverse demand function of the slaughterhouse and $c_{i}^{S}$ is the unit marketing and processing cost of the slaughterhouse. After aggregation of quantities and costs across slaughterhouses, the profit maximization problem of a representative slaughterhouse with respect to quantity yields the following long-term price relation between the slaughterhouse and farm prices: 
$P^{s}=P^{f}\left(1+\frac{\theta^{s f}}{\gamma^{f}}\right)+c^{s}$

where, $\theta^{s f}=\frac{\partial Q^{f}}{\partial q^{s}} \frac{q^{s}}{Q^{f}}$ is the conjectural elasticity measuring the slaughterhouse's oligopsony power towards the farmers and $\gamma^{f}=\frac{\partial Q^{f}}{\partial P^{f}} \frac{P^{f}}{Q^{f}}$ is the elasticity of farm supply. A value of 1 for $\theta^{s f}$ indicates monopsony power of the slaughterhouse towards farmers and a value of 0 indicates competitive behaviour. Values between 0 and 1 indicate oligopsony power of the slaughterhouse towards farmers. Equation (4) and (6) can be combined to yield a long-term relationship between farm and retail prices:

$P^{r}\left(1-\frac{\theta^{r c}}{\epsilon^{r}}\right)=P^{f}\left(1+\frac{\theta^{s f}}{\gamma^{f}}\right)\left(1+\frac{\theta^{r s}}{\gamma^{s}}\right)+c^{s}\left(1+\frac{\theta^{r s}}{\gamma^{s}}\right)+c^{r}$

\subsubsection{Price volatility transmission}

In this section, the framework of Thille (2006) is followed to derive a theoretical relationship between the degree of market power and price volatility transmissions. Because the framework of Thille (2006) considers only one stage in the chain (a processor), the framework is extended to the case of multiple chain actors. The following linear farm supply and consumer demand functions that take into account supply and demand shocks, respectively, are assumed:

$P^{f}=a+\alpha Q^{f}+\varepsilon^{f}$

$P^{r}=b-\beta Q^{r}+\varepsilon^{r}$

where, $\varepsilon^{f}$ is an exogenous farm supply shock, $\varepsilon^{r}$ is an exogenous consumer demand shock, and $a, b$, $\alpha$ and $\beta$ are coefficients that can be estimated. The coefficients $\alpha$ and $\beta$ are the slopes of the inverse farm supply and inverse consumer demand curves, respectively. Equation (8) and (9) are linear specifications of equation (1) and (2), respectively. It is assumed that any supply or demand shock at the slaughterhouse stage originates from the farm sector (e.g. due to animal diseases or other disruptions to production) and from consumers (e.g. variations in demand due to e.g. changing consumer preferences, NGO campaigns on meat or animal welfare), respectively. No shocks in the marketing and processing costs of the slaughterhouse are assumed to occur. The same assumption holds for the marketing costs of the retailer. The farm supply shock $\varepsilon^{f}$ is proxied by a farm price shock, and the consumer demand shock $\varepsilon^{r}$ is proxied by a retail price shock.

In the context of this paper, price volatility transmission refers to the extent to which price volatilities at different stages of the chain respond to farm and retail price shocks. To relate the degree of market power with price volatility transmission, the profit maximization problems of the slaughterhouse and the retailer should be solved for. The degree of market power is measured using the conjectural variation. Since farmers are assumed to behave competitively, the conjectural elasticity measuring the degree of farmer market power is equal to zero. Therefore, the profit maximization problem of farmers is not solved for. This confines the analysis of price volatility transmission to the slaughterhouse and retail stages. That is, the extent to which slaughterhouse and retail price volatilities respond to farm and retail price shocks will be investigated.

To solve the profit maximization problem of the retailer, the inverse supply function of the slaughterhouse is first derived by substituting (8) into (6), and is given by: 
$P^{s}=\left(a+\alpha Q^{f}+\varepsilon^{f}\right)\left(1+\frac{\theta^{s f}}{\gamma^{f}}\right)+c^{s}$

Given the slaughterhouse derived supply function provided in (10), the profit function of the retailer is specified as follows:

$\pi^{r}=\left(b-\beta Q^{r}+\varepsilon^{r}\right) q^{r}-\left(\left(a+\alpha Q^{f}+\varepsilon^{f}\right)\left(1+\frac{\theta^{s f}}{\gamma^{f}}\right)+c^{s}\right) q^{r}-c^{r} q^{r}$

Following Thille (2006), equation (11) is first used to solve the profit maximization problem of the retailer with respect to quantity $\left(q^{r}\right)$ and obtain an expression for $Q^{r}$. Substituting the resulting expression of $Q^{r}$ into (9) and taking variances on both sides results in the following expression of the retail price volatility:

$\sigma_{r}^{2}=\sigma_{\varepsilon^{r}}^{2}\left(1-\frac{\beta}{\beta+\alpha+\beta \theta^{r c}+\alpha \theta^{r f}\left(1+\frac{\theta^{s f}}{\gamma^{f}}\right)+\alpha\left(\frac{\theta^{s f}}{\gamma^{f}}\right)}\right)^{2}+\sigma_{\varepsilon^{f}}^{2}\left(\frac{\beta}{\beta+\alpha+\beta \theta^{r c}+\alpha \theta^{r f}\left(1+\frac{\theta^{s f}}{\gamma^{f}}\right)+\alpha\left(\frac{\theta^{s f}}{\gamma^{f}}\right)}\right)^{2}\left(1+\frac{\theta^{s f}}{\gamma^{f}}\right)^{2}$

where, $\sigma_{r}^{2}$ is the retail price volatility (variance), $\sigma_{\varepsilon^{r}}^{2}$ is the variance of the retail price shock, $\sigma_{\varepsilon^{f}}^{2}$ is the variance of the farm price shock, $\theta^{r f}=\frac{\partial Q^{f}}{\partial q^{r}} \frac{q^{r}}{Q^{f}}$ is the conjectural elasticity measuring the degree of retailer oligopsony power towards the farmers, and $\theta^{r c}$ and $\theta^{s f}$ are the conjectural variations as defined in (4) and (6) respectively. Equation (12) reveals that, as retail market power increases $\left(\theta^{r c}\right.$ and $\theta^{r f}$ ) relative to the slaughterhouse market power $\left(\theta^{s f}\right)$, the response of the retail price volatility to a retail price shock (consumer demand shock) becomes much higher than the response to a farm price shock (farm supply shock). This is particularly true if the inverse farm supply curve is steep (i.e. large $\alpha$ ) and/or the inverse consumer demand curve is flatter (i.e. small $\beta$ ). Furthermore, it can be shown that a stronger slaughterhouse market power can increase the response of the retail price volatility to farm price shocks (due to the expression $\left(\left(1+\frac{\theta^{s f}}{\gamma^{f}}\right)^{2}\right.$ ).

In equation (12), it can further be seen that in the absence of market power in the chain (i.e. $\theta^{r c}=$ $\theta^{r f}=\theta^{s f}=0$ ), the retail price volatility depends mainly on the slopes of the inverse farm supply and consumer demand curves (i.e. $\alpha$ and $\beta$, respectively). It can also be noted that, in the absence of market power, the steeper is the inverse consumer demand curve (i.e. larger $\beta$ ), the higher will be the effect of a farm price shock (farm supply shock) on retail price volatility. Also, the steeper is the inverse farm supply curve (i.e. larger $\alpha$ ), the higher will be the effect of a retail price shock (consumer demand shock) on retail price volatility.

To obtain an expression of the slaughterhouse price volatility, the derived demand function of the slaughterhouse is obtained by substituting equation (9) into (4). This leads to:

$P^{s}=\left(b-\beta Q^{r}+\varepsilon^{r}\right)\left(\frac{\left(1-\frac{\theta^{r c}}{\epsilon^{r}}\right)}{\left(1+\frac{\theta^{r s}}{\gamma^{s}}\right)}\right)-\frac{c^{r}}{\left(1+\frac{\theta^{r s}}{\gamma^{s}}\right)}$

Using equation (13), the profit function of the slaughterhouse can be expressed as: 
$\pi^{S}=\left(\left(b-\beta Q^{r}+\varepsilon^{r}\right)\left(\frac{\left(1-\frac{\theta^{r c}}{\epsilon^{r}}\right)}{\left(1+\frac{\theta^{r S}}{\gamma^{s}}\right)}\right)-\frac{c^{r}}{\left(1+\frac{\theta^{r s}}{\gamma^{s}}\right)}\right) q^{s}-\left(a+\alpha Q^{f}+\varepsilon^{f}\right) q^{S}-c^{s} q^{s}$

Solving $Q^{r}$ by maximizing the slaughterhouse's profit with respect to quantity $\left(q^{S}\right)$, substituting the resulting expression back into equation (13), and taking variances on both sides results in the following equation for the slaughterhouse price volatility:

$\sigma_{s}^{2}=\sigma_{\varepsilon^{r}}^{2}\left(\left(\frac{\left(1-\frac{\theta^{r c}}{\epsilon^{r}}\right)}{\left(1+\frac{\theta^{r S}}{\gamma^{s}}\right)}\right)-\frac{\beta\left(\frac{\left(1-\frac{\theta^{r c}}{\epsilon^{r}}\right)}{\left(1+\frac{\theta^{r s}}{\gamma^{s}}\right)}\right)^{2}}{\beta \frac{\left(1-\frac{\theta^{r c}}{\epsilon^{r}}\right)}{\left(1+\frac{\theta^{r S}}{\gamma^{s}}\right)}+\alpha \theta^{s f}+\alpha}\right)^{2}+\sigma_{\varepsilon^{f}}^{2}\left(\frac{\beta\left(\frac{\left(1-\frac{\theta^{r c}}{\epsilon^{r}}\right)}{\left(1+\frac{\theta^{r s}}{\gamma^{s}}\right)}\right)}{\beta \frac{\theta^{r c}}{\left.\epsilon^{r}\right)}+\alpha \theta^{s f}+\alpha}\right)^{2}$

Equation (15) shows that the response of the slaughterhouse price volatility to a retail price shock is much higher than the response to a farm price shock when retail market power is much higher than the slaughterhouse market power. This is particularly true when the inverse farm supply curve is steep (i.e. large $\alpha$ ) and/or the inverse consumer demand curve is flatter (i.e. small $\beta$ ). The inelasticity of farm supply implied by a steep inverse farm supply curve causes large movements in the retail price whenever there is a demand shock (i.e. farm supply does not respond to the demand shock). This large movement or volatility in the retail price is then transmitted to the slaughterhouse stage. This is especially true if the retailers have strong market power.

\subsection{Empirical framework}

\subsubsection{Price transmission}

This section investigates whether prices in the pork supply chain are transmitted consistent with a long-term cointegrating relationship as described by equation (4), (6) or (7). Time-series data can exhibit non-stationary behaviour that can lead to either a cointegrating relationship or a spurious regression (Brooks, 2008). Therefore, before investigating price transmissions between farm, slaughterhouse and retail stages, each of the price series is tested for stationarity. The Augmented Dickey-Fuller test, the Philips-Perron test and the Dickey-Fuller GLS test are applied to test the stationarity of the series. The null hypothesis in all tests is the presence of a unit root in the series (i.e. the series are non-stationary). If the series are all non-stationary in levels and are stationary when firstdifferenced, the series are said to be integrated of order one and a linear combination of the prices may exist that is stationary (Brooks, 2006). This linear combination is termed as the cointegrating relationship that ties the price series in the long-run. If an equilibrium long-run cointegrating relationship(s) exist, deviations of prices from this equilibrium will be corrected in the short-run (Brooks, 2008).

The Johansen test for cointegration (Johansen and Juselius, 1992) is used to test the presence of one or more cointegrating relationship between the price series. For price series that are integrated of order one, a vector error correction model (VECM) is used to model price transmissions consistent with a long-term cointegrating relationship. The VECM is specified as follows:

$\Delta P_{t}=\pi P_{t-1}+\sum_{i=1}^{p} \Gamma_{i} \Delta P_{t-i}+\Theta D_{t}+\varepsilon_{t}$ 
where, $P_{t}=\left[\begin{array}{lll}P_{t}^{f} & P_{t}^{s} & P_{t}^{r}\end{array}\right]^{\prime}$ and $\varepsilon_{t}=\left[\begin{array}{lll}\varepsilon_{t}^{f} & \varepsilon_{t}^{s} & \varepsilon_{t}^{r}\end{array}\right]^{\prime}$.

In equation (16), $\pi$ is a $k \times r$ matrix where $k$ is the number of price series (here 3 ) and $r$ is the rank of the matrix $\pi$ which is also the number of cointegrating vectors. In equation (16), $\pi=\alpha \beta$ where $\alpha$ is a $k \times r$ matrix of adjustment coefficients of each price series to deviations from the long-run cointegrating vectors and $\beta$ is a $r \times k$ matrix of cointegrating vectors.

A maximum of two cointegrating vectors is possible for the three price series (i.e. farm, slaughter and retail prices). In the theoretical framework, possible cointegrating vector(s) between the prices are given by equations (4), (6) and (7). More specifically, if the series are found to be cointegrated, the matrix $\beta P_{t-1}$ can take the form of one or two of the following equations:

$P_{t-1}^{r}\left(1-\frac{\theta^{r c}}{\epsilon^{r}}\right)-P_{t-1}^{S}\left(1+\frac{\theta^{r s}}{\gamma^{s}}\right)-c^{r}$

$P_{t-1}^{S}-P_{t-1}^{f}\left(1+\frac{\theta^{s f}}{\gamma^{f}}\right)-c^{S}$

$P_{t-1}^{r}\left(1-\frac{\theta^{r c}}{\epsilon^{r}}\right)-P_{t-1}^{f}\left(1+\frac{\theta^{s f}}{\gamma^{f}}\right)\left(1+\frac{\theta^{r s}}{\gamma^{s}}\right)-c^{s}\left(1+\frac{\theta^{r s}}{\gamma^{s}}\right)-c^{r}$

In (17), (18) and (19), the terms in parentheses and the constants $c^{r}$ and $c^{S}$ are coefficients to be estimated. If the terms in parentheses are different from 1, it implies the presence of market power in the respective chain stages. For instance, in equation (19), if the term $\left(1-\frac{\theta^{r c}}{\epsilon^{r}}\right)$ is different from 1 , it implies the existence of retailer oligopoly power towards consumers. In equation (16), short-run price dynamics are captured by the $\Gamma_{i}$ coefficients. The lag length $p$ to capture short-run dynamics is determined by using various information criteria. A Granger causality test is conducted on the $\Gamma_{i}$ coefficients to see if prices transmit in the short-run from one stage of the chain to another. Deterministic terms such as trends and seasonality are captured by the coefficients matrix $\Theta$.

\subsubsection{Price volatility transmission}

The theoretical models in equation (12) and (15) are empirically estimated to investigate the responses of slaughterhouse and retail price volatilities to farm and retail price shocks. In equation (12) and (15), the right hand terms other than $\sigma_{\varepsilon^{r}}^{2}$ and $\sigma_{f}^{2}$ are coefficients to be estimated. In line with the theoretical models in (12) and (15), the retail price volatility is measured as the variance in the retail price. At time $t$, the retail price volatility $\sigma_{r}^{2}$ in equation (12) is given by the square in the change in the retail price $\sigma_{r, t}^{2}=\left(\Delta P_{t}^{r}\right)^{2}$. Similarly, at time $t$, the slaughterhouse price volatility $\sigma_{s}^{2}$ in equation (15) is given by $\sigma_{s, t}^{2}=\left(\Delta P_{t}^{S}\right)^{2}$. The retail price shock is proxied by the residual term $\varepsilon_{t}^{r}$ in the retail price equation of equation (16) and its variance is given by $\sigma_{\varepsilon_{t}^{r}}^{2}=\left(\varepsilon_{t}^{r}\right)^{2}$ (i.e. $\sigma_{\varepsilon^{r}}^{2}$ in equation (12) and (15)). Similarly, the variance in the farm price shock $\sigma_{\varepsilon^{f}}^{2}$ is given by $\sigma_{\varepsilon_{t}^{f}}^{2}=\left(\varepsilon_{t}^{f}\right)^{2}$ (i.e. $\sigma_{\varepsilon^{f}}^{2}$ in equation (12) and (15)) where $\varepsilon_{t}^{f}$ is the residual term in the farm price equation of equation (16). The residual terms $\varepsilon_{t}^{r}$ and $\varepsilon_{t}^{f}$ are assumed to have a mean of zero.

Equation (12) and (15) are estimated using OLS. More formally, the estimated equations are specified as follows:

$\sigma_{r, t}^{2}=a_{r} \sigma_{\varepsilon_{t}^{r}}^{2}+b_{r} \sigma_{\varepsilon_{t}^{f}}^{2}+u_{r, t}$ 


$$
\sigma_{s, t}^{2}=a_{s} \sigma_{\varepsilon_{t}^{r}}^{2}+b_{s} \sigma_{\varepsilon_{t}^{f}}^{2}+u_{s, t}
$$

In the above equations, $a_{r}$ and $a_{s}$ are coefficients measuring the effects of the variance in retail price shocks on slaughterhouse and retail price volatilities, respectively. The effects of the variance in farm price shocks on slaughterhouse and retail price volatilities are measured by the coefficients $b_{r}$ and $b_{s}$, respectively. In line with the theoretical models in equation (12) and (15), the test for the presence of market power in the German fresh pork supply chain is made by investigating whether retail and slaughterhouse retail price volatilities respond more to retail price shocks than to farm price shocks. More specifically, $a_{r}$ significantly larger than $b_{r}$, and $a_{s}$ significantly larger than $b_{s}$ may indicate that retail market power is larger than slaughterhouse market power.

\subsection{Data}

The empirical framework is applied using monthly price data from January 2000 to December 2011 along the German fresh pork supply chain. Monthly farm pig prices are obtained from the Federal Institute of Agriculture and Food in Bonn (Bundesanstalt für Landwirtschaft und Ernährung). The farm prices are a weighted average price of all slaughter pigs in Germany (according to European carcass classes $\mathrm{S}, \mathrm{E}, \mathrm{U}, \mathrm{R}, \mathrm{O}, \mathrm{P})$. Slaughterhouse pork prices are proxied by wholesale pork prices per $\mathrm{kg}$ collected on the meat wholesale market in Hamburg (FleischGroßmarkt Hamburg). These prices are a simple average of prices of different pork cuts. The retail price data from 2004 to 2011 are collected by the GfK - consumer panel. The pre-2004 retail prices were collected through special price collectors from the Agricultural Market Information Company in Bonn who visited several stores in Germany to collect product prices. The retail prices are a simple average of different pork cuts. While the farm and slaughterhouse prices exclude VAT, the retail prices include VAT. All prices are expressed in euro per kilogram. Table 3.1 below presents the summary statistics of prices. The evolution of prices over time is presented in Figure 3.2.

Table 3.1 - Summary statistics of farm, slaughterhouse and retail prices

\begin{tabular}{llll}
\hline & Farm $\left(P_{t}^{f}\right)$ & Slaughterhouse $\left(P_{t}^{S}\right)$ & Retail $\left(P_{t}^{r}\right)$ \\
\hline Mean $(€ / \mathrm{kg})^{1}$ & 1.41 & 2.02 & 5.83 \\
Maximum $(€ / \mathrm{kg})$ & 1.99 & 2.70 & 6.47 \\
Minimum $(€ / \mathrm{kg})$ & 1.02 & 1.60 & 5.29 \\
Std. Dev. & 0.16 & 0.23 & 0.26 \\
Observations & 144 & 144 & 144 \\
\hline
\end{tabular}

Prices are in euro per kilogram of slaughter weight 


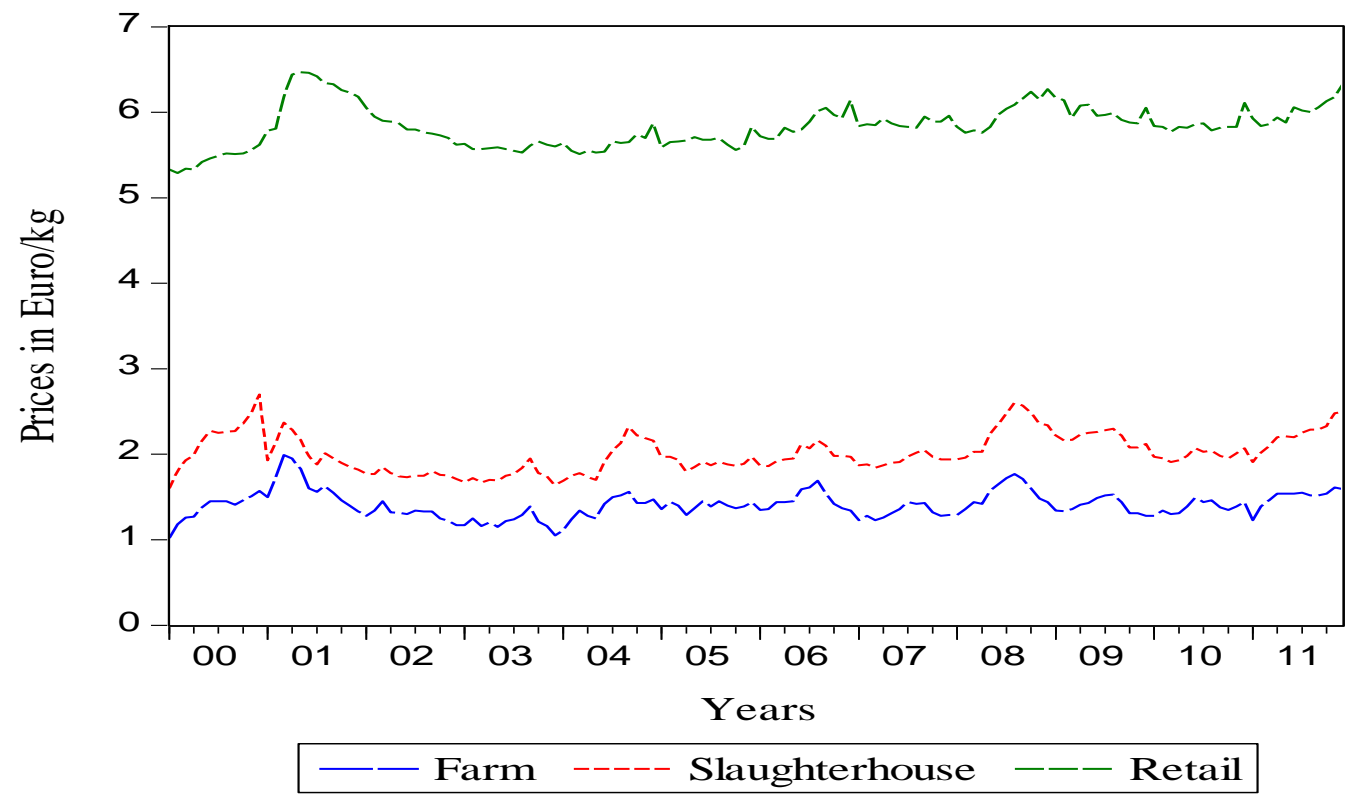

Figure 3.2 -Monthly plots of prices in the German fresh pork supply chain

\subsection{Results and discussion}

\subsubsection{Price transmission}

Table 3.2 reports the results of the unit root tests. All three tests show that the null of non-stationarity could not be rejected at the $1 \%$ critical level for all prices in levels. Unit root tests on first differences show that all three prices are stationary in first differences at the $1 \%$ critical level, implying that the three price series are integrated of order one. It further implies that a linear combination of the three prices may exist that is stationary. 
The VECM was first estimated with a lag length of one and seasonality terms. Nevertheless, since the Lagrange Multiplier autocorrelation test suggested the presence of autocorrelation in the residuals, a lag length of five was added to the model. According to Parker and Shonkwiler (2014), the German hog cycle has an approximate duration of four years. However, price cycles were not taken into account in the model due to the short length (11 years) of the data series available for this paper. Results should therefore be interpreted with caution. Seasonality terms in Table 3.4 are particularly significant in the farm and retail price equations. Since the $12^{\text {th }}$ month was dropped from the equations, the seasonality coefficients can be interpreted as the change of prices relative to the $12^{\text {th }}$ month. The results in the farm equation show that farm prices increase in the $2^{\text {nd }}$ and $6^{\text {th }}$ month relative to the $12^{\text {th }}$ month. This can be associated with the tightening up of supply in those months. However, retail prices are significantly lower in all months relative to the $12^{\text {th }}$ month. This latter result can be associated with the large demand for pork meat the $12^{\text {th }}$ month (for instance due to Christmas holidays) and therefore high prices relative to the rest of the year. Because the Johansen cointegration test suggested one cointegrating relation, a Likelihood Ratio coefficient restriction test was applied to the VECM to identify the cointegrating relation suggested by theory (given by equation (4), (6) or (7)). The result of this test (obtainable upon request from the authors) identified equation (7) as the long-run cointegrating relation.

Results in Table 3.4 show that the retail and farm prices are cointegrated and therefore are driven by similar forces in the long-run. This result indicates that retail and farm prices are the main price setters in the chain. The result is plausible due to the fact that pig prices are the main reference prices for pork meat prices in the chain. The high concentration of the retail sector (Anders, 2008) suggests this chain actor can be considered as a price setter. As shown in Table 3.4, the adjustment coefficients (coefficients on $\beta P_{t-1}$ in Table 3.4) indicate that retail price deviations from the long-run equilibrium relation $\left(p_{t-1}^{r}=3.06 p_{t-1}^{f}+1.52\right)$ are corrected every month. However, monthly farm price deviations from the long-run equilibrium are not corrected each month as indicated by the nonsignificant adjustment coefficient in the farm price equation. This result indicates the important role that the retail sector plays in maintaining the long-term price equilibrium relation. In Table 3.4 , the adjustment coefficient in the slaughterhouse price equation is statistically significant and positive. The sign of the adjustment coefficient indicates that at time $t-1$, when the farm price increases (decreases) relative to the equilibrium relation, the slaughterhouse price also increases (decreases); however, the slaughterhouse price decreases (increases) back at time $t$. The result indicates a contemporaneous relationship between the farm and slaughterhouse prices.

The cointegrating vector $p_{t-1}^{r}-3.06 p_{t-1}^{f}-1.52$ can also be estimated without normalizing with respect to any price. Such estimation gives the cointegrating vector $3.42 p_{t-1}^{r}=10.48 p_{t-1}^{f}+5.20$. This vector results from estimating equation (7) of the theoretical framework. Since we have $(1+$ $\left.\frac{\theta^{s f}}{\gamma^{f}}\right)\left(1+\frac{\theta^{r s}}{\gamma^{s}}\right) \neq 1$ (i.e. 10.48), this suggests the presence of oligopsony power in the German pork chain (either slaughterhouse towards farm or retail towards slaughterhouse or both). Similarly, since $\left(1-\frac{\theta^{r c}}{\epsilon^{r}}\right) \neq 1$ (i.e. 3.42 ), this suggests the presence of oligopoly power of the retailer towards consumers. The result on oligopsony power confirms Anders (2008) and Weber and Anders (2007) who state that German retailers may be using market power to mark-down margins of slaughterhouses. The result also supports the assertion made by Bakucs et al. (2009) that slaughterhouses possess regional market power towards farmers. Although the role of livestock wholesalers was not modelled in this paper, the above result also indicates that the price pressure that slaughterhouses put on farm prices could not be curtailed by German livestock wholesalers who act as intermediaries between the 
farm and slaughterhouse stages. It should however be noted that, although the theoretical model presented in equation (7) makes a distinction between the oligopsony power exercised at the slaughterhouse level from that exercised at the retail level, the estimated empirical model cannot make that distinction (i.e. the term $\left(1+\frac{\theta^{s f}}{\gamma^{f}}\right)\left(1+\frac{\theta^{r s}}{\gamma^{s}}\right)$ in equation (16) is a single parameter). The presence of oligopoly power of retailers towards consumers is rather unexpected given the strong price competition that exists between retailers (Anders, 2008; Weber and Anders, 2007). The result indicates that, although retailers compete on keeping prices as low as possible, they still charge prices above marginal costs. Had the German retail market been perfectly competitive, a rational expectation would be that retailers would charge a price equal to marginal cost.

Table 3.4 - Price transmission (VECM)

\begin{tabular}{cccc}
\hline Independent variables $^{1}$ & $\Delta P_{t}^{f}$ & $\Delta P_{t}^{S}$ & $\Delta P_{t}^{r}$ \\
\hline$\beta P_{t-1}$ & $0.02(0.02)$ & $0.06(0.03)^{* *}$ & $-0.13(0.02)^{* *}$ \\
$\Delta p_{t-1}^{f}$ & $0.40(0.14)^{* *}$ & $0.61(0.20)^{* *}$ & $0.19(0.14)$ \\
$\Delta p_{t-1}^{s}$ & $-0.17(0.09)$ & $-0.30(0.12)^{* *}$ & $0.02(0.10)$ \\
$\Delta p_{t-1}^{r}$ & $-0.21(0.08)^{* *}$ & $-0.11(0.12)$ & $-0.34(0.09)^{* *}$ \\
$\Delta p_{t-5}^{f}$ & $0.01(0.13)$ & $0.13(0.19)$ & $0.05(0.14)$ \\
$\Delta p_{t-5}^{S}$ & $0.25(0.09)^{* *}$ & $0.18(0.12)$ & $0.06(0.09)$ \\
$\Delta p_{t-5}^{r}$ & $-0.02(0.08)$ & $-0.03(0.11)$ & $-0.17(0.08)$ \\
$S 1$ & $-0.04(0.03)$ & $-0.17(0.04)^{* *}$ & $-0.17(0.03)^{* *}$ \\
$S 2$ & $0.06(0.03)^{* *}$ & $-0.02(0.04)$ & $-0.13(0.03)^{* *}$ \\
$S 3$ & $0.04(0.03)$ & $-0.00(0.04)$ & $-0.13(0.03)^{* *}$ \\
$S 4$ & $-0.01(0.03)$ & $-0.03(0.04)$ & $-0.07(0.03)^{* *}$ \\
$S 5$ & $0.05(0.03)$ & $0.02(0.04)$ & $-0.08(0.03)$ \\
$S 6$ & $0.09(0.03)^{* *}$ & $0.06(0.04)$ & $-0.12(0.03)^{* *}$ \\
$S 7$ & $0.01(0.03)$ & $-0.02(0.04)$ & $-0.15(0.03)^{* *}$ \\
$S 8$ & $0.03(0.03)$ & $0.04(0.04)$ & $-0.15(0.03)^{* *}$ \\
$S 9$ & $-0.01(0.03)$ & $0.02(0.04)$ & $-0.14(0.03)^{* *}$ \\
$S 10$ & $-0.05(0.03)$ & $-0.05(0.04)$ & $-0.14(0.03)^{* *}$ \\
$S 11$ & $0.01(0.03)$ & $0.00(0.04)$ & $-0.11(0.03)^{* *}$ \\
Constant & $-0.01(0.02)$ & $0.01(0.03)$ & $0.12(0.02)^{* *}$ \\
Cointegrating vector & $P_{t-1}^{r}-3.06^{* *} P_{t-1}^{f}-1.52$ & \\
$\left(\beta P_{t-1}\right)$ & $(-9.61)$ & &
\end{tabular}

${ }^{1}$ The asterisk $* *$ indicates significant values at the 5\% level. Standard errors are in parentheses. A lag length of 1 was first selected based on the suggestion of three information criteria (i.e. final prediction error, Akaike information criterion and Hannan-Quinn information criterion). A lag length of 5 was added to remove autocorrelation in the residuals.

In Table 3.4, seasonality terms are significant particularly in the farm and retail price equations. Since the $12^{\text {th }}$ month (December) was dropped from the equations, the seasonality coefficients can be interpreted as the change of prices relative to prices in December. The results in the farm price equation show that farm prices increase in the $2^{\text {nd }}$ (February) and $6^{\text {th }}$ (June) months relative to farm prices in the December. The higher farm prices in February and June can be associated with the low supply of pigs in those two periods (post-Christmas and Easter holidays, respectively). Retail prices on the other hand drop in those two months compared to prices in the $12^{\text {th }}$ month. The lower retail prices in those two months can be due to promotional price reductions by retailers to induce an increase in consumer demand. 
Granger causality tests were conducted to test for short-run price transmission. The results of these tests are reported in Table 3.5 below. The tests show that, in the short-run, prices transmit from the farm to the slaughterhouse stage and vice versa. However, no short-run transmission is detected between the slaughterhouse and retail prices. The latter result can be attributed to the use of long-term contracts between slaughterhouses and retailers. The absence of transmission from the slaughterhouse to the retail stage also confirms the finding on the rigidity of retail prices advanced by Weber and Anders (2007). The Granger causality test shows that retail prices are not affected by short-term changes in farm prices. In Table 3.4, it was shown that retail prices correct price deviations from the long-run equilibrium relation. Coupled with the result from the Granger causality tests, this suggests that the retail price only corrects its own deviations from the equilibrium and does not adjust to the deviations of the equilibrium farm price. A rather surprising result is the short-run transmission of prices from the retail to the farm stage given the presence of slaughterhouses as intermediaries. This result is possibly caused by the presence of retailers like REWE and EDEKA that have integrated backwards to the slaughtering and processing stages (European Commission, 2010) and therefore deal directly with farmers.

Table 3.5 - Granger causality test results

\begin{tabular}{llll}
\hline & To farm & To slaughterhouse & To retail \\
\hline From farm & $\mathrm{NA}^{2}$ & $10.11^{* *}$ & 1.67 \\
From slaughterhouse & $3.65^{*}$ & $\mathrm{NA}$ & 0.05 \\
From retail & $6.28^{* *}$ & 0.82 & $\mathrm{NA}$ \\
\hline
\end{tabular}

${ }^{\mathrm{I}}$ The asterisk ** indicates significant values at the 5\% level. Standard errors are in parentheses. Reported values are Wald statistics.

${ }^{2}$ NA: Not applicable

\subsubsection{Price volatility transmission}

Estimation results of equation (20) and (21) are reported in Table 3.6 below. The results show that retail price shocks significantly affect retail price volatility. However, farm price shocks do not significantly affect retail price volatility. Moreover, the magnitude of the coefficient on retail price shocks $\left(\sigma_{\varepsilon^{r}, t}^{2}\right)$ is much larger than that on farm price shocks $\left(\sigma_{\varepsilon^{f}, t}^{2}\right)$. As suggested in the theoretical framework (equation (12) and (15)), these results suggest that German retailers may be possessing stronger market power relative to slaughterhouses. The results also imply a rather steep inverse farm supply curve, which in turn implies a price inelastic farm supply. This assertion is consistent with the findings of Bakucs et al. (2009) on the price inelasticity of farm pig supply in Germany. The absence of farm price shock transmission to the retail stage can be an indication of the limited price negotiation power of slaughterhouses. This can be detrimental to slaughterhouses in case of a sudden increase in farm prices as margins can be squeezed. It was hypothesized based on equation (12) that a stronger slaughterhouse market power can increase the response of the retail price volatility to farm price shocks. Results in Table 3.6 indicate however that German slaughterhouses may not possess enough countervailing power. Consumers can benefit from the non-transmission of farm price shocks as prices will be stable. However, they can loose from the non-transmission of sudden farm price drops.

Similar to the retail price volatility equation, the magnitude of the coefficient on retail price shocks $\left(\sigma_{\varepsilon^{r}, t}^{2}\right)$ is much larger than that on farm price shocks $\left(\sigma_{\varepsilon^{f}, t}^{2}\right)$ in the slaughterhouse price volatility equation. The coefficient on farm price shocks is also not statistically significant. These results provide further evidence that German retailers may be possessing stronger market power relative to 
slaughterhouses. The results also provide further evidence that farm supply is inelastic. According to Rabobank (2011), retailers renegotiate contracts with their suppliers mainly in case of a sudden rise in input costs. In contrast, results of this chapter suggest that retailers may not be renegotiating contracts in response to input price shocks. Contrasting the results in Table 3.6 with those in Table 3.5, the fact that "predictable" farm price changes (Table 3.5) transmit in the short-run to the slaughterhouse stage while the "unpredictable" farm price changes (Table 3.6) do not can be an indication that retailers may be renegotiating contracts with slaughterhouses only in responses to "predictable" farm price changes. Results show on the other hand that retailers may be renegotiating contracts in response to sudden demand shocks as evidenced by the response of slaughterhouse price volatility to retail price shocks. While the transmission of a sudden drop in the retail price may harm slaughterhouses and farmers, the transmission of a sudden increase in retail prices can benefit them.

The non-transmission of farm price volatility to the retail stage is in line with assertions made in previous studies (for instance, Alexandri (2011) and Serra (2011)) It should be noted however that the theoretical relationship between market power and price volatility transmission is valid under restrictive conditions. Such conditions include for instance the linear specification of the inverse farm supply and consumer demand functions. The elasticities of consumer demand and farm supply also determine the theoretical relationship between market power and price volatility transmission. To our knowledge, this chapter is the first to examine price volatility transmission along the German fresh pork supply chain. Nevertheless, results of this paper can still be contrasted to the claims made by Weber and Anders (2007) about the rigidity of German meat retail prices. While this chapter finds that German retail pork prices are rigid to farm price shocks (see Table 3.6), it finds that they are not rigid to retail price shocks (proxy for consumer demand shocks). Therefore, this paper did not support the finding of Weber and Anders (2007) that German retail meat prices are rigid. The difference in the approach followed in the two papers should however be noted. The approach of Weber and Anders (2007) consisted of calculating the number of weeks meat prices in retail stores remain unchanged while this paper investigated the response of retail (and slaughterhouse) price volatility to retail and farm price shocks. The extent to which price volatility transmits in the chain can also depend on whether the food product is a premium or a bulk product (Assefa et al., 2016). Assefa et al. (2016) showed that price increases in premium products can easily be transmitted to consumers. Therefore, the transmission of farm price shocks can be detected if one used data for premium pork cuts. Although this chapter did not distinguish between types of meat cuts, differentiating the price volatility transmission analysis between premium and bulk products can be an interesting avenue for future research.

Besides implying the degree of market power in the chain, results reported in Table 3.6 also indicate that demand shocks are important sources of price volatility in the German fresh pork supply chain. The fact that retail price shocks transmit to the upstream stages of the chain (slaughterhouse, farm) shows that these upstream stages can be easily exposed to price shocks caused by news on animal health scares. News of food scares results in consumer panic and loss of confidence in the safety of consuming meat products (Feindt and Kleinschmit, 2011; Kupferschmidt, 2011; Serra, 2011; Thomson et al., 2012) and therefore in lower meat prices. The transmission of the sudden drop in retail prices can in turn be harmful to farmers. One point worth noting is the low $R^{2}$ of the slaughterhouse volatility equation. The low $R^{2}$ is an indication that additional factors unaccounted in the model cause the slaughterhouse price volatility to increase. Other factors can include input costs other than pigs. 
Table 3.6 - Price volatility transmission (OLS)

\begin{tabular}{cll}
\hline Independent variables $^{1}$ & \multicolumn{1}{c}{$\sigma_{r, t}^{2}$} & $\sigma_{s, t}^{2}$ \\
\hline$\sigma_{\varepsilon^{r}, t}^{2}$ & $1.57(0.37)^{* *}$ & $1.27(0.58)^{* *}$ \\
$\sigma_{\varepsilon^{f}, t}^{2}$ & $0.40(0.39)$ & $0.63(0.80)$ \\
$R^{2}$ & 0.41 & 0.02 \\
\hline
\end{tabular}

${ }^{1}$ The asterisk ** indicates significant values at the 5\% level. Standard errors are in parentheses. The equation for the retail price variance included a one lag moving average term $\left(u_{r, t-1}\right)$ to correct for autocorrelation of residuals. Standard errors for the retail price variance equation are White robust standard errors.

\subsection{Conclusions}

This paper investigated the relationship between price volatility transmission and market power in the German fresh pork supply chain. The empirical analysis used monthly farm, slaughterhouse and retail prices. Price transmission along the chain was investigated by estimating a vector error correction model. Next, price volatility transmissions were investigated through least square regressions using price residuals from the first step. Estimation was based on theoretical models developed in order to relate both types of transmissions with the degree of market power. Results from the price transmission analysis showed that, while farm and slaughterhouse prices transmitted bi-directionally in the short-run, retail prices were found to be irresponsive to short-term price changes coming from the farm and slaughterhouse stages. The results further established a long-run cointegrating relationship between the farm and retail prices indicating that the two prices followed the same long-run trend. The slaughterhouse price adjusted to this equilibrium relationship. The analysis on price volatility transmissions showed that both slaughterhouse and retail price volatilities do not respond to farm price shocks. However, price volatilities in both stages responded to retail price shocks.

The price transmission analysis suggested the existence of slaughterhouse oligopsony and retail oligopsony/oligopoly power. Although German retailers operate in a market that is characterised by strong price competition, the cointegration analysis revealed that retailers have oligopoly market power and may therefore be charging consumer prices above marginal costs. The cointegration analysis also showed that oligopsony power results in the marking down of input prices. Market power in the German fresh pork supply chain was also reflected in the results from the price volatility transmission analysis. Results indicated that retailers might be using market power to curtail the transmission of farm price shocks while they transmit retail price shocks backwards into the chain. Retail market power limits the transmission of both price and price volatility transmission in the chain. Although the transmission of price volatility is undesirable, the non-transmission of price volatility can also be undesirable. For instance, while the non-transmission of a sudden farm price drop to consumers can harm consumers, the non-transmission of a sudden consumer price rise to the farm stage can harm farms. Therefore, a competitive market whereby both predictable and non-predictable price signals flow though the chain should be encouraged. The negative effects of price volatility transmissions can be minimized through policy measures that support the price risk management initiatives of chain actors. 


\section{References}

Acharya, R.N., Kinnucan, H.W. and Caudill, S.B. (2011). Asymmetric farm-retail price transmission and market power: a new test. Applied Economics, 43(30), 4759-4768.

Agricultural Market Information Company. http://www.ami-informiert.de/ami-maerkte.html.

Alexandri, C. (2011). Analysis of price transmission along the agri-food chains in Romania. Agricultural Economics and Rural Development, 8(2), 171-189.

Anders, S. M. (2008). Imperfect competition in German food retailing: Evidence from State level data. Atlantic Economic Journal, 36 (4), 441-454.

Appelbaum, E.(1982). The estimation of the degree of oligopoly power. Journal of Econometrics, 19 (2-3), 287-299.

Assefa, T.T., Meuwissen, M.P.M. and Oude Lansink, A.G.J.M. (2015). Price Volatility Transmission in Food Supply Chains: A Literature Review. Agribusiness , 31 (1), 3-13.

Assefa, T.T., Meuwissen, M.P.M. and Oude Lansink, A.G.J.M. (2016). Price volatility perceptions, management strategies, and policy options in EU food supply chains. In Garrido, A., Brummer, B., M'Barek, R., Meuwissen, M.P.M. and Morales-Opazo, C. (Eds.), Agricultural Markets Instability. Revisiting the recent food crisis (pp. 178-192). New York, NY: Routledge.

Bakucs, L.Z., Fertő, I., Hockmann, H. and Perekhozhuk, O. (2009). Market power on the edge? An analysis of the German and Hungarian hog markets. Agrarwirtschaft, 58 (8), 337-345.

Brooks, C. (2008). Introductory Econometrics for Finance. New York, NY: Cambridge.

Brümmer, B., Korn, O., Schlüßler, K., Jaghdani, T.J. and Saucedo, A. (2013). Volatility in the after crisis period - A literature review of recent empirical research, Working Paper 1, ULYSSES project, EU 7th Framework Programme, Project 312182 KBBE.2012.1.4-05, http://www.fp7-ulysses.eu/ , 46 pp.

Buguk, C., Hudson, D. and Hanson, D. (2003). Price volatility in agricultural markets: An examination of U.S. catfish markets. Journal of Agricultural and Resource Economics, 28(1), 86-99.

Chavas, J.P., and Mehta, A. (2004). Price dynamics in a vertical sector. American Journal of Agricultural Economics, 86(4), 1078-1093.

Deimel, M., Frentrup, M. and Theuvsen, L. (2008). Transparency in food supply chains: empirical results from German pig and dairy production. Journal on Chain and Network Science, 8 (1), 21-32.

European Commission (2011). Study on the Competitiveness of the European Meat Processing Industry Volatility of farm incomes, prices and yields in the European Union. Retrieved from http://ec.europa.eu/enterprise/sectors/food/files/report compmeat en.pdf.

FAO, IFAD, IMF, OECD, UNCTAD, WFP, the World Bank, the WTO, IFPRI and the UN HLTF (2011). Price volatility in food and agricultural markets: policy responses. Retrieved from http://www.oecd.org/dataoecd/40/34/48152638.pdf. 
Feindt, P.H. and Kleinschmit, D. (2011). The BSE crisis in German newspaper: Reframing responsibility. Science as Culture, 20 (2), 183-208.

FleischGroßmarkt Hamburg. http://www.fleischgrossmarkt.de/.

GfK. http://www.gfk.com/de/loesungen/verbraucherpanel/

Johansen, S. and Juselius, K. (1992). Testing structural hypotheses in a multivariate cointegration analysis of the PPP and the UIP for UK. Journal of Econometrics, 53 (1-3), 211-244.

Kupferschmidt, K. (2011). Dioxin scandal triggers food debate in Germany. Canadian Medical Assoiation Journal, 183 (4), 221-222.

Kutlina-Dimitrova, Z. (2015). The economic impact of the Russian import ban: A CGE analysis. Retrieved from http://trade.ec.europa.eu/doclib/docs/2015/december/tradoc_154025.pdf

Lence, S.H. (2007). The Transformation of Spain's Pork Sector: Can It Continue? Choices, 22 (1), 2530 .

Meyer, J. and von Cramon-Taubadel, S. (2004). Asymmetric price transmission: A survey. Journal of Agricultural Economics, 55(3), 581-611.

Parker, P.S. and Shonkwiler, J.S. (2014). On the centenary of the German hog cycle: new findings. European Review of Agricultural Economics, 41 (1), 47-61.

Piot-Lepetit, I. (2011). Price volatility and price leadership in the EU beef and pork meat market. In Piot-Lepetit, I. and M'Barek, R. (Eds.), Methods to Analyse Agricultural Commodity Price Volatility (pp. 85-106). N.Y., Springer Science and Business Media.

Rabobank (2011). Rethinking the food and agribusiness supply chain; impact of agricultural price volatility on sourcing strategies. Retrieved from http://hugin.info/133178/R/1549493/476482.pdf.

Sanjuán, A.I. and Gil, J.M. (2010). Price transmission analysis: a flexible methodological approach applied to European pork and lamb markets. Applied Economics, 33 (1), 123-131.

Schulze, B., Spiller, A. and Theuvsen, L. (2007). A broader view on vertical coordination: lessons from German pork production. Journal on Chain and Network Sciences, 7 (1), 35-53.

Serra, T., Gil, J.M. and Barry, B.K. (2006). Local polynomial fitting and spatial price relationships: price transmission in EU pork markets. European Review of Agricultural Economics, 33 (3), 415-436.

Serra, T. (2011). Food scares and price volatility: The case of the BSE in Spain. Food policy, 36(2), $179-185$.

Sexton, R.J. and Zhang, M. (2001). An assessment of the impact of food industry market power on U.S. consumers. Agribusiness, 17(1), 59-79.

Tangermann, S. (2011). Risk management in agriculture and the future of the EU's Common Agricultural Policy. Retrieved from http://ictsd.org/downloads/2011/12/risk-management-inagriculture-and-the-future-of-the-eus-common-agricultural-policy.pdf. 
Theuvsen, L. and Franz, A. (2007). The Role and Success Factors of Livestock Trading Cooperatives: Lessons from German Pork Production. International Food and Agribusiness Management Review, 10(3), 90-112.

Thille, H. (2006). Inventories, market structure, and price volatility. Journal of Economic Dynamics and Control, 30 (7), 1081-1104.

Thomson, B., Poms, R. And Rose, M. (2012). Incidents and impacts of unwanted chemicals in food and feeds. Quality Assurance and Safety of Crops and Foods, 4 (2), 77-92.

USDA (2010). The German Food Retail Market. Retrieved from http://gain.fas.usda.gov/Recent\%20GAIN\%20Publications/Retail\%20Foods_Berlin_Germany_7-312012.pdf.

Van Asseldonk, M.A., Kuiper, W.E and Huirne, R.B. (2000). Classical Swine Fever epidemic and price volatility. Paper presented at the $9^{\text {th }}$ International Symposium on Veterinary Epidemiology and Economics, Breckenridge, Colorado, USA.

Verreth, D.M.I., Emvalomatis, G., Bunte, F., Kemp, R. and Oude Lansink, A.G.J.M. (2015). Price Transmission, International Trade, and Asymmetric Relationships in the Dutch Agri-Food Chain. Agribusiness, 31 (4), 521-542.

Von Ledebur, O. and Schmitz J. (2012). Price volatility and farm income stabilization. Paper selected for presentation at the 123rd EAAE Seminar, Dublin, Ireland.

Weber, S.A. and Anders, S.M. (2007). Price rigidity and market power in German retailing. Managerial and decision economics, 28 (7), 737-749. 


\section{Chapter 4}

\section{Price risk perceptions and management strategies in selected European food supply chains: An exploratory approach}

Tsion Taye Assefa, Miranda P.M. Meuwissen, Alfons G.J.M. Oude Lansink Accepted for publication in Wageningen Journal of Life Sciences 


\begin{abstract}
Agricultural prices in European food markets have become more volatile over the past decade exposing agribusinesses to risk and uncertainty. This chapter goes beyond the farm stage and explores through interviews the price risk perceptions and management strategies in multiple stages of the food supply chain. Respondents were farmers, wholesalers, processors, and retailers in six European food supply chains. Results show that price risk management strategies in EU food chains are diverse and well beyond traditional instruments such as futures and forward contracts. We further find that deviations of prices by more than 10 to $15 \%$ from expected levels were perceived as price volatility by a majority of the chain actors. The qualitative exploratory and comparative approaches followed in this chapter provide new insights on price risk management, a deeper understanding of price risk perceptions and highlights the interrelation of price risk management decisions with other business decisions.
\end{abstract}

Keywords: Price risk, perceptions, management strategies, European Union, exploratory, interviews, food supply chains.

\title{
4.1. Introduction
}

Prices in European agricultural markets have become increasingly volatile in the past decade (Tangermann, 2011). The decoupling of farm income supports through successive reforms of the Common Agricultural Policy has led to a market oriented EU (European Union) farm sector that is increasingly exposed to market price volatility (Bardaji et al., 2011). Price volatility implies uncertainty which may in turn lead to reduced investment in productive inputs and reduced supply by farmers (Seal and Shonkwiler, 1987; Rezitis and Stavropoulos, 2009; Sckokai and Moro, 2009). The negative effects of price volatility also extend to actors in the downstream stages of food supply chains. According to a report by Rabobank (2011), the downstream stages of the food supply chain are increasingly faced with price and supply uncertainty and are obliged to alter their sourcing strategies to mitigate the negative effects. Food security of consumers spending a large share of their income on food is also threatened by price volatility (Hernandez et al., 2013). The above assertions suggest that managing the risk from price volatility should be done at all levels of the food supply chains.

Risk perception and management among farmers has been extensively investigated within the current literature (see for instance Martin, 1996; Meuwissen et al., 2001; Hall et al., 2003; Bergfjord, 2009). Although the literature found that farmers perceive price risk as an important source of agricultural risk, it failed to explore the price risk management strategies farmers adopt in practise. This is because the studies relied on structured questionnaires that pre-specified strategies instead of asking farmers which strategies they use in practise. The pre-specified strategies are in general limited to traditional instruments such as hedging in derivative markets, forward contracts, and diversification. To our knowledge, the studies by Heyder et al. (2010) and of von Davier et al. (2010) were the only ones that addressed price risk and its management in downstream stages of the food supply chain. Similar to the farm level studies, these two studies also failed to explore actual price risk management practises as they also relied on structured questionnaires. Furthermore, the structured questionnaires generally ascribe a particular strategy to a particular source of risk (e.g. futures contracts for volatile prices) (Van Winsen et al., 2013). This undermines the discovery of other strategies that would not normally be considered solutions to that particular source of risk while they could in fact be solutions. A more 
open-ended exploratory approach to data collection could uncover price risk management strategies previously unexplored in previous quantitative studies.

Although assessing farmers' risk perception in a categorical and quantitative manner is analytically convenient, it is unnatural for farmers to think about risk in this manner (Van Winsen et al., 2013). Price risk perception can be better understood with more open-ended approaches to data collection. Although it is generally agreed that price volatility implies risk, it is not clear whether it is perceived as such by food chain actors. This paper will explore through forty-two semi-structured interviews the price volatility perceptions and management strategies of farmers, wholesalers, processors and retailers in six EU food supply chains. The six chains are the Bulgarian wheat, French wheat, German pork, Dutch cheese, Dutch tomato, and Spanish tomato supply chains. Actors' price risk perception is explored with respect to two elements. The first is the percentage price deviation from expected values which actors perceive as price volatility. The second element concerns the factors that determine whether perceived price volatility is perceived as risky. Exploring actors' perceptions of price risk helps to better understand actors' choices of price risk management strategies.

The benefits of qualitative exploratory research for the field of agricultural risk management are demonstrated in this chapter. By qualitatively exploring food chain actors' price risk management strategies, this chapter informs quantitative risk management research on previously unexplored and non-traditional price risk management practises. Future studies can then investigate the adoption level of the explored strategies through large scale surveys that use an up-to-date list of price risk management strategies in their questionnaires. The usefulness of comparative methodological approaches in risk management studies are further demonstrated in this chapter. The comparison of perceptions and strategies across different food chains and different stages of the chains highlights the context specific nature of price risk management. Findings of this research are also informative to policy makers. Chain actors' price risk perceptions can help define 'excessive' level of price volatility needed for policy intervention. On the other hand, gaps in the identified strategies inform policy makers of where in chain policy intervention is needed.

In the remainder of this paper, section 4.2 briefly discuss related agricultural risk management researches, section 4.3 details the methodological approaches used in this chapter, section 4.4 presents the results and section 4.5 discusses the results. Section 4.6 concludes the chapter and draws research and policy implications.

\subsection{Previous research}

Previous research on risk perceptions and management strategies in the agricultural sector has mainly focused on the farm stage. Wilson et al. (1987) defined risk perception as "the awareness of the factors in the social and economic environment that create risk and the degree to which one factor is more critical than the other". This definition is shared by most of the studies that investigated farmers' risk perceptions. The methodological approach these studies followed is to list a set of possible sources of agricultural risks and ask farmers to rate the importance of each source of risk using Likert scales (for instance, Martin (1996), Meuwissen et al. (2001), Hall et al. (2003), Bergfjord (2009), Wilson et al. (1987), Patrick et al. (1985), Knutson et al. (1998), Greinier et al. (2009)). A common finding of these studies is the high score that farmers assign to price risk (for instance, Meuwissen et al. (2001), Bergfjord (2009), Wilson et al. (1987), Patrick et al. (1985), Knutson et al. (1998)). The inconsistency in the terminologies the authors use to define price risk reflects, nevertheless, a lack of agreement 
about what price risk really is. Some of the terms used by the authors are "price changes" (Martin, 1996), "declining prices" (Greinier et al., 2009), and "price volatility" (Morales et al., 2009). What farmers perceive as price risk therefore remains unclear.

The above cited studies adopted a similar approach to assess farmers' risk management strategies. Farmers were presented with a list of pre-specified risk management strategies and asked to rate the importance or the relevance of each strategy using Likert scales. The main price risk management strategies these studies considered were forward contracts, futures and options, and off-farm and onfarm diversification. The scores assigned to the risk sources and those assigned to the risk management strategies were then compared. Surprisingly, many authors did not find a match between the score assigned to price risk and those assigned to the considered price risk management strategies (for instance, Martin (1996), Meuwissen et al. (2001), Hall et al. (2003); Bergfjord (2009)). Although price risk ranked at the top of the list of risk sources, the importance or relevance scores assigned to the listed price risk management strategies were unexpectedly low. This raises the question whether the strategies considered are indeed the strategies farmers adopt to deal with price risk. The structured nature of the questionnaires used in these studies restricts the identification of the possible set of strategies that farmers use in practice.

The only two studies that investigated the price risk perceptions and management strategies of actors downstream from the farm stage are those of Heyder et al. (2010) and von Davier et al. (2010). Heyder et al. (2010), who surveyed German agribusiness firms, used actors' expectations of price volatility developments in the next five years as a measure of perceived price risk. Similar to farm-level studies, a set of pre-defined price risk management strategies were presented to the actors who then had to evaluate the relevance of each strategy using Likert scales. The study by von Davier et al. (2010) relied on a media content analysis to identify perceptions about causes and developments of price risk and suggested management strategies. A limitation of both studies is that they failed to explore actual management strategies adopted by firms. Another limitation is that these studies did not investigate the actual levels of price volatility that chain actors perceived as risky.

In summary, previous research provides limited evidence on actual price risk perceptions and management strategies in the chain. The reliance on structured questionnaires limits the opportunity to explore actual practices. The downstream sector of the chain has remained overlooked in previous research, as the focus has been mainly on the farm sector. These gaps in the literature are addressed in this research by following an exploratory methodological approach and by including the downstream stages of the chain in the analyses.

\subsection{Materials and methods}

\subsubsection{Exploration through in-depth interviews}

Exploration is used as a methodological approach "when a group, process, activity or situation has received little or no systematic empirical scrutiny or has been largely examined using prediction and control rather than flexibility and open-mindedness" (Stebbins, 2001). Previous research has given little attention to the price risk perceptions and management strategies of actors in food supply chains. At the farm stage, the structured nature of the questionnaires distributed to farmers restricts the identification of the set of strategies farmers adopt in practice. An exploratory approach was therefore deemed appropriate to investigate chain actors' price risk perceptions and management strategies. 
Data was collected using in-depth interviews with semi-structured questions. Some structure was imposed on the questions to guide the interview process and keep the focus on the key topics that were the subjects of the investigation. The imposed structure also assured some consistency in the questions across respondents. The questions, nevertheless, allowed some room for probing and in-depth inquiry. Probing was facilitated by including 'non-standardized' or semi-structured questions. Nonstandardization in interviews is "most helpful when exploring new topics, sensitive [...] issues, and when the businesses are highly variable in their characteristics" (Healey and Rawlinson, 1993). The newness of the topic of price risk perceptions and management strategies, the sensitive nature of disclosing price related business strategies, and the wide ranging types of companies included in this chapter justified the use of semi-structured interviews.

\subsubsection{Sample selection}

A sample was constructed with representatives from five EU countries, four types of food products, four stages of the food supply chain, and different types of agribusinesses. Although the selected sample is not a statistically representative one, it accounts for the diversity in EU food chains in terms of chain structure and type of agribusinesses. The process of selecting respondents followed a series of steps. In the first step, we selected four classes of food products, namely, meat, dairy, cereals, and vegetables. Next, we selected food chains per class of food product, i.e. the fresh pork, cheese, wheatbread, and fresh tomato supply chains. The selection of these chains further distinguishes between supply chains of fresh and processed food products.

In a third step, selected indicators were used to choose the EU countries for which the above food supply chains will be investigated. The final food chains selected were the Dutch cheese, Dutch tomato, German pork, French wheat, Bulgarian wheat, and Spanish tomato supply chains. The indicators used to select these chains were the shares of area used for tomatoes in total land for fresh vegetables, shares of pig production in total livestock production, shares of cheese production in raw milk collected, and shares of wheat in total cereal production. Data compiled from the Eurostat on production and area of agricultural land during the period 2006 to 2013 was used to calculate the indicators. These indicators were used to rank the countries and determine the level of importance of each product in each country.

The fourth step in the sample selection process involved the selection of individual firms along each of the selected chains. Prior to selecting the firms, interviews were conducted with experts in each of the six supply chains. The expert interviews inquired about the key characteristics of the investigated supply chains. Respondent firms were then selected by taking into account these chain characteristics. The key chain characteristics that guided the selection of the respondents were membership in a cooperative/producer organization (for farms), ownership structure (private versus cooperative for the wholesale and processing sectors), size of farm/firm, and export orientation. The experts were also asked to provide contact addresses of potential interviewees. Additional addresses of interviewees were obtained through a snowball process where the initial respondents were asked if they knew other people who would be interested in participating in the interviews.

The respondents were selected along the four stages of the food supply chain, i.e. farm, wholesale, processing and retail. The initial objective was to select at least two respondents per chain stage to diversify the respondents based on the above characteristics (for example, one farmer who is member of a cooperative versus one who is not). It was not, however, possible to reach any respondents for some of the chain stages. In particular, German pig slaughterhouses/processors and retailers were often 
not willing to participate, most likely because price related strategies are confidential in these companies. The respondents at the farm stage were farm owners, whereas the respondents at the other stages were more diverse and included general managers, sales managers, sourcing managers, and financial directors. The sample selection process resulted in the selection of a total of 42 people for the interviews. The respondents were 15 farmers, 15 wholesalers, 9 processors, and 3 retailers. Table 4.1 and 2 summarize the characteristics of the participant farms and companies, respectively. 
Table 4.1 - Characteristics of participant farms

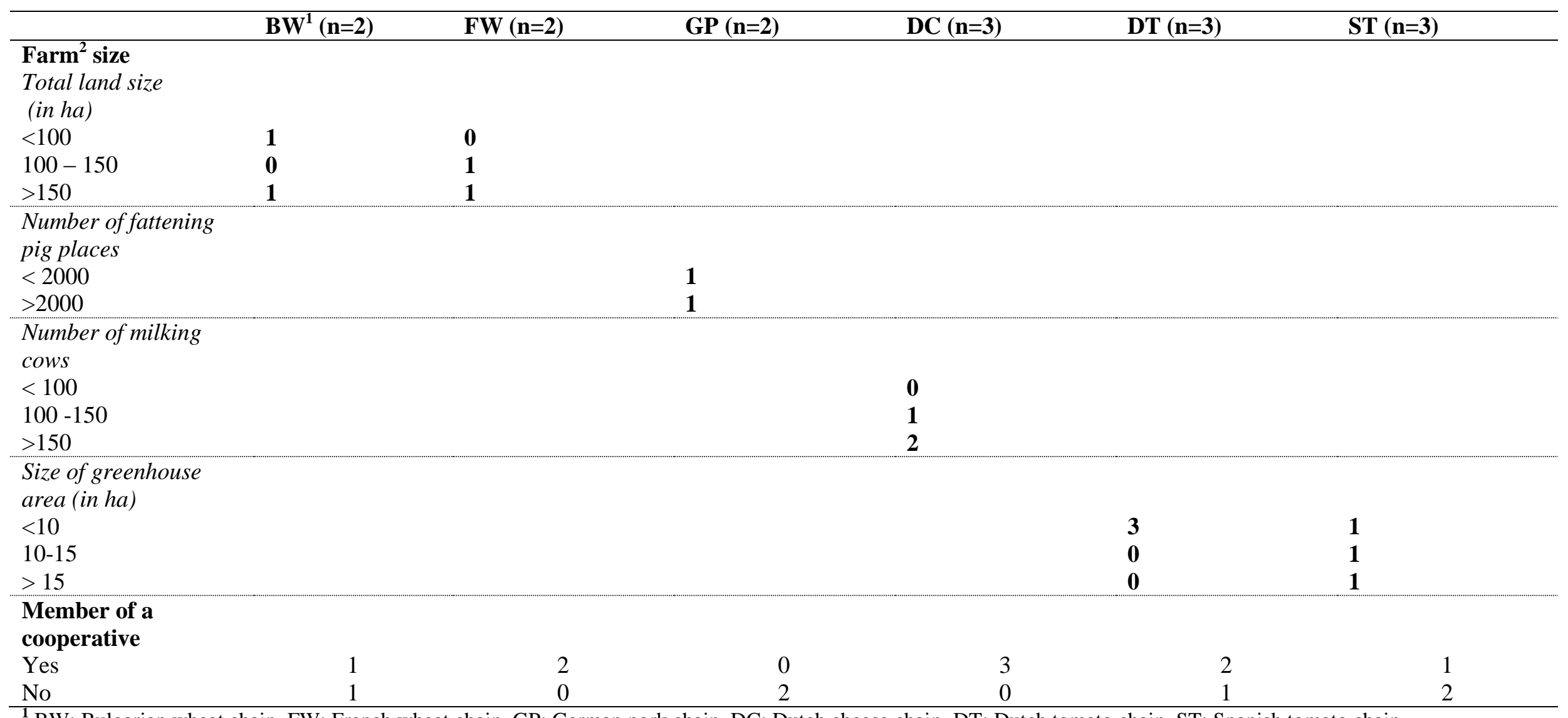

${ }^{1}$ BW: Bulgarian wheat chain, FW: French wheat chain, GP: German pork chain, DC: Dutch cheese chain, DT: Dutch tomato chain, ST: Spanish tomato chain

${ }^{2}$ Farmers source pig feed in GP and cattle feed in DC. Farmers sell wheat in BW and FW, pigs in GP, milk in DC and tomatoes in DT and ST. 
Table 4.2 - Characteristics of participant wholesalers, processors and retailers

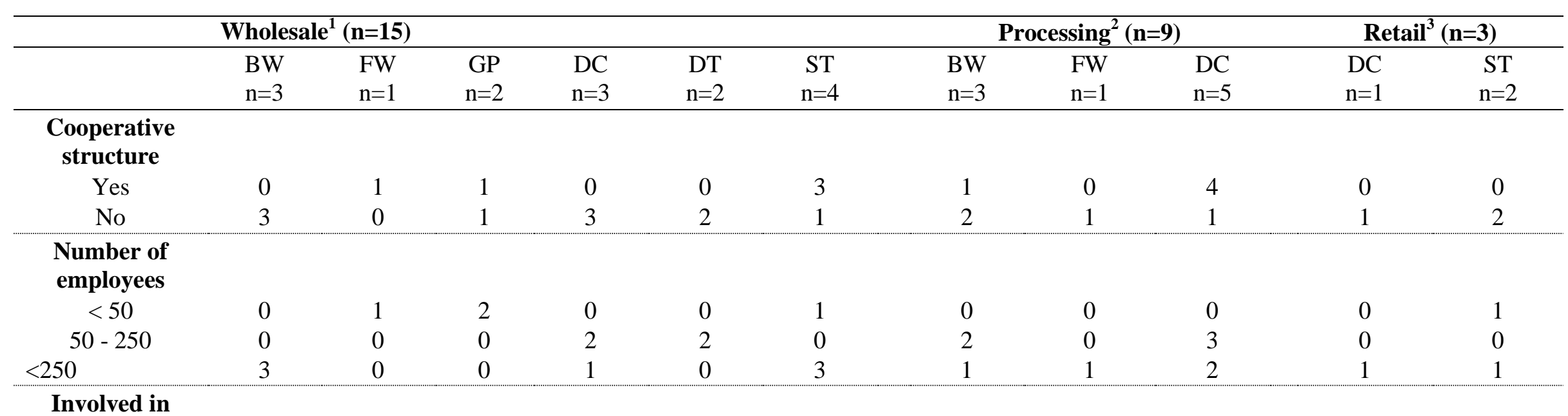

Involved in

exports

Yes

No

$3 \quad 0$

$\begin{array}{lll}0 & 0 & 3\end{array}$

$3 \quad 2$

2

$0 \quad 0$

23

$\begin{array}{ll}3 & 0 \\ 1 & 3\end{array}$

1

1

4
1

4

${ }^{1}$ BW: Bulgarian wheat chain, FW: French wheat chain, GP: German pork chain, DC: Dutch cheese chain, DT: Dutch tomato chain, ST: Spanish tomato chain. Wholesalers source wheat grain in BW and FW, pigs in GP, cheese in DC, and tomatoes in DT and ST. Wholesalers sell wheat grain in BW and FW, pigs in GP, cheese in DC, and

tomatoes in DT and ST. One of the wholesalers is a large Dutch cooperative buying tomatoes from Spain. The suppliers in Spain are not a member of the Dutch cooperative.

${ }^{2}$ Processors source wheat grain $(\mathrm{n}=2)$ in $\mathrm{BW}$ and in FW, and milk in DC. Processors sell wheat flour $(\mathrm{n}=2)$ and bread $(\mathrm{n}=1)$ in $\mathrm{BW}$, wheat flour in FW, and cheese in DC.

${ }^{3}$ Retailers source cheese in DC and tomatoes in ST. Retailers sell cheese in DC and tomatoes in ST. One of the retailers is a British supermarket buying tomatoes from Spain. 


\subsubsection{Interview questions}

The interview questions consisted of four major blocks, with two structured and two semi-structured blocks of questions. The first block was an introductory block that used structured questions to inquire about characteristics such as farm size, company size, farmer cooperative membership, and legal form (cooperative/non-cooperative) of companies. In the second block of the interview, structured questions were used to evaluate how challenging the respondents have found various sources of business risks in the past 5-7 years. Likert scales from 1 (= extremely challenging) to 7 (= not challenging at all) were used for this purpose. The aim of this second block was to determine how challenging price volatility was relative to other business risks. The list of business risks presented was related to the sourcing and selling activities of the farms and companies.

The third block of the interview consisted of questions about the actors' perceptions of price risk and the fourth block consisted of questions about the strategies used by the actors to manage the risk from price volatility. Both blocks of questions were made semi-structured to get a deep understanding of actors' perceptions and management strategies. The semi-structured nature of the questions further allowed the questions to be refined as the interviews progressed. To gain an understanding of their perception of price risk, the respondents were asked to provide the percentage price deviation from an expected price level which they perceived as price volatility. Actors were asked to give the percentage price deviations with respect to the periods that prices are mostly set in the respective chains (i.e. daily, weekly or monthly). They were then asked to indicate the strategies they would use if faced with the indicated or a higher level of price volatility.

The interview responses revealed that actors' strategic responses to price volatility depended not only on the level of price volatility faced but also on whether such level of price volatility is perceived as risky. The interview questions were thus refined to include questions on the factors that determine the riskiness of a certain level of price volatility. Actors were not always able to think of strategies they would use to specifically manage the risk from price volatility. Further probing questions on actors' past experiences with price volatility were therefore needed to get a deeper understanding of actors' strategic choices. The chain actors were probed on whether they have faced price volatility in the past and on the strategies they have used to manage the risk from price volatility.

The interviews were conducted between January and July 2014. The questions were sent one day in advance to the interviewees to allow them to prepare prior to the interviews. Each interview lasted between forty-five minutes and one hour and a half. The interviews were conducted by the authors with accompanying translators in some cases. The responses were audio-recorded and transcribed on the same day the interviews took place.

\subsubsection{Analysis}

We used content analysis of the interview transcripts to describe the price risk perceptions and management strategies of the food chain actors. This type of research design is usually appropriate when existing theory or research literature on a phenomenon is limited (Hsieh and Shannon, 2005). The process of content analysis includes open coding, creating categories and abstraction Elo and Kyngas (2008). Elo and Kyngas (2008) define open coding as the writing of notes and headings to describe the content of the interview transcripts. They define abstraction as the naming of the 
categories and sub-categories of notes and headings generated in the open coding process. The nature of content analysis is therefore such that a pre-defined conceptual framework is not used to guide the research. In this chapter, content analysis is used to identify the factors that determine whether a certain level of price volatility is perceived as risky and to identify the categories of strategies actors use to manage the risk from price volatility.

\subsection{Results}

\subsubsection{Price risk perceptions}

The degree to which various business risks have been a challenge to each actor in the past 5-7 years is shown in Table 4.3. The risks relate to business-to-business input sourcing and output selling activities. The 'challenging' or ' $\mathrm{C}$ ' columns of Table 4.3 reveal that price volatility has been a prime challenge for a majority of the actors. This Table further emphasizes that price volatility is not the sole concern of farmers as is often believed. An interesting finding is the comparable scores the majority of the actors assigned to high input/low output prices and input/output price volatility. The following subsections describe and compare actors' perceptions of price risk. 
Table 4.3 - Number of actors who rated each business risk as challenging (C), moderately challenging (MC), or not challenging (NC)

\begin{tabular}{|c|c|c|c|c|c|c|c|c|c|c|c|c|}
\hline & \multicolumn{3}{|c|}{$\operatorname{Farm}^{1}(n=15)$} & \multicolumn{3}{|c|}{ Wholesale $^{2}(\mathrm{n}=15)$} & \multicolumn{3}{|c|}{ Processing $^{3}(\mathrm{n}=9)$} & \multicolumn{3}{|c|}{ Retail $^{4}(\mathbf{n}=3)$} \\
\hline & $\mathrm{C}$ & MC & $\mathrm{NC}$ & $\mathrm{C}$ & $\mathrm{MC}$ & $\mathrm{NC}$ & $\mathrm{C}$ & $\mathrm{MC}$ & $\mathrm{NC}$ & $\mathrm{C}$ & $\mathrm{MC}$ & $\mathrm{NC}$ \\
\hline High input prices & 3 & 2 & 0 & 6 & 4 & 5 & 4 & 2 & 3 & 2 & 1 & 0 \\
\hline Low quality of input supply & 0 & 1 & 4 & 3 & 2 & 10 & 1 & 1 & 7 & 1 & 0 & 2 \\
\hline Inconsistent quality of input supply & 0 & 1 & 4 & 6 & 1 & 8 & 2 & 1 & 6 & 1 & 0 & 2 \\
\hline Poor on-time delivery of inputs purchased & 0 & 0 & 5 & 3 & 2 & 10 & 1 & 0 & 8 & 1 & 0 & 2 \\
\hline Input price volatility & 1 & 0 & 4 & 8 & 2 & 5 & 6 & 0 & 3 & 1 & 1 & 1 \\
\hline Imbalance of market power with input suppliers & 1 & 0 & 4 & 5 & 5 & 5 & 1 & 0 & 8 & 1 & 0 & 2 \\
\hline \multicolumn{13}{|l|}{ Output selling related risks } \\
\hline Low output prices & 9 & 2 & 4 & 10 & 1 & 3 & 6 & 1 & 1 & $\mathrm{Ni}^{5}$ & $\mathrm{Ni}$ & $\mathrm{Ni}$ \\
\hline Instability in demand volume & 3 & 1 & 11 & 5 & 3 & 6 & 3 & 1 & 4 & $\mathrm{Ni}$ & $\mathrm{Ni}$ & $\mathrm{Ni}$ \\
\hline Low demand volume & 3 & 0 & 12 & 6 & 1 & 7 & 5 & 0 & 3 & $\mathrm{Ni}$ & $\mathrm{Ni}$ & $\mathrm{Ni}$ \\
\hline Poor on-time payment for deliveries & 1 & 0 & 14 & 5 & 1 & 8 & 4 & 1 & 3 & $\mathrm{Ni}$ & $\mathrm{Ni}$ & $\mathrm{Ni}$ \\
\hline
\end{tabular}

${ }^{1}$ Highlighted in bold are the number of farmers, wholesalers, processors and retailers who found high input/low output prices and input/output price volatility as challenging. C: Challenging ( $=1,2,3$ in Likert scale), MC: Moderately challenging ( $=4$ in Likert scale), NC: Not challenging (= 5, 6, 7 in Likert scale). Input sourcing related challenges were not inquired in the case of wheat and tomato farmers

${ }^{2}$ One of the wholesalers was not familiar with the selling related challenges of the company as the company sold its output to the parent company.

${ }^{3,4}$ The selling related challenges were not inquired for companies (bakery and retailers) selling directly to final consumers.

${ }^{5}$ Not inquired. 
Table 4.4 - Percentage deviations in prices perceived as price volatility

\begin{tabular}{|c|c|c|c|c|}
\hline & Farm & Wholesale & Processing & Retail \\
\hline Percentage deviation $^{1}$ & $\begin{array}{ll}> & \text { Wheat grain: } 10 \% \\
> & \text { Pig feed: } 10 \% \\
> & \text { Pigs: } 10 \% \\
> & \text { Cattle feed: } 15 \% \\
> & \text { Milk: } 10 \% \\
> & \text { Tomatoes: } 20 \%\end{array}$ & $\begin{array}{ll}> & \text { Wheat grain: } 10 \% \\
> & \text { Pigs: } 10 \% \\
> & \text { Cheese: } 10 \% \\
> & \text { Tomatoes: } 20 \%\end{array}$ & $\begin{array}{l}>\quad \text { Wheat grain and } \\
\text { flour: } 10 \% \\
>\text { Milk and Cheese }{ }^{2}: \\
10 \%\end{array}$ & $\begin{array}{l}>\text { Cheese: } 3 \% \\
>\quad \text { Tomatoes: } 20 \%\end{array}$ \\
\hline
\end{tabular}

${ }^{1}$ Percentage deviations from an expected price level that exceed the specified percentages are perceived as price volatility by the chain actors. The percentages are averages across respondents, rounded to the nearest decimal. Percentages are expressed relative to the price settlement period in each chain, namely monthly in the Dutch cheese chain and weekly in the rest of the chains.

${ }^{2}$ Note that only one cheese processor perceived a price deviation greater than $20 \%$ as volatility, the rest of the processors perceived a price deviation less than $5 \%$ as volatility.

Table 4.5 - Persistence of price volatility perceived as risky

\begin{tabular}{|c|c|c|c|}
\hline Farm $^{1}$ & Wholesale & Processing & Retail \\
\hline $\begin{array}{l}\text { A year or a production cycle } \\
(\mathrm{DC}, \mathrm{DT}, \mathrm{BW}, \mathrm{GP}, \mathrm{ST}) \\
\text { Depending on stock level and }^{2} \\
\text { position in forward contract } \\
(\mathrm{FW})\end{array}$ & $\begin{array}{l}>\text { Depending on stock level and } \\
\text { position in forward contract (BW, } \\
\text { DC, FW) } \\
>\text { One week and longer }{ }^{2}(\mathrm{GP}, \mathrm{DT}, \mathrm{ST})\end{array}$ & $\begin{array}{l}\text { Depending on stock level } \\
\text { and position in forward } \\
\text { contract }(\mathrm{BW}, \mathrm{DC})\end{array}$ & $\begin{array}{l}\text { A year (DC } \\
\text { ST) }\end{array}$ \\
\hline
\end{tabular}

\footnotetext{
${ }^{1}$ BW: Bulgarian wheat chain, FW: French wheat chain, GP: German pork chain, DC: Dutch cheese chain, DT: Dutch tomato chain, ST: Spanish tomato chain.

${ }^{2}$ Price volatility is perceived as risky if a high input or low output price level persists for the specified period or longer.

${ }^{3}$ Price volatility is perceived as risky when output prices drop (input prices rise) and stay low (high) during the period that input prices (output prices) are fixed through contracts at a high (low) level. It is perceived as risky when output prices drop while there are goods in stoc
} 


\section{a. Percentage price deviations perceived as price volatility}

Simple averages of the percentage price deviations which chain actors perceived as price volatility were calculated per chain and chain stage. Table 4.4 provides a summary of the average percentages per chain and chain stage. Deviations of prices by more than 10-15\% from their expected levels were perceived as price volatility by a majority of respondents. Actors in the Dutch and Spanish tomato chains were an exception to this, as the majority perceived a price deviation higher than $20 \%$ as price volatility. Similarly, Dutch dairy farmers argued that feed prices (maize in particular) are volatile if prices deviate by more than $20 \%$ from their expected values. Recurring and large changes in the prices of fresh tomatoes and cattle feed explain the price volatility perceptions of the tomato and dairy farmers.

Actors specified percentage price deviations with respect to the periods that prices are set in the respective chains. In the Dutch cheese supply chain this period is monthly. Although cheese prices are set for a longer time period (exceeding one month), Dutch cheese processors, wholesalers, and retailers form cheese price expectations on a monthly basis because milk prices serve as reference prices for cheese. In the tomato and pork chains prices are mostly set on a weekly basis. In the wheat supply chains, although high frequency trading can take place at the wholesale stage, weekly price expectations seem to be the norm.

A comparison across chain stages shows some similarities and differences in the specified percentage price deviations. On average, the percentage price deviations (Table 4.4) are rather comparable across chain stages and chains. An examination of the percentages specified at the level of the individual respondent reveals some differences in perceptions. Processors and retailers seem to perceive lower percentages of price deviations as price volatility compared to farmers and wholesalers. For example, a deviation greater than $5 \%$ in grain and flour prices was perceived as price volatility by a Bulgarian and a French wheat miller. Similarly, the Dutch retailer indicated that a deviation higher than $3 \%$ in cheese prices is perceived as price volatility.

\section{b. Factors determining the riskiness of price volatility}

\section{Persistence of price volatility}

Price volatility, defined as a percentage price deviation from the expected level, is not perceived as risky by all interviewed actors. The persistence of price deviation was found to be one of the factors that determine whether price volatility is perceived as risky. The degree of persistence perceived as risky is summarized in Table 4.5 per chain and chain stage. A finding common to most of the interviewed farmers is that a high input price or low output price persisting for at least one year or production cycle (i.e. a year for wheat and dairy farmers, and one production cycle for pig and tomato farmers) is perceived to be more risky than weekly or monthly changes in prices. A situation perceived to be even more risky is when a persistent high output price level (or low input price level) unexpectedly changes to a persistent low output price level (or high input price level) between years or production cycles. When such reversals in price levels occur, it becomes challenging for farmers to reverse major investments made during good price years. Though undesirable, more frequent price changes (within the year or production cycle) were seen as less risky because farmers cannot easily respond to these changes anyway. Similar to farmers, retailers tended to be more concerned about 
changes in yearly prices. Their reasoning is that higher frequency price changes can compensate each other during the year. This reasoning was also shared by some of the interviewed farmers.

Price changes occurring during the year were found to be more of a challenge for the wholesale and processing stages. This is particularly true for the wheat and cheese wholesalers and processors. Fixed-price sales contracts that are not matched with fixed-price purchase contracts (and vice versa) and storage are the main causes of this challenge. For instance, it is risky when output prices drop and stay low during the period that an input price is fixed at a high level through a contract (and vice versa for input prices). Sudden drops in output price are also risky for goods in stock. Cooperative German pig, Spanish tomato, and Dutch tomato wholesalers were concerned about both weekly changes and persistent changes in the pig and tomato prices received by their member farmers.

\section{Reason of price volatility}

According to the interviewees, the reasons why prices deviate from their expected levels also determined whether price volatility is perceived as risky. Price changes caused by sudden and major changes in local weather conditions and changes in global demand and supply conditions (caused for instance by conflicts in major producing countries or by border restrictions of major importing countries) were seen as worrying by actors in the cheese and wheat supply chains. Actors in the tomato supply chains mainly considered price changes caused by sudden and major changes in local weather conditions as risky ones. In the pork supply chain, the most challenging price changes were those caused by animal health related crises. Predictable seasonal price changes and price changes believed to have arisen from speculation were not considered as risky by most of the actors.

\section{Stability in margins}

In addition to the above factors, the direction of the price deviation determined the riskiness of price volatility. The interviews revealed that actors are more concerned about downside price changes (increase in input price or decrease in output price) than price volatility in the sense of fluctuations (both upside and downside) in prices. Moreover, stability in margins was found to be more important than stability in prices. All interviewed actors argued that a sudden and large decrease in an output price is not a concern if it is matched by a proportionate and immediate decrease in the input price (and vice versa). In practice, this rarely happens due to a number of factors, such as time lags in production, contracts (either on the buying or selling side), and the influence of retailers on prices.

\subsubsection{Price risk management strategies}

Strategies actors use to manage risk can be classified in several ways. Waters (2007) for instance provides eight categories of risk management strategies used by managers. The eight categories are ignoring risk, reducing the probability of risk, reducing the consequence of risk, transferring risk, making contingency plans, adapting to risk, opposing a change and moving to another environment. Hardaker et al. (2004) classified farm level risk management strategies into two broad categories and further sub-categories. The two broad categories are on-farm strategies and strategies to share risks with others. In this paper, we provide our own classification of price risk management strategies. The categories provided emerged from the content analysis of the interview transcripts. Four categories of price risk management strategies were identified: Survival, adaptive, control and hedging strategies. Each category of strategy is briefly described below. Table 4.6 lists the management strategies 
classified in each strategy category. The number of actors that adopted each category of strategy is presented in Table 4.7.

\section{Survival strategies}

Survival strategies are strategies aimed at minimizing losses, such as reducing physical production and major investments, improving efficiency, and diversification. These strategies, which are mainly longterm strategies, were mostly adopted by farmers. As farmers cannot easily respond to short-term price changes, a majority of them concentrated their strategies on price changes that persist for at least one year or production cycle. Producers of storable products, as French wheat farmers in our sample attested, can be considered an exception to this as their ability to store wheat gives them the flexibility to decide when and how to sell. The interviewed Bulgarian wheat farmers, on the other hand, indicated a limited capacity to store wheat during the year. Survival strategies were also adopted by cooperative pig and tomato wholesalers. The only strategy these wholesalers can adopt to minimize the losses of member farmers in times of sudden price drops is to wait one more week before selling farmers' pigs and tomatoes to processors and retailers, respectively. Keeping pigs and tomatoes for a longer period of time can result in further losses in the values of the produce.

\section{Adaptive strategies}

The focus of strategies in this category is on flexibility, following the market, and securing a stable margin regardless of price movements Most of the interviewed wholesalers and processors, except for cooperative pig and tomato wholesalers, adopted adaptive strategies. Setting buying and selling prices on the same day, linking output prices to input prices, and avoiding open long-term fixed price forward contracts are some of the major adaptive strategies these actors adopted. The focus is on flexibility achieved through quick adaptation to market price movements. Not only was there an interest for flexible prices but also for flexible production. For instance, a Bulgarian wheat baker argued that switching from flour to bread production can be a solution in times of big drops in grain prices, and from bread to flour in case of big rises in grain prices. The aim of this strategy is to avoid the drop in bread sales during bread price increases as bread is a staple product in Bulgaria. A specialty cheese processor argued that switching from processing milk to processing more volumes of cheese can be a solution to manage the risk from milk price volatility. In case of a large drop in milk prices, it becomes profitable to process more cheese than processing and selling milk because of the value that cheese adds to the low priced milk.

\section{Control strategies}

Strategies in this category focus on achieving price stability by taking control over prices. The expected interest in control strategies through price-fixing contracts and vertical integration was not found among most of the chain actors. This is particularly true for wholesalers and processors. Interest in contracts and vertical integration was however found among farmers (for instance, Dutch dairy, German pig, and French wheat farmers). Producing and trading premium products is another way of exercising control over prices. Examples include the production of specialty cheese by cheese processors, and the production and trading of tomatoes with no pesticide residues and of tomatoes of specialty varieties by tomato farmers, wholesalers, and retailers. Many of the interviewed actors argued that prices of premium products are not as volatile and low as standard products. This argument prevailed in particular among actors downstream from the farm stage. For retailers, transmitting sudden increases in input prices is easier when the product is a premium product. 
Improved marketing of produce through promotion and better services to fill customers' needs is another method to add value to the product and command higher and more stable prices. In the Dutch tomato chain, product value addition is achieved through closer collaboration between growers' associations and the retail sector.

\section{Hedging strategies}

Although hedging through futures and option contracts is a widely accepted price volatility management strategy, its use was limited among the interviewed actors. Interest to use these instruments in the future was, nevertheless, expressed by a German pig farmer, a French wheat farmer, a Bulgarian wheat wholesaler, a pig wholesaler, a Dutch cheese wholesaler, and a Dutch cheese processor. The absence of active futures markets for these products in the respective countries was mentioned as the main reason for the current non-use of these instruments. Except for one German pig farmer and one French wheat farmer who currently use options, no mention of interest in hedging with futures and options was made by any of the remaining interviewed farmers. 
Table 4.6 - Price volatility management strategies

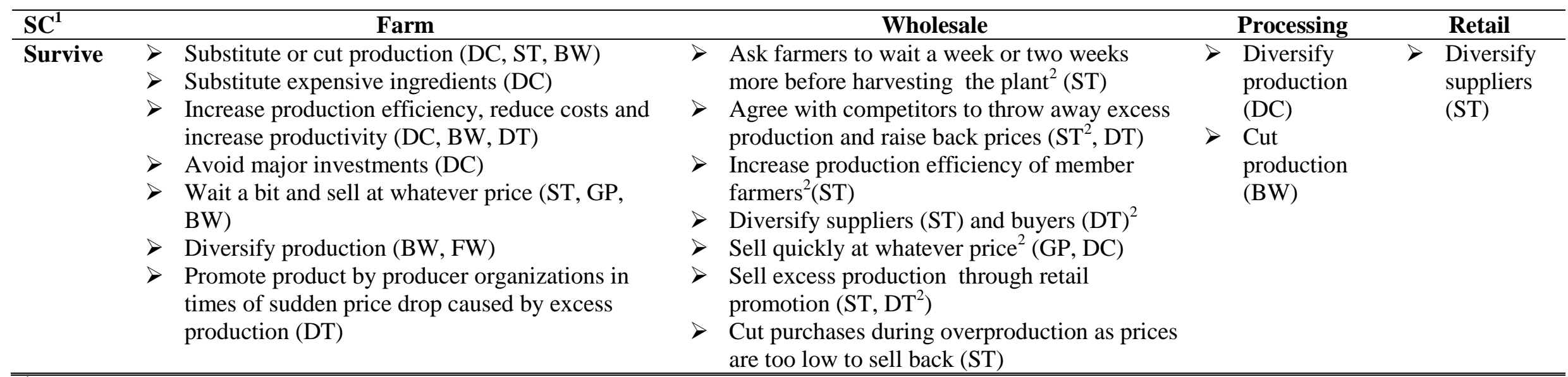

${ }^{1}$ SC: Strategy category. Note that BW: Bulgarian wheat chain, FW: French wheat chain, GP: German pork chain, DC: Dutch cheese chain, DT: Dutch tomato chain, ST: Spanish tomato chain.

${ }^{2}$ Strategies used by cooperative wholesalers, whose main objectives are to minimize the losses that member farmers face in times of sudden drop in prices. 
Table 4.6 - Price volatility management strategies (Continued)

\begin{tabular}{|c|c|c|c|c|}
\hline$\overline{\text { SC }}$ & Farm & Wholesale & Processing & Retail \\
\hline Adapt & $\begin{array}{l}\text { Shorter } \\
\text { contracts with } \\
\text { small } \\
\text { quantities per } \\
\text { contract (FW) } \\
\text { Closely follow } \\
\text { market } \\
\text { development, } \\
\text { improve price } \\
\text { predictions and } \\
\text { concentrate } \\
\text { production in } \\
\text { high price } \\
\text { weeks (ST, } \\
\text { DT) }\end{array}$ & 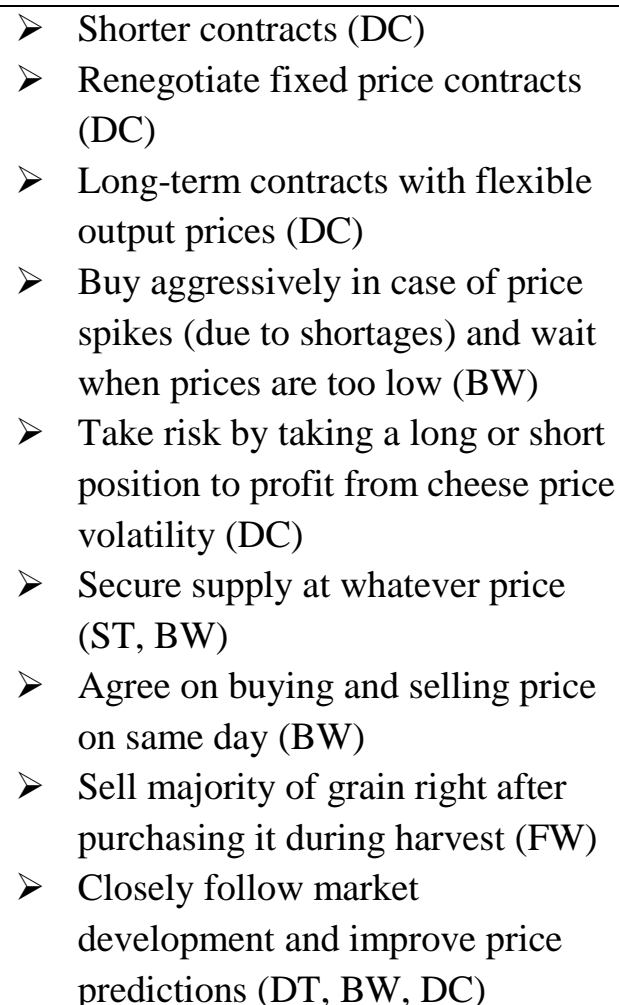 & $\begin{aligned}> & \text { Use milk pools to set output prices }{ }^{3} \text { (DC) } \\
> & \text { Shorter sales contracts (DC) } \\
> & \text { Contracts with flexible output prices (flexible with milk } \\
& \text { prices; use output price bands to share price risk with } \\
& \text { retailer; cost-plus pricing) (DC) } \\
> & \text { Switch production among alternative products (DC, BW) } \\
> & \text { Adjust production volume (BW) } \\
> & \text { Agree on input and output price on same day (FW, BW) } \\
> & \text { Avoid storage/buy only for daily needs (BW) } \\
> & \text { Transmit price changes (BW) } \\
> & \text { Buy spot milk to take advantage of volatility (sudden } \\
& \text { drop in milk prices) instead of buying from own } \\
& \text { cooperative member farmers (DC) } \\
> & \text { Renegotiate fixed price contracts (DC) }\end{aligned}$ & $\begin{array}{l}\text { Secure supply at } \\
\text { whatever price } \\
\text { (DC) } \\
>\quad \text { Transmit price } \\
\text { changes (price } \\
\text { decreases in } \\
\text { particular due to } \\
\text { competition) } \\
\text { (DC, ST) }\end{array}$ \\
\hline
\end{tabular}


Table 4.6- Price volatility management strategies (Continued)

\begin{tabular}{|c|c|c|c|c|}
\hline $\mathrm{SC}$ & Farm & Wholesale & Processing & Retail \\
\hline
\end{tabular}

Table 4.6 - Price volatility management strategies (Continued)

\begin{tabular}{|c|c|c|c|c|}
\hline SC & Farm & Wholesale & Processing & Retail \\
\hline Hedge & $\begin{array}{l}\text { Hedge in futures market }\left(\mathrm{GP}^{4}, \mathrm{FW}\right) \\
\text { Use average seasonal price offered by } \\
\text { cooperatives }(\mathrm{FW})\end{array}$ & $\begin{array}{l}>\text { Hedge in futures market }{ }^{4} \\
(\mathrm{DC}, \mathrm{GP}, \mathrm{BW}) \\
>\quad \text { Use options }(\mathrm{FW})\end{array}$ & $\begin{array}{l}>\text { Hedge in future market }{ }^{4}(\mathrm{DC}) \\
>\text { Over-the-counter contracts for } \\
\text { milk }^{4}(\mathrm{DC})\end{array}$ & $>$ None \\
\hline
\end{tabular}

${ }^{4}$ Strategies not yet implemented, but planned for the future 
Table 4.7 - Number of actors per strategy category and chain stage

\begin{tabular}{|c|c|c|c|c|c|}
\hline Strategy $^{1}$ category & Farm $(n=15)$ & Wholesale $(n=15)$ & Processing $(n=9)$ & Retail $(n=3)$ & Total \\
\hline Survival & 13 & 7 & 2 & 0 & 12 \\
\hline Adaptive & 2 & 10 & 9 & 3 & 24 \\
\hline Control & 5 & 4 & 3 & 1 & 13 \\
\hline Hedging & 3 & 3 & 1 & 0 & 7 \\
\hline
\end{tabular}

${ }^{1}$ Note that one actor can use a combination of strategies 


\subsection{Discussion}

This chapter demonstrated how open-ended approaches to data collection can be used to explore nontraditional developments in agricultural price risk management practises. Most of the previous quantitative risk management studies have considered traditional instruments such as hedging in derivative markets, forward contracts, and diversification as the main instruments farmers use to manage price risk (for instance in Martin (1996), Meuwissen et al. (2001), Hall et al. (2003), Bergfjord, 2009). This chapter showed that a notable development in farmers' strategies is to create added value through selection of better varieties to plant, production with less pesticide residues, product promotion, and collaboration with the retail sector to develop improved products. Prices of premium products are perceived to be more stable than standard quality products. Another development is the avoidance of long-term fixed price contracts particularly by wholesalers and processors. Although long-term contracts are often argued to minimize risk and uncertainty (for instance in Heyder et al. (2010)), this chapter finds the contrary. In this chapter we find that chain actors perceive fixed price long-term contracts as risky if one is not able to secure such contracts both on the input and output sides.

Besides uncovering developments in price risk management practises, this chapter also showed that price risk management strategies are diverse and interrelated with other business decisions. At the farm stage, price risk management affects investment decisions (i.e. increasing production efficiency, reducing costs and increasing productivity), product development decisions (i.e. improving output quality) and decisions on vertical and horizontal collaborations (i.e. closer relationship with retailers for improved product development). Production decisions of processors are also affected by price risk management strategies (i.e. cut production, adjust production). At the wholesale stage, it was found that collaboration decisions are affected by price risk management strategies (i.e. Sell excess production through retail promotion, merger among wholesalers to gain more market power and secure higher output price, closer relationship with retailers for better marketing/promotion of produce to add value to the produce).

The semi-structured interviews also allowed for the flexibility to have a deeper understanding of chain actors' risk perceptions. This is in contrast with previous quantitative risk management studies which measured risk perceptions by rating the relative importance of different agricultural risks through Likert scales (for instance, Martin (1996), Meuwissen et al. (2001), Hall et al. (2003), Bergfjord (2009), Wilson et al. (1987), Patrick et al. (1985), Knutson et al. (1998), Greinier et al. (2009)). This chapter went beyond showing the relative importance of price risk and identified the factors that determined whether price volatility is perceived as risky. Through a closer investigation of the identified factors, one can further detect a link between price risk perceptions and the adopted management strategies. Concern about the persistence of price changes in the long run, as opposed to monthly or weekly price changes during the year or production cycle, can explain why most farmers adopt long-term strategies (that include diversification, achieving cost efficiency and quality product development). Wholesalers and processors, on the other hand, worry about monthly or weekly price changes from expected prices, and therefore choose flexibility to manage the risk from these price changes.

This chapter showed through a comparative approach that the choice of price risk management strategies is context specific. While farmers' strategies tend to fit more within the 'survival' category, those of wholesalers and processors fit more into the category of 'adaptive' strategies. Strategies also 
differed across chains. While Dutch tomato farmers are inclined towards strategies that require closer horizontal and vertical collaborations, Spanish tomato farmers tend to adopt more individual strategies. In the wheat chain, Bulgarian wheat farmers' strategies are limited to long-term strategies implemented on an annual basis (i.e. crop diversification, cutting production, planting new varieties). French wheat farmers on the other hand use also short-term strategies such as short-term contracts. Although this chapter did not quantify the impact of chain characteristics on the choice of price risk management strategies, it provides the basis on which such studies can be conducted in the future. A wider sample could be used to test the statistical generalizability of the results.

Despite the small sample used, this chapter has demonstrated the relevance of the qualitative and exploratory methodological approach for agricultural risk management research. It provided new insights in risk management practises, a deeper understanding of risk perceptions and highlighted the interrelation of risk management decisions with other business decisions. Such benefits could also extend to the wider field of agricultural research. A natural extension of this research could be to test whether the strategies identified in this chapter apply to a wider sample of food chain actors. Future research could also test the effectiveness of the identified strategies in reducing the risk from price volatility.

\subsection{Conclusions and implications}

Food and agricultural commodity prices have been increasingly volatile both at the global and EU levels since the last decade. Although the current literature proposes alternative strategies to deal with price risk, the proposed strategies have often targeted the farm stage. The scope of the proposed strategies has also been limited to few strategies with forward contracts, futures, options and diversification being the main ones. In this chapter, we took a broader approach and explored the strategies used both at the farm and beyond the farm stages of the food supply chain. The strategies were explored by conducting forty-two in-depth interviews with farmers, wholesalers, processors, and retailers in six EU food-supply chains. The chain actors' perceptions of price risk were also explored during the interviews to gain a better understanding of actors' choices of price risk management strategies. The two key perception elements explored were the percentage price deviation which actors perceived as price volatility and the factors that determined whether price volatility is perceived as risky.

Results show that a deviation in prices by more than 10 to $15 \%$ from their expected levels is perceived as price volatility by a majority of the respondents. Three main factors determined whether chain actors perceived price volatility as risky: the persistence, the reason and the stability of margins. Whereas farmers and retailers perceive persistent price deviations as risky, wholesalers and processors perceive short-term price changes occurring during the year or production cycle as risky. Farmers' strategies are mostly survival strategies through output and cost reduction in response to adverse price movements. Wholesalers and processors focus on adaptive strategies that allow them to secure stable margins regardless of price movements. Retailers' main focus is to secure a continuous supply of quality produce for their customers rather than to reduce price volatility. Overall, this chapter highlighted the diversity in perceptions and strategies along EU food chains and challenged current assumptions that price risk management strategies are limited to few traditional instruments.

This chapter has several implications for agricultural risk management research. First, it demonstrated the benefits of qualitative exploratory research to discover current and new practises in agricultural 
risk management. Second, it showed that a qualitative approach can highlight the interrelation of price risk management practises with other business decisions. Third, the chapter showed that a comparative methodological approach can be used to stress the context specific nature of agricultural risk management decisions. This chapter has also policy implications. The 10 to $15 \%$ price deviation perceived as price volatility provides an important signal for price stabilizing policy interventions in agricultural markets. Some strategy gaps could be filled with policy interventions. Areas for policy support include the further encouragement of cooperation among farmers and along the chain (interprofessional organizations), the establishment of futures markets where such markets are missing, and the timely dissemination of improved and accessible market price data and predictions. Such price data could be used to support chain actors' production and sales decisions, as well as contract decisions. 


\section{References}

Bardaji, M., Garrido, A., Iglesias, E., Blanco, M., and Bielza, M. (2011). What market measures in the future CAP after 2013? Retrieved from http://www.europarl.europa.eu/studies.

Bergfjord, O.J. (2009). Risk perception and risk management in Norwegian aquaculture. Journal of Risk Research., 12 (1), 91-104.

Elo, S. and Kynga, S. (2008). The qualitative content analysis process. Journal of Advance Nursing, 62(1), 107-115.

Greinier, R., Patterson, R., and Miller, O. (2009). Motivations, risk perceptions, and adoption of conservation practices by farmers. Agricultural Systems, 99 (2), 86-104.

Hall, D.C., Knight, T.O., Coble, K.H., Baquet, A.E., and Patrick, G.F. (2003). Analysis of beef producers' risk management perceptions and desire for further risk management education. Review of Agricultural Economics, 25(2), 430-448.

Hardaker, J.B., Huirne, R.B.M., Anderson, J.R. and Lien, G. (2004). Coping with risk in agriculture. USA: CABI publishing

Healey, M.J. and Rawlinson, M.B. (1993). Interviewing business owners and managers: A review of methods and techniques. Geoforum, 24(3), 339-355.

Hernandez, M.A., Ibarra, R., and Trupkin, D.R. (2013). How far do shocks move across borders? Examining volatility transmission in major agricultural futures markets. European Review of Agricultural Economics, 41(2), 1-25.

Heyder, M., Theuvsen, L., and Von Davier, Z. (2010). Strategies for coping with uncertainty: The adaptation of food chains to volatile markets. Journal on Chain and Network Science, 10(1), 17-25.

Hsieh, H. F., and Shannon, S. E. (2005).Three approaches to qualitative content analysis. Qualitative Health Research, 15 (9), 1277-1288.

Knutson, R.D., Smith, E.G., Anderson, D.P., and Richardson, J.W. (1998). Southern farmers' exposure to income risk under the 1996 farm bill. Journal of Agricultural and Applied Economics, 30(1), 35-46.

Martin, S. (1996). Risk management strategies in New Zealand agriculture and horticulture. Review of Marketing and Agricultural Ecoomics, 64(1), 31-44.

Meuwissen, M.P.M, Huirne, R.B.M., and Hardaker, J.B. (2001). Risk and risk management: An empirical analysis of Dutch livestock farmers. Livestock Production Science, 69 (1), 43-53.

Morales, C., Alberto, G., Peter, P., and Csaba, S. (2008). Risks perceptions and risk management instruments in the European Union: Do farmers have a clear idea of what they need? Paper presented at the European Association of Agricultural Economists international Congress, Ghent.

Patrick, G.R., Wilson, P.N., Barry, P.J., Boggess, W.G., and Young, D.L. (1985). Risk perceptions and management responses: Producer-generated hypotheses for risk modelling. Southern Journal of Agricultural Economics, 17(2), 231-238. 
Rabobank (2011). Rethinking the food and agribusiness supply chain; impact of agricultural price volatility on sourcing strategies. Retrieved from http://hugin.info/133178/R/1549493/476482.pdf.

Rezitis, A. and Stavropoulos, K. (2009). Modelling pork supply response and price volatility: The case of Greece. Journal of Agicultural. and Applied Economics, 41 (1), 145-162.

Sckokai, P. and Moro, D. (2009). Modelling the impact of the CAP single farm payment on farm investment and output. Europena Review of Agricultural Economics, 36 (3), 395-423.

Seal, J. and Shonkwiler, J. (1987). Rationality, price risk, and response. Southern Journal of Agricultural Economics, 19 (1), 111-118.

Stebbins, R.A. (2001). Exploratory Research in the Social Sciences. London: Sage.

Tangermann, S. (2011). Risk management in agriculture and the future of the EU's Common Agricultural Policy. Retrieved from http://ictsd.org/downloads/2011/12/risk-management-inagriculture-and-the-future-of-the-eus-common-agricultural-policy.pdf.

Van Winsen, F., de Mey, Y., Lauwers, L., Van Passel, S., Vancauteren, M., and Wauters, E. (2013). Investigating risk perception closer to the actual understanding of risk by farmers. Agricultural Systems, $122(1), 42-52$.

Von Davier, Z., Heyder, M., and Theuvsen, L. (2010). Media analysis on volatile markets' dynamics and adaptive behaviour for the agri-food system. International Journal of Food Systems Dynamics., 1 (3), 212-223.

Waters, D. (2007). Supply Chain Risk Management: Vulnerability and Resilience in Logistics. USA: Kogan Page.

Wilson, P.N., Luginsland, T.R., and Armstrong, D.V. (1987). Risk perceptions and management. Journal of Dairy Science, 71 (2), 545-551. 
Chapter 5

\section{The effectiveness of price volatility management strategies in food supply chains}

Tsion Taye Assefa, Meuwissen P.M. Meuwissen, Alfons G.J.M. Oude Lansink Submitted 


\begin{abstract}
Price volatility implies risk and may be undesirable from managerial and investment perspectives. Current literature on the effectiveness of strategies to manage price volatility mainly focuses on the farm stage and considers only a few farm-level strategies. This paper outlines a method to investigate the effectiveness of price volatility management strategies for different actors along the food supply chain and for a broader set of strategies. The paper first develops a decision rule, based on the meanvariance utility framework, for the implementation of a strategy. The price volatilities the chain actor faces with and without a strategy are then compared to evaluate the effectiveness of a strategy in reducing the price volatility faced by the chain actor. The method is illustrated using price data for the Spanish fresh tomato and French wheat supply chains.
\end{abstract}

Key words: Effectiveness, strategies, price volatility, food chains

\title{
5.1. Introduction
}

The rise in price volatility since the 2007/2008 food price crisis has sparked considerable research interest in the impacts of price volatility on food chain actors. Assefa et al. (2016) have shown that the impacts of price volatility are not limited to farmers but also extend to the rest of the supply chain. For instance, García-Germán et al. (2013) shows the impacts of price volatility on consumers through a literature review. Price volatility implies uncertainty and thus may be undesirable for managers and investors (Piot-Lepetit, 2011; Rabobank, 2011); the risk from price volatility has to therefore be properly managed. Supply chain actors use diverse strategies to manage the risk from price volatility (Assefa et al., 2016). Insight into the effectiveness of these strategies could help chain actors to choose strategies to reduce their exposure to price volatility.

A large body of literature exists on the effectiveness of strategies to manage price volatility (or price risk) for farmers. Neyhard et al. (2013), for instance, studied the effect of a combination of futures, options and cash markets on the financial performance of dairy farms and concluded that the cash market provides a natural hedge for farm income. The effectiveness of futures and options was also investigated by Manfredo et al (2003) for grain farmer cooperatives. Their study also included overthe-counter contracts and yield insurance. The best strategies were put options and a combination of put options, futures contract and yield insurance (Manfredo et al., 2003). The effectiveness of forward contracts has also been studied. For example, Bielza et al. (2007) investigated the effect of a cash forward contract between a potato cooperative and its member farmers on the risk exposure of the cooperative. The authors concluded that such an instrument is effective when combined with hedging in the futures market. Kimura and Anton (2010) explored the effect of forward contracts on the income variability of crop farmers. They found that forward contracts reduce the price risk faced by the farmer.

Existing literature on the effectiveness of price volatility management strategies (PVMS) mainly focuses on the farm stage. A review by Assefa et al. (2015), however, has shown that price volatility transmits along the chain, thereby increasing the risks faced by other food chain actors. This suggests the need to evaluate the effectiveness of strategies for different actors in the chain. Another limitation of the current literature is the focus on storable products, such as grains (Manfredo et al., 2003) and potatoes (Bielza et al., 2007), and on products traded in the futures market, such as milk (Neyhard et al., 2013).A final limitation is that the strategies covered by the current literature are limited to 
options, futures and forward contracts, whereas supply chain actors adopt a broader range of strategies to manage the risk from price volatility (Assefa et al., 2016).

This chapter addresses the above limitations by outlining a method to investigate the effectiveness of PVMS for different actors in food supply chains. The method accommodates strategies not currently addressed in the literature. Effectiveness is assessed by comparing the price volatility when no PVMS is implemented (the base scenario) with the price volatility when a PVMS is implemented.

The remainder of the paper is organised as follows. Section 5.2 describes the conceptual framework that guides the research and section 5.3 describes the method to evaluate the effectiveness of PVMS. Section 5.4 presents the data used and the scenarios to illustrate the method described in section 5.3. Section 5.5 presents the results. Section 5.6 discusses the results and the method, and makes concluding remarks.

\subsection{Conceptual framework}

Consistent with a mean-variance decision framework, a chain actor is assumed to implement a PVMS if the utility from implementing a strategy is higher than the utility derived when no PVMS strategy is implemented. The utility from implementing a strategy is specified as:

$U_{s}=P^{s} Q^{s}-C\left(Q^{s}\right)-S\left(Q^{s}\right)-\frac{1}{2} \alpha Q^{s^{2}} V_{p}^{S}$,

where, for the scenario where strategy $s$ is implemented, $U_{S}$ is the utility, $P^{s}$ is the output price the chain actor faces, $Q^{S}$ is the quantity of product sold, $C\left(Q^{S}\right)$ is the total production cost, $S\left(Q^{S}\right)$ is the cost of strategy $s, \alpha$ is the coefficient of risk aversion, and $V_{p}^{s}$ is the variance of the output price. The utility derived when no strategy is implemented is given by:

$U_{b}=P^{b} Q^{b}-C\left(Q^{b}\right)-\frac{1}{2} \alpha Q^{b^{2}} V_{p}^{b}$

where, for the base scenario when no strategy is implemented, $U_{b}$ is the utility, $P^{b}$ is the output price, $Q^{b}$ is the quantity of product sold, $C\left(Q^{b}\right)$ is the total production cost, and $V_{p}^{b}$ is the variance of the output price.

The chain actor decides to implement a strategy if:

$P^{s} Q^{s}-C\left(Q^{s}\right)-S\left(Q^{s}\right)-\frac{1}{2} \alpha Q^{s^{2}} V_{p}^{s}>P^{b} Q^{b}-C\left(Q^{b}\right)-\frac{1}{2} \alpha Q^{b^{2}} V_{p}^{b}$.

The chain actor is assumed to implement a PVMS if the utility from implementing a strategy is higher than the utility from not adopting a strategy. The drop in base price that induces the chain actor to implement a strategy, termed the threshold price drop, is determined by first expressing the utility under the base scenario in terms of an expected base price and a price drop from the expected base price, as follows:

$U_{b}=E\left(P^{b}\right)(1-D) Q^{b}-C\left(Q^{b}\right)-\frac{1}{2} \alpha Q^{b^{2}} V_{p}^{b}$,

where $E\left(P^{b}\right)$ is the expected price in the base scenario and $D$ is the actual percentage by which the price drops from its expected level in the base scenario. The product $E\left(P^{b}\right)(1-D)$ is the price the 
chain actor faces in the base scenario, i.e., $P^{b}$ in equation (3). To find the threshold price drop that triggers a strategy, equation (4) can be substituted in the right-hand side of equation (3) to obtain the following expression for $D$ :

$D>\frac{-P^{S}-C\left(Q^{b}\right)+\frac{1}{2} \alpha Q^{S} V_{p}^{S}-\frac{1}{2} \alpha Q^{b} V_{p}^{b}+C\left(Q^{S}\right)+S\left(Q^{S}\right)}{E\left(P^{b}\right)}+1$.

The term on the right-hand side of equation (5) shows the maximum percentage by which base prices can drop from their expected level without triggering the implementation of a PVMS. If the percentage price drop exceeds the term in the right-hand side of equation (5), the implementation of a strategy is triggered. This term is the threshold price drop $\left(D^{T}\right)$ and can be denoted as:

$$
D^{T}=\frac{-P^{S}-C\left(Q^{b}\right)+\frac{1}{2} \alpha Q^{S} V_{p}^{S}-\frac{1}{2} \alpha Q^{b} V_{p}^{b}+C\left(Q^{S}\right)+S\left(Q^{S}\right)}{E\left(P^{b}\right)}+1 .
$$

The threshold price drop is expressed as a percentage. Equation (6) shows that the higher the cost of the strategy $\left(S\left(Q^{S}\right)\right)$ or the price volatility under strategy $s\left(V_{p}^{S}\right)$, the higher the $D^{T}$. In other words, a costly strategy and a strategy resulting in a high level of price volatility will discourage the chain actor from implementing a strategy. In this situation, the chain actor will tolerate a large $D^{T}$. It can also be noted from equation (6) that a risk-loving chain actor (large $\alpha$ ) will tolerate a large $D^{T}$.

Noting that the threshold $D^{T}$ establishes a minimum base price, equation (5) implies that a strategy is implemented if:

$E\left(P^{b}\right)(1-D)<E\left(P^{b}\right)\left(1-D^{T}\right)$,

where $E\left(P^{b}\right)(1-D)=p^{b}$ is the actual base price and $E\left(P^{b}\right)\left(1-D^{T}\right)$ is the minimum expected base price; the chain actor will decide to implement a strategy for any price less than this minimum. Note that equation (7) implies $D>D^{T}$, which in turn implies equation (5).

\subsection{Method}

The effectiveness of PVMS in reducing the price volatility faced by a chain actor was computed in three steps. In step 1, base prices were calculated. Next, in step 2, prices faced under alternative PVMS were calculated. Finally, in step 3, the volatility of base prices was compared with the volatility of prices under alternative PVMS.

\section{Step 1: Base prices}

Base prices were calculated for a given time period and represent the prices chain actors would face if they sold their produce at spot prices during the considered period. Base farm output prices were set equal to national averages of historical spot prices (equation 8). This assumes that historical farm output prices do not reflect the pricing strategies used by individual farmers. Farmers generally operate in competitive markets with a large number of suppliers and there is limited opportunity for an individual farmer to influence market prices through his or her strategies. More formally, base farm output prices are given by:

$p_{f, t}^{b, i}=p_{f, t}^{s p o t, i}$ 
where, for product $i$ at time $t, p_{f, t}^{b, i}$ is the base farm output price and $p_{f, t}^{s p o t, i}$ is the historical spot farm output price.

In the base scenario, the intermediate stage (wholesaler or processor) buys its agricultural input from the farm stage at the base farm output price and sells its output to the retail stage at the base intermediate output price. Unlike the farm stage, the base output price at the intermediate stage was not set equal to historical prices. The output market of the intermediate stage is generally noncompetitive due to increased concentration at the retail stage. The retail stage may have significant market power that enables it to influence the output prices of the intermediate stage by using pricing strategies aimed at lowering and stabilising its own input price (Weber and Anders, 2007; Anders, 2008). The wholesale and processing stages, which in general are more concentrated than the farm stage, may also have market power that enables them to influence their output prices through their pricing strategies (Bakucs and Ferto , 2009). If historical intermediate prices were used as base prices, then the volatility observed in these base prices will be a reflection of existing pricing strategies and of market power in the chain. To "remove" the effects of existing strategies and market power on base price volatility, a solution is to recalculate base intermediate output prices using farm base prices and an average marketing margin. Base output prices at the wholesale and processing stages are given by:

$p_{w, t}^{b, i}=p_{f, t}^{b, i}+M_{w f, t}^{i}, \quad$ and

$p_{p, t}^{b, i}=\left(p_{f, t}^{b, i} \times C R_{p f}^{i}\right)+M_{p f, t}^{i}$

where, for product $i$ at time $t, p_{w, t}^{b, i}$ is the base output price for the wholesaler, $p_{p, t}^{b, i}$ is the base output price for the processor, $M_{w f, t}^{i}$ is the wholesale-farm marketing margin, $M_{p f, t}^{i}$ is the processing-farm marketing margin and $C R_{p f}^{i}$ is the fixed conversion ratio of farm output to processor output.

In the base scenario, the retail stage buys its agricultural input from the intermediate stage (either wholesaler or processor) at intermediate base output prices and sells its output to consumers at base retail prices. Base retail prices are calculated using base intermediate output prices and are given by:

$p_{r, t}^{b, i}=p_{w, t}^{b, i}+M_{r w, t}^{i}$, or

$p_{r, t}^{b, i}=p_{p, t}^{b, i}+M_{r p, t}^{i}$

where, for product $i$ at time $t, p_{r, t}^{b, i}$ is the base retail price, $M_{r w, t}^{i}$ is the retail-wholesale marketing margin and $M_{r p, t}^{i}$ is the retail-processing marketing margin.

The marketing margins can be fixed either in absolute terms or in percentage terms during the given period. To check the sensitivity of results to the calculation of the margin, both types of margins were considered. Absolute and percentage margins were calculated as follows:

$M_{j k, t}^{i}=M_{j k}^{i}=\frac{\sum_{t}\left(p_{j, t}^{h, i}-p_{k, t}^{h, i}\right)}{T}$ for absolute margin, and

$M_{j k, t}^{i}=p_{k, t}^{b, i} \times\left(1+R_{j k}^{i}\right)$ for percentage margin,

where, $R_{j k}^{i}=\frac{\sum_{t}\left(\left(p_{j, t}^{h, i}-p_{k, t}^{h, i}\right) / p_{k, t}^{h, i}\right)}{T}$. 
Note that historical prices (i.e. $p_{j, t}^{h, i}$ and $p_{k, t}^{h, i}$ ) are used to calculate the average percentage or absolute margin. In the above equations, $M_{j k, t}^{i}$ does not vary over $t$ in the case of the absolute margin, but does vary over $t$ in the case of the percentage margin. The fixed absolute margin is given by $R_{j k}^{i}$. The period for which margins and prices are calculated is given by $T$.

\section{Step 2: Prices under alternative PVMS}

Chain actors are assumed to buy their inputs at base prices but implement a PVMS to manage output price volatility. Following the conceptual framework, a strategy is triggered whenever the drop in base output price is greater than the threshold price drop, i.e., $D>D^{T}$. If the drop in base prices is less than or equal to the threshold price drop, i.e. $D \leq D^{T}$, the chain actor faces base prices. In practice, data are not available for $D^{T}$. An alternative approach is to ask chain actors to indicate the average percentage price drop from expected spot (base) prices that would trigger them to implement a strategy. The threshold price drop obtained in this manner is assumed to take into account all the variables in the right-hand side of equation (6).

Each period $t$ ( $t$ reflects a time period, i.e. week, month or year), the chain actor decides whether to implement a strategy. Two types of PVMS are modelled in this paper. The chain actor manages price volatility by implementing strategies that either (1) adjust the timing of sales or (2) adjust the selling price. When a strategy of type 1 is implemented at time $t$, the chain actor manages price volatility by not selling the output in that period and therefore does not face any price in that period. When a strategy of type 2 is implemented at time $t$, the chain actor sells the output at a new price instead of selling at the prevailing base output price. The new price is calculated from the base output price and other factors that could determine the new price. The following conditions summarise the determination of output prices under alternative PVMS.

\section{Type 1 strategy}

If $p_{j, t}^{b, i}<E\left(p_{j, t}^{b, i}\right) *\left(1-D^{T, i}\right)$, then postpone sales. Otherwise, the actor faces $p_{j, t}^{b, i}$.

\section{Type 2 strategy}

If $p_{j, t}^{b, i}<E\left(p_{j, t}^{b, i}\right) *\left(1-D^{T, i}\right)$, then the actor faces $p_{j, t}^{s, i}=f\left(p_{j, t}^{b, i}, x\right)$. Otherwise, the actor faces $p_{j, t}^{b, i}$.

In the above conditions, for product $i$, actor $j$ and time $t, p_{j, t}^{b, i}$ is the base output price, $E\left(p_{j, t}^{b, i}\right)$ is the expected base output price, and $D^{T, i}$ is the threshold price drop for product $i$. The output price faced can be equal to the base price $\left(p_{j, t}^{b, i}\right)$ or to the price faced if a strategy is implemented $\left(p_{j, t}^{s, i}\right)$. The term $E\left(p_{j, t}^{b, i}\right) *\left(1-D^{T, i}\right)$ indicates the minimum expected base price that chain actors are willing to receive without implementing any strategy. Note that if a strategy of type 1 is implemented, no price is faced at time $t$ because the chain actor postpones sales. For strategies of type 2, other factors determining the new output price are denoted by $x$.

The expected base output price $E\left(p_{j, t}^{b, i}\right)$ is the trend predicted base output price. It was calculated by first regressing the base prices calculated in step $1\left(p_{j, t}^{b, i}\right)$ on a constant and a trend. The estimated coefficients were then used to calculate the trend predicted expected price $E\left(p_{j, t}^{b, i}\right)$. 


\section{Step 3: Price volatility under the base scenario and PVMS}

The effectiveness of a PVMS was computed by comparing base price volatilities and price volatilities under alternative PVMS for the selected time period. The volatility measures were computed using price residuals instead of prices. The price residuals are price deviations from the trend predicted prices. The computation of price residuals is shown in equation (15) for base prices and in equation (16) for prices under alternative PVMS:

$r_{j, t}^{b, i}=p_{j, t}^{b, i}-E\left(p_{j, t}^{b, i}\right)$

$r_{j, t}^{s, i}=p_{j, t}^{s, i}-E\left(p_{j, t}^{s, i}\right)$

where, for product $i$, actor $j$ and time $t, r_{j, t}^{b, i}$ is the residual of the base output price, $E\left(p_{j, t}^{b, i}\right)$ is the trend predicted base price as defined in step $2, r_{j, t}^{s, i}$ is the residual of the price under strategy $s$, and $E\left(p_{j, t}^{s, i}\right)$ is the trend predicted price under strategy $s$, which was obtained by regressing the prices obtained in step $2\left(p_{j, t}^{s, i}\right)$ on a constant and a trend.

Five measures of volatility were calculated using the residuals from equations (15) and (16): the coefficient of variation, the skewness, the kurtosis, and the $5^{\text {th }}$ and $95^{\text {th }}$ percentiles. The coefficient of variation was calculated as the ratio of the residuals' standard deviations to the mean of the trend predicted prices. The $5^{\text {th }}$ and $95^{\text {th }}$ percentiles were also expressed as a ratio by dividing each by the mean of the trend predicted prices.

Basing volatility measures on price residuals expresses volatility as the deviation of prices from predictable price trends. The coefficient of variation indicates the average deviation from the mean price, whereas the skewness indicates the upside or downside risk of prices. For output prices, a large value of positive skewness is desirable as this implies that the chain actor has a probability of receiving extremely high prices for output. The kurtosis indicates the peak around the mean and the fatness of the tails. For output prices, high kurtosis implies higher risk. Although the majority of the prices are concentrated around the mean, the probability of receiving extreme prices (high or low) is also higher. The 5th and 95th percentiles together indicate the range in which 90 per cent of all price residuals fall.. A narrower range between the $5^{\text {th }}$ and $95^{\text {th }}$ percentiles is desirable as it implies less variation in prices. Higher $5^{\text {th }}$ and $95^{\text {th }}$ percentiles are also desirable for output prices.

\subsection{Data and scenarios}

\subsubsection{Data}

The method described above was applied to data from the Spanish fresh tomato and French wheat supply chains. The two chains differ in the storability of the products. The storability of a product can influence the type of PVMS implemented. Weekly farm and wholesale tomato price data for the period January 2005 to December 2014 were obtained from the website of the Spanish Ministry of Agriculture, Food and Environment (Ministerio de Agricultura, Alimentacion y Medio Ambiente). For the French wheat supply chain, monthly wheat and flour prices for the period January 2005 to December 2014 were obtained from the website of the French Ministry of Agriculture, Agrifood and Forestry (Ministère de l'agriculture, de l'agroalimentaire et de la forêt). In addition, daily futures price data for wheat traded in MATIF for the period were obtained from www.quandl.com for the period 
April 2003 to September 2012. The threshold price drops that trigger the implementation of a PVMS were obtained from Assefa et al. (2016): a 20\% drop for the Spanish tomato chain and a 10\% drop for the French wheat chain. Descriptive statistics of prices are shown in Table 5.1.

Table 5.1 - Descriptive statistics of prices for the Spanish tomato and French wheat supply chains

\begin{tabular}{lccccc}
\hline & \multicolumn{2}{c}{ Spanish tomatoes spot prices } & \multicolumn{2}{c}{ French wheat spot prices } & \multirow{2}{*}{$\begin{array}{c}\text { French wheat } \\
\text { futures }\end{array}$} \\
\cline { 1 - 4 } Mean & 0.532 & 0.958 & 0.175 & 0.514 & 0.159 \\
Median & 0.510 & 0.910 & 0.180 & 0.540 & 0.146 \\
Maximum & 1.300 & 2.350 & 0.280 & 0.580 & 0.292 \\
Minimum & 0.220 & 0.480 & 0.100 & 0.410 & 0.099 \\
Std. Dev. & 0.182 & 0.260 & 0.053 & 0.058 & 0.043 \\
$\begin{array}{l}\text { Number of } \\
\text { observations }\end{array}$ & 521 & 521 & 120 & 120 & 19449 \\
\hline
\end{tabular}

Note: All prices are in euro/kg

\subsubsection{Scenarios}

The prices under the base and alternative (PVMS) scenarios are defined below for the Spanish tomato and French wheat supply chains. The PVMS and the assumptions used to calculate prices were derived from the interviews conducted by Assefa et al. (2016).

\section{Spanish tomatoes}

\section{Base scenario}

In the base scenario, farmers and wholesalers are assumed to sell their outputs at weekly base (spot) prices, denoted by $p_{f, t}^{b, s t}$ for farmers and $p_{w, t}^{b, s t}$ for wholesalers. Farm base prices were set equal to the weekly historical farm prices for the period January 2005 to December 2014. Wholesale base prices were calculated using equation (9). An absolute margin of $M_{w f}^{s t}=0.42$ and a percentage margin of $R_{w f}^{s t}=0.44$ were calculated using weekly historical farm and wholesale prices for the period January 2005 to December 2014 (i.e. using equations (13) and (14), respectively).

\section{PVMS}

Two PVMS are illustrated for the farm stage and one for the wholesale stage. Prices under these strategies were computed for the period January 2005 to December 2014. The strategy type (type 1 or 2 ) is indicated in parentheses next to each strategy. The threshold price drop that triggers a strategy was set to $D^{T, s t}=0.2$. In the strategies presented below, $t(1,2, \ldots, 52)$ represents a particular week in a year and a production year spans from October to September. The first week of October is denoted by $t=1$ and the last week of September by $t=52$. 
Farm strategy 1 - Cut tomato plant after April (Type 1):

Spanish tomato prices significantly drop between May and September because of imports from the Netherlands. In this strategy, the farmer sells at base prices between October and April but cuts the tomato plant after April if the base price is less than the minimum expected base price. If the base price is greater than this minimum, the farmer continues selling at weekly base prices until the farmer decides to cut the plant or until the next harvest (October), whichever comes first. The output price the farmer faces during the production year is given by the following conditions:

For $t \in[O c t, \ldots, A p r]$, the farmer faces $p_{f, t}^{b, s t}$.

For $t \in[$ May, ..,Sep $]$, if $p_{f, t}^{b, s t}<E\left(p_{f, t}^{b, s t}\right) *(1-0.2)$ then the farmer cuts the plant and does not face any price until the start of the next harvest in October. Otherwise, the farmer continues facing $p_{f, t}^{b, s t}$.

Farm strategy 2 - Wait and sell (Type 1):

During the year (October to September), the farmer waits one week before harvesting the tomatoes if the base price in that week is less than the minimum expected base price. The farmer harvests the tomatoes the following week because the tomatoes can be damaged if left longer on the plant. The output price the farmer faces during the production year is given by the following conditions:

For $t \in[O c t, \ldots, A p r]$, if $p_{f, t}^{b, s t}<E\left(p_{f, t}^{b, s t}\right) *(1-0.2)$, then the farmer leaves the tomatoes on the plant and therefore does not face any price in that week. Otherwise, the farmer faces $p_{f, t}^{b, s t}$.

Wholesale strategy 1 - Annual contract (Type 2):

At the beginning of October each year, the wholesaler enters into an annual sales contract with the retailer (for the period from October to September) if the wholesaler expects that base tomato prices will drop during the year below the minimum expected price level. If the average of the base price in the previous year was less than the average of the expected base price of the previous year minus a threshold price drop, then the wholesaler expects the same to happen in the current year and therefore decides to enter into a contract. The contract price is set equal to the base price in the first week of October of the year the contract is entered into. The output price the wholesaler faces during the year is given by the following conditions:

If $\frac{\sum_{z=1}^{52} p_{w, t-z}^{b, s t}}{52}<\frac{\sum_{z=1}^{52} E\left(p_{w, t-Z}^{b, s t}\right)}{52} *(1-0.2)$, then the wholesaler faces $p_{w, t}^{s, s t}=p_{w, t=1}^{b, s t}$ for the whole year.

Otherwise, the wholesaler faces $p_{w, t}^{b, s t}$ during the year.

In the above condition, $p_{w, t=1}^{b, s t}$ is the base price in October of the year the contract is entered into.

\section{French wheat}

\section{Base scenario}

In the base scenario, wheat farmers and flour processors are assumed to sell their outputs at monthly base (spot) prices denoted by $p_{f, t}^{b, f w}$ for farmers and $p_{p, t}^{b, f w}$ for processors. Farm base prices were set equal to monthly historical farm prices for the period January 2005 to December 2014. Processor base 
prices were calculated using equation (10). An absolute margin of $M_{p f}^{f w}=0.27$ and a percentage margin of $R_{p f}^{f w}=1.26$ were calculated using monthly historical farm and processor prices for the period January 2005 to December 2014. The (farm) wheat to (processing) flour conversion ratio was set to $C R_{p f}^{f w}=1.4$. In the strategies presented below, $t(1,2, \ldots, 12)$ represents a particular month in a year and a production year spans from July to June.

\section{PVMS}

Two PVMS are illustrated for the farm stage and one for the processing stage. Prices faced under these strategies were computed for the period January 2005 to December 2014. The threshold price drop that triggers a strategy was set at $D^{T, f w}=0.1$.

Farm Strategy 1 - Annual contract with futures prices (Type 2):

In July (harvest) each year, the farmer decides whether to sell all of next year's harvest through a contract with the processor. If the base price in July of the current year is less than its minimum expected level, then the farmer expects the same to happen next July and therefore decides to enter into a contract to fix the price of next year's harvest. The contract price is equal to the current July price of a futures contract expiring next harvest. The farmer is assumed to sell all the output through the contract. If the farmer does not enter into a contract, then the farmer stores next year's harvest and sells it at next year's monthly base prices. The price the farmer faces next year is given by the following conditions:

If $p_{f, t=7, c y}^{b, f w}<E\left(p_{f, t=7, c y}^{b, f w}\right) \times(1-0.1)$, then the farmer faces $p_{f, t}^{s, f w}=F_{f, t=7, c y}^{f w}$ for next year's harvest. Otherwise, the farmer faces $p_{f, t}^{b, f w}$ during the next year.

In the above conditions, $p_{f, t=7, c y}^{b, f w}$ is the base price in July of the current year, $E\left(p_{f, t=7, c y}^{b, f w}\right)$ is the trend prediction of the July price of the current year, and $F_{f, t=7, c y}^{f w}$ is the nearby futures price at the time of hedging (Average of the daily futures prices in July of the current year).

Farm strategy 2 - Hedge in the futures market (Type 2):

In July each year, the farmer decides whether to hedge next year's harvest in a futures market. If the price in the current July is less than its minimum expected level, then the farmer expects the same to happen next July and therefore decides to hedge next year's harvest in a futures market. The farmer is assumed to hedge the entire harvest. If the farmer does not hedge, then the farmer stores next year's harvest and sells it at next year's monthly base prices. The price the farmer faces next year is given by the following conditions:

If $p_{f, t 78, c y}^{b, f w}<E\left(p_{f, t=7, c y}^{b, f w}\right) \times(1-0.1)$, then the farmer faces $p_{f, t}^{s, f w}=p_{f, t=7, n y}^{b, f w}+F_{f, t=7, c y}^{f w}-$ $F_{f, t=7, n y}^{f w}$ for next year's harvest. Otherwise, the farmer faces $p_{f, t}^{b, f w}$ during the next year.

In the above conditions, $p_{f, t=7, n y}^{b, f w}$ is the base price in July of next year and $F_{f, t=7, n y}^{f w}$ is the nearby futures price at the time of next year's harvest (Average of the daily futures prices in July of next year). 
Processor strategy 1 - Six-month contract (Type 2):

Each month of the year, the processor decides whether to sell flour at monthly base prices or to fix prices for the next six months by entering into a contract with the retailer. If the average of the base prices in the previous six months is less than the average of the expected base prices in the previous six months minus a threshold price drop, then the processor expects the same to happen in the next six months and therefore decides to enter into a contract. The contract price is set equal to the base price at the time the contract is entered into. If the processor does not enter into a contract, the processor faces the monthly base prices. The output price the processor faces during the year is given by the following conditions:

If $\frac{\sum_{z=1}^{6} p_{p, t-z}^{b, f w}}{6}<\frac{\sum_{z=1}^{6} E\left(p_{p, t-z}^{b, f w}\right)}{6} *(1-0.1)$, then the processor faces $p_{p, t}^{s, f w}=p_{p, t=c m}^{b, f w}$ for the next six months. Otherwise, the processor faces $p_{p, t}^{b, f w}$ for the next six months.

In the above conditions, $p_{p, t=c m}^{b, f w}$ is the base price in the month the contract is entered into.

\subsection{Results}

The effectiveness of PVMS was evaluated for the Spanish tomato and French wheat chains by comparing the base scenario and alternative strategies across different volatility measures. Results for the Spanish tomato chain (Table 5.2) are presented first, followed by results for the French wheat chain (Table 5.3).

Spanish tomato chain

Table 5.2 - Price volatility under the base scenario and PVMS: Spanish fresh tomato chain

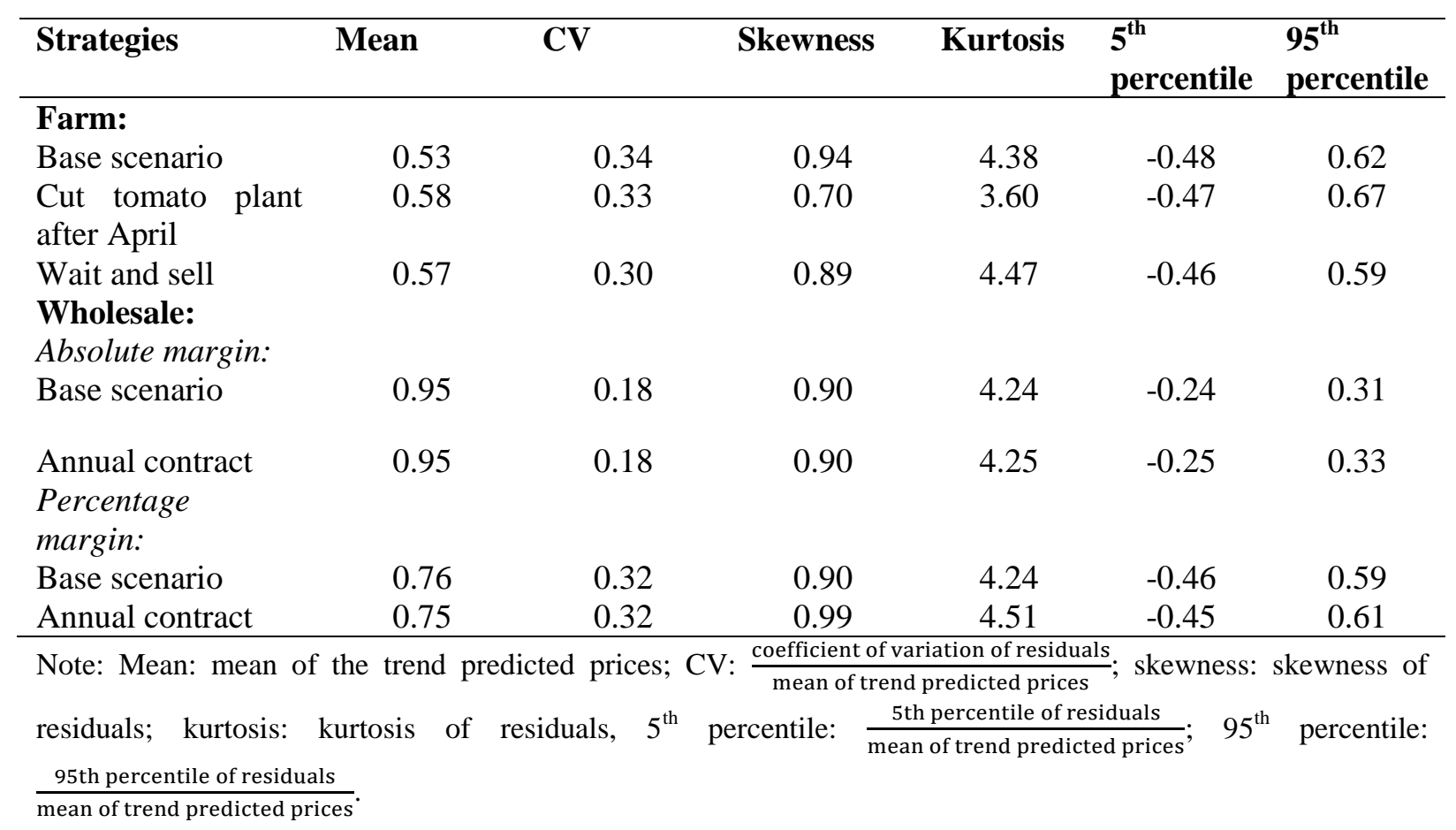


The farm strategy of waiting and selling performs better than the base scenario in terms of a higher mean price, a lower $\mathrm{CV}$ and a higher $5^{\text {th }}$ percentile. The range within which prices deviate from expected level (range between the $5^{\text {th }}$ and $95^{\text {th }}$ percentile) is also narrowest for the strategy of waiting and selling (i.e. difference between the absolute value of 0.46 and 0.59). The skewness is highest for the base scenario, indicating that a farmer can receive extremely high prices if no PVMS is implemented. In contrast, considering the distribution of price residuals (i.e. kurtosis), cutting the tomato plant if prices drop significantly after April is a better strategy as it lowers the probability of extremely low prices. A risk-averse farmer would choose such a strategy.

The wholesale strategy of entering into an annual contract performs similarly to the base scenario, in particular if margins are fixed in absolute terms. This result indicates that the use of contracts was rarely triggered during the sample period (i.e. 2005-2014). As a check, the average historical wholesale price, the average base wholesale price with absolute margin and the average base wholesale price with percentage margin were calculated and compared for the 2005-2014 period. The comparison showed that the average historical price was equal to the average base wholesale output price with absolute margin. This indicates that the use of an absolute margin to calculate wholesale prices is more consistent with how prices are set by Spanish tomato wholesalers.

French wheat supply chain

Table 5.3 - Price volatility under the base scenario and PVMS: French wheat chain

\begin{tabular}{|c|c|c|c|c|c|c|}
\hline Strategies & Mean & $\mathbf{C V}$ & Skewness & Kurtosis & $\begin{array}{l}5^{\text {th }} \\
\text { percentile }\end{array}$ & $\begin{array}{l}95^{\text {th }} \\
\text { percentile }\end{array}$ \\
\hline \multicolumn{7}{|l|}{ Farm: } \\
\hline Base scenario & 0.18 & 0.27 & 0.38 & 2.63 & -0.31 & 0.60 \\
\hline $\begin{array}{l}\text { Annual contract with } \\
\text { futures prices }\end{array}$ & 0.15 & 0.18 & 0.83 & 3.07 & -0.20 & 0.39 \\
\hline $\begin{array}{l}\text { Hedge in futures } \\
\text { market }\end{array}$ & 0.15 & 0.18 & 0.83 & 3.07 & -0.21 & 0.40 \\
\hline \multicolumn{7}{|l|}{ Processor: } \\
\hline Base scenario & 0.53 & 0.13 & 0.02 & 1.92 & -0.18 & 0.21 \\
\hline $\begin{array}{l}\text { Six-month contract } \\
\text { Percentage margin: }\end{array}$ & 0.54 & 0.13 & 0.17 & 2.39 & -0.19 & 0.22 \\
\hline Base scenario & 0.60 & 0.26 & 0.02 & 1.92 & -0.36 & 0.43 \\
\hline Six-month contract & 0.60 & 0.26 & 0.14 & 2.36 & -0.42 & 0.48 \\
\hline
\end{tabular}

Note: Mean: mean of the trend predicted prices; CV: $\frac{\text { coefficient of variation of residuals }}{\text { mean of trend predicted prices }}$ skewness: skewness of residuals; kurtosis: kurtosis of residuals, 5th percentile: $\frac{5 \text { th percentile of residuals }}{\text { mean of trend predicted prices }}$ 95th percentile: 95th percentile of residuals

mean of trend predicted prices

Table 5.3 shows that the two farm strategies perform similarly. The mean price, the CV, the skewness, the kurtosis and the $5^{\text {th }}$ percentile are almost the same across these two strategies. Both strategies have a lower mean than the base scenario. This indicates that wheat prices are much higher during the year than at harvest time. Both strategies reduce the $\mathrm{CV}$ relative to the base scenario, indicating that prices vary less at harvest time than during the year. Although both strategies result in a lower mean price than in the base scenario, the farmer still has a non-zero probability of receiving higher prices under these two strategies as indicated by the skewness, which is much higher than in the base scenario. Both strategies would be attractive to a risk-averse farmer, as both result in a lower CV and narrower range between the $5^{\text {th }}$ and $95^{\text {th }}$ percentiles. 
The results for the processor show that the six-month contract performs similarly to the base scenario in terms of the mean price, the $\mathrm{CV}$, and the $5^{\text {th }}$ and $95^{\text {th }}$ percentiles. However, the contract results in higher kurtosis and skewness of residuals. This indicates that, although there is a probability of facing extreme output prices if contracts are used (as indicated by the higher kurtosis), these extreme values are positively skewed. That is, the processor has a non-zero probability of facing extremely high prices for flour. Similar to the Spanish tomato chain, a comparison was made between average base flour prices and average historical flour prices. The comparison revealed that French wheat processors set flour prices with absolute margins on wheat prices.

\subsection{Discussion and conclusions}

This paper developed a method to evaluate the effectiveness of PVMS in reducing the price volatility faced by food supply chain actors. Using the mean-variance utility framework, a simple trigger rule was developed for the implementation of a PVMS. The trigger rule consists of setting a threshold price drop from an expected base (spot) price; prices less than this threshold price drop trigger the chain actor to implement a strategy. An average percentage that represents this threshold can be directly enquired from chain actors and implicitly takes into account other decision variables that influence utility, such as the average cost of a strategy, the quantity produced and sold, the production costs and the risk attitude of the chain actor. The decision rule adopted in this paper is particularly useful in cases of limited data availability.

It should be noted however, that the threshold price drops considered in this paper did not account for differences in the decision variables across strategies and chain actors. Taking into account differences in costs across strategies requires the determination of a threshold price drop for each strategy. Whereas a costly strategy would result in a higher threshold price drop (i.e. a chain actor can tolerate a larger drop in spot prices), a less costly strategy would result in a lower threshold price drop. Similarly, the threshold price drop would be lower for a risk-averse chain actor and higher for a riskloving chain actor. Future research could take into account differences in threshold price drops by enquiring about chain actors' risk attitudes and about the threshold price drop that would trigger them to implement a specific strategy. Enquiring about the threshold price drop for each strategy has the added benefit of accommodating a diverse set of strategies. Furthermore, Assefa et al. (2016) have shown that food chain actors consider implementing a strategy when the drop in prices is persistent, i.e., when prices remain below a threshold level for a certain period of time. This duration could also be enquired for each strategy.

An advantage of the method outlined in this paper is that it can accommodate non-traditional PVMS, such as waiting a week and then selling tomatoes or cutting the tomato plant to minimise losses. The method is also appropriate for traditional strategies, such as hedging in futures markets and contracts. The paper has further shown that the method is suitable to evaluate the effectiveness of strategies for both storable (e.g., tomatoes) and non-storable (e.g., wheat) products. For instance, the strategy of waiting a week and then selling tomatoes follows from the non-storable nature of tomatoes. Likewise, the storable nature of wheat facilitates the existence of futures markets for wheat.

The results from the Spanish tomato and French wheat chains have shown that long-term contracts do not necessarily lead to lower price volatility compared with selling in the spot market. In other studies, forward contracts have been shown to reduce price volatility (Heyder et al., 2010; von Davier, 2010; Kimura and Anton, 2010). The effectiveness of contracts depends on the way contract prices are set 
by the actors and this may explain the different findings between studies. Future research could test the sensitivity of results to alternative specifications of contract prices. Various volatility measures (i.e., $\mathrm{CV}$, kurtosis, skewness, $5^{\text {th }}$ and $95^{\text {th }}$ percentiles) and mean prices were used to evaluate the effectiveness of strategies. Although some of the strategies performed better on some measures, they performed worse on other measures, thereby making it difficult to choose a strategy. In such a case, information about the risk attitude of the chain actor can provide additional information to support the choice of strategy.

This paper did not explicitly account for the effect of market power at the processing and wholesale stages on price volatility. The paper assumed that price volatility at these two stages only depended on the spot price volatility in the farm sector (base farm price volatility) and on the PVMS the actors implemented. In practice, the presence of market power at the processing, wholesale and retail stages can alter the effectiveness of PVMS. For example, powerful retailers wish to maintain stable and low consumer prices (Rabobank, 2011) and may therefore not increase the prices that wholesalers or processors receive when input costs at these two stages increase. This implies that the wholesale or processing output price volatilities calculated using the method described in this paper are likely to be lower if the presence of market power at the retail stage is taken into account. Modelling the joint effects of market power and PVMS on price volatility is an interesting avenue for further research. It should also be noted that, even in the absence of market power, the replication of a strategy by several chain actors can alter the effect of the strategy on price volatility. For instance, if all Spanish tomato farmers decided to adopt the strategy of waiting one week before selling their tomatoes, then prices would drop even more in the week that farmers sell their tomatoes, thereby exacerbating price volatility. Modelling the complex pricing interactions of chain actors is an interesting avenue for future research.

A final point concerning this method is the relationship between PVMS for inputs and outputs. This paper assumed that actors implement a strategy only to manage output price volatility. Although this may reflect reality, relaxing this assumption may lead to a more comprehensive evaluation of the effectiveness of a strategy. Assefa et al. (2016) indicated, for instance, that one of the interviewed French flour processors altered its wheat purchase strategies as a result of contracts with the retailer. To avoid a squeeze in margin caused by a rise in wheat prices during the contract period, the processor altered its strategy from buying wheat during the contract period to buying wheat at the time the contract was entered into. Such a strategy is expected to affect the volatility of both wheat prices and flour prices faced by the processor.

This paper developed a method to evaluate the effectiveness of PVMS for different actors in a food supply chain. The method was illustrated using data from the Spanish fresh tomato and French wheat supply chains. The paper also highlighted issues that should be considered in the evaluation of strategies along the chain. The method accommodates traditional strategies, such as forward and futures contracts, as well as non-traditional strategies, such as those that involve the timing of sales. Given that price volatility affects all actors in the food supply chain and that the strategies used by chain actors to manage the risk from price volatility are quite diverse (Assefa et al., 2016), further research that builds on the method outlined in this paper is necessary. The empirical tractability of the method makes it useful for food chain actors and policy makers. Food chain actors can apply the method to evaluate the effectiveness of their own strategies. Policy makers can use the method to identify chain stages where PVMS are ineffective in reducing price volatility; policy measures can then be designed to support these chain stages. 


\section{References}

Anders, S. M. (2008). Imperfect competition in German food retailing: Evidence from State level data. Atlantic Economic Journal, 36 (4), 441-454.

Assefa, T.T., Meuwissen, M.P.M. and Oude Lansink, A.G.J.M. (2015). Price Volatility Transmission in Food Supply Chains: A Literature Review. Agribusiness , 31 (1), 3-13.

Assefa, T.T., Meuwissen, M.P.M. and Oude Lansink, A.G.J.M. (2016). Price volatility perceptions, management strategies, and policy options in EU food supply chains. In G., Alberto, Brummer, B., M'Barek, R., Meuwissen, M. and Morales-Opazo, C. (eds), Agricultural Markets Instability. Revisiting the recent food crisis (pp. 178-192). New York, NY: Routledge.

Bakucs, L.Z., Fertö, I., Hockmann, H. and Perekhozhuk, O. (2009). Market power on the edge? An analysis of the German and Hungarian hog markets. Agrarwirtschaft, 58 (8), 337-345.

Bielza, M., Garrido, A. and Sumpsi, J.M. (2007). Feasibility of a cash forward contract: An application to the French and Spanish potato sectors. Agribusiness, 23(2), 245-261.

García-Germán, S. et al., 2013. Literature review of impacts of food price volatility on consumers in developed and developing countries. Working Paper 2, ULYSSES project, EU 7th Framework Programme, Project 312182 KBBE.2012.1.4-05, http://www.fp7-ulysses.eu/, 52 pp.

Heyder, M., Theuvsen, L., and Von Davier, Z. (2010). Strategies for coping with uncertainty: The adaptation of food chains to volatile markets. Journal on Chain and Network Sciences, 10(1), 17-25.

Kimura, S. and C. Le Thi (2011). Farm Level Analysis of Risk and Risk Management Strategies and Policies: Technical Note ( OECD Food, Agriculture and Fisheries Working Papers, No. 48). OECD Publishing.

Manfredo, M., Richards and McDermott (2003). Risk management techniques for agricultural cooperatives: An empirical evaluation. Paper presented at the NCR-134 conference on applied commodity price analysis, forecasting, and market risk management, St. Louis, Missouri.

Ministère de l'agriculture, de l'agroalimentaire et de la forêt.

https://www.data.gouv.fr/en/organizations/ministere-de-l-agriculture-de-l-agroalimentaire-et-de-laforet/\#datasets

Ministerio de Agricultura, Alimentacion y Medio Ambiente. http://www.magrama.gob.es/es/ .

Neyhard, J., Tauer, L. and Gloy, B. (2013). Analysis of price risk management strategies in dairy farming using whole-farm simulations. Journal of Agricultural and Applied economics, 42 (2), 313 327.

Piot-Lepetit, I. (2011). Price volatility and price leadership in the EU beef and pork meat market. In Piot-Lepetit, I. and M'Barek, R. (eds), Methods to Analyse Agricultural Commodity Price Volatility (pp. 85-106). New York, NY: Springer Science and Business Media.

Quandl. https://www.quandl.com/. 
Rabobank (2011). Rethinking the food and agribusiness supply chain; impact of agricultural price volatility on sourcing strategies. Retrieved from http://hugin.info/133178/R/1549493/476482.pdf .

Von Davier, Z., Heyder, M., and Theuvsen L. (2010). Media analysis on volatile markets' dynamics and adaptive behaviour for the agri-food system. International journal of Food System Dynamics, 1 (3), 212-223.

Weber, S.A. and Anders, S.M. (2007). Price rigidity and market power in German retailing. Managerial and decision economics, 28 (7), 737-749. 
Chapter 6

\section{Revenue insurance premium rates accounting for farm heterogeneity: The case of the Dutch ware potato sector}

Tsion Taye Assefa, Miranda Meuwissen, Alfons Oude Lansink

Submitted 


\begin{abstract}
This paper calculates premium rates for an agricultural revenue insurance contract for Dutch ware potato farmers. Premium rates are calculated for groups of farms categorised according to farms' expected yields and yield variances. The analysis uses balanced panel data on ware potato output and inputs from 56 specialised Dutch arable farms and prices of ware potato futures contracts traded in the European Energy Exchange, for the period 2010 to 2014. First, a Just-Pope production function is estimated to predict each farm's expected yield and yield variance, which are later used to group farms into four categories (i.e. high expected yield, low expected yield, high relative variance and low relative variance). Next, the dependencies between prices and yields in each category are modelled with a Gaussian and a $\mathrm{t}$ copula. Results show that the Gaussian copula best represented the dependencies between prices and yields. Estimated premium rates differed across the categories: $32.1 \%$ on guaranteed revenue per hectare for the high expected yield category, $22.2 \%$ for low expected yield, $33.1 \%$ for high relative variance, and $24.0 \%$ for the low relative variance category. The results imply that charging the same average premium rate to all Dutch ware potato farms can lead to adverse selection. Furthermore, using farm-level yields results in higher premium rates than if yields are aggregated over farms.
\end{abstract}

Key words: Revenue insurance, premium rate, adverse selection, copula, farm heterogeneity, Dutch potato

\title{
6.1. Introduction
}

The income of farmers within the European Union (EU) has become increasingly volatile because of increases in both price and yield volatility. The increased price volatility can be attributed to the continuous liberalisation of EU agricultural markets, combined with decreasing price support (Assefa et al., 2016). Although the Common Agricultural Policy (CAP) of the EU has traditionally used various measures to stabilise prices, the situation has changed over recent decades as various trade agreements have required a gradual liberalisation of the EU agricultural market (Meuwissen et al., 2011; Severeni and Cortignani, 2011). The increase in yield volatility is a result of recurrent extreme weather events and more regulated use of herbicides, medicines and vaccines (El Benni et al., 2016). Private insurance is available to farmers to cope with yield losses, in addition to the ad hoc disaster relief assistance provided by governments for extreme production losses (Bielza et al., 2007a). EU agricultural insurance schemes mainly focus on protecting against yield risk and no insurance schemes exist that protect farmers against price risk (Osama Ahmed and Teresa Serra, 2015; Bielza et al., 2007a; European Commission, 2007). Meuwissen et al. (2003, 2008) have attributed the absence of revenue or income insurance in the EU to a combination of demand-side factors, such as the existence of ad hoc disaster relief within the CAP, and supply-side factors, such as the presence of asymmetric information and systemic risks.

In the current CAP (2014-2020), the European Commission recognises the need to subsidise income insurance to help farmers cope with both yield and price volatility (Severeni and Cortignani, 2011; Perez Blanco et al., 2014; El Benni et al., 2016). The risk management toolkit contains animal and plant insurance (art.37), mutual funds for animal and plant diseases and environmental incidents (art.38), and income stabilisation tools (art.39) in the form of mutual funds to address income volatility (European Commission, 2016a). In Article 39, income refers to the sum of revenues the farmer receives from the market, including any form of public support, deducting input costs (European 
Commission, 2016a). The case of the Netherlands shows that, despite the legal provisions to support the total income of farms in mutual funds, current mutual funds insure mainly against weather and disease risks (Meuwissen et al., 2013). It should be noted that few revenue insurance initiatives have existed in the EU. A private company in the United Kingdom launched a revenue insurance scheme for cereals in 1998, based upon yield statistics from the Home-Grown Cereals Authority and prices of LIFFE commodity futures (Bielza et al., 2007a; Meuwissen et al., 2003). However, since the uptake was minimal, the scheme was cancelled in the subsequent season (Bielza et al., 2007a). A possible reason for the low uptake may have been farmers' unfamiliarity with derivative types of contracts (Meuwissen et al., 2003).

A proper calculation of premium rates is critical for the efficient implementation of any insurance program (Tejeda and Goodwin, 2008). Under- and overvalued premium rates can distort the insurance market and may pose a risk to the economic sustainability of insurance programmes (Ahmed and Serra, 2015). For an agricultural revenue insurance contract, proper modelling of the dependence between prices and yields is necessary for a proper valuation of premium rates. A further aspect for consideration is the calculation of premium rates that accurately reflect an individual farmer's risk level. Premium rates calculated in such a manner reduce the problem of adverse selection. Adverse selection refers to a situation where mainly farms with higher likelihoods of loss remain in the insurance pool because low-risk farms are overcharged and high-risk farms are under-charged (Goodwin, 2001; Bielza et al., 2007a). In crop insurance programmes, the problem of adverse selection is associated with the actuarial practice of calculating premium rates using the average yield in the farm's geographical area as the insurable yield (Goodwin, 1994). This leads to premium rates that are not commensurate with farmers' likelihoods of losses (Goodwin, 1994). One solution to this problem is to use the individual farm's actual production history when determining the insurable yield (Goodwin, 1994). Another solution is to classify farms into homogeneous risk groups (Glauber, 2004). Goodwin (1994) proposes the use of observable characteristics (e.g. input use, crop diversification and farm size ) that affect yield risk to assign farms to homogenous risk groups.

A recent development in the agricultural insurance literature is the application of copulas to model dependencies between yields of different crops, i.e. yields of the same crop in different geographical areas, and between prices and yields. Copulas are flexible instruments that can capture the joint distribution of variables without a priori knowledge of and restrictions on the marginal distributions of each variable (Tejeda and Goodwin, 2008). Unlike simple correlation coefficients, such as Spearman's rank correlation and Kendall's tau, copulas account for the state-dependent nature of the dependencies between variables by capturing dependencies in the tails of the distributions (Zhu et al., 2008). Only a few studies have applied copulas to rate agricultural revenue insurance contracts. For the US market, Goodwin and Hungerford (2014) and Zhu et al. (2011) applied copulas to county-level crop yields and futures prices of corn and soybeans. Similarly, Ghosh et al. (2011) applied copulas to county-level corn yields and futures prices. To the best of our knowledge, the study by Ahmed and Serra (2015) is the only study that has applied copulas to rate an agricultural revenue insurance contract within the EU. Their case studies focused on the Spanish orange and apple markets. All these studies used aggregate yield data instead of farm-level data to evaluate premium rates, which can lead to the problem of adverse selection. Related to the use of aggregated yield data, a further limitation of these studies is that the premium rate calculations do not account for the risk heterogeneity of farms.

The objective of this chapter is to calculate premium rates that account for farm risk heterogeneity for an agricultural revenue insurance contract in the Dutch ware potato sector. The EU ware potato sector is a free market with no market regulations that influence market prices (European Commission, 2016b). This makes EU ware potato farmers more susceptible to price volatility than farmers in 
regulated markets, such as grains (Melyukhina, 2011). Given the policy support for income stabilisation tools for mutual funds, current Dutch mutual funds could benefit from the provision of revenue insurance contracts to their member farmers. The implementation of such schemes can be facilitated by the existence of futures contracts for ware potatoes traded in the EEX, which can provide objective reference prices to rate agricultural revenue insurance contracts.

The chapter models the joint dependence of prices and yields using copulas and the premium calculations account for possible risk heterogeneity that may exist among Dutch potato farms. This chapter uses farm-level data to calculate premium rates, enabling a more accurate assessment of the loss likelihoods of individual farms. To account for the risk heterogeneity of farms, premium rates are calculated for homogeneous risk groups of farms. Categorisation of farms is based on yield variances and expected yields, as both determine the farms' likelihoods of losses. Farms' expected yields and yield variances are derived from the estimation of a Just-Pope production function, thereby providing a theoretical basis for the estimation of expected yields and variances.

The remainder of this paper is organized as follows. Section 6.2 provides a brief description of the EU and Dutch ware potato sectors. Section 6.3 provides the methods. Section 6.4 presents the data employed. Section 6.5 presents and discusses the results and section 6.6 concludes the chapter.

\subsection{The potato sector in the $\mathrm{EU}$ and the Netherlands}

Major producers of ware potato in the EU are Germany, the Netherlands, France, the UK and Belgium (termed the EU-5) (European Commission, 2007; Bunte et al., 2009). Although Poland has long been a major producer, the long-term decline in its production has strengthened the market position of the EU-5. The concentration of ware potato in the EU-5 can be attributed to the production cost advantage of the region and because these countries are situated near big concentrations of consumers (European Commission, 2007). No common market organisation exists within the EU for the ware potato sector (European Commission, 2007; Bielza et al., 2007b), which is the most competitive sector in EU agriculture (European Commission, 2016b). The sector has not benefited from any CAP interventions, either in the form of price support or coupled direct subsidies (European Commission, 2007); however it is eligible for decoupled direct payments under the Single Area Payment Scheme (European Commission, 2007). The absence of regulation in the potato market results in potato prices being more volatile than prices of other crops, such as grains (Melyukhina, 2011). In addition, potato markets are poorly integrated due to their perishable nature, which limits their transportability (Meuwissen et al., 2011). Potato prices are therefore also more volatile than the prices of commodities with highly integrated markets, which can benefit from negative correlation of yields in widely dispersed places (Meuwissen et al., 2011). According to Bielza et al. (2007b), ware potato growers can be exposed to an inter-seasonal price coefficient of variation that ranges from $30 \%$ to $70 \%$ (Bielza et al., 2007b).

Potato is one of the most important arable crops in the Netherlands and the most susceptible to weather conditions (Langeveld et al., 2003). Ware potatoes are usually planted in April and harvested in October, and cultivated on both sandy and clays soils (Langeveld et al., 2003). Major weather risks affecting potato yields are frosts that occur around the planting season and wet conditions at harvest time (Botzen et al., 2010; Langeveld et al., 2003). Ware potatoes are produced within a multi-crop rotational plan by arable farms (Botzen et al., 2010; Ogurtsov et al, 2007). Rotation helps to enhance the fertility of the soil on which potato is grown and to reduce weeds (European Commission, 2007). Using panel data from 97 Dutch arable farms covering a period of six years (2002-2007), Melyukhina 
(2011) have shown that price risk is more prominent in Dutch arable farming than yield risk. The research attributed the relatively low yield risk to the mild climatic conditions in the Netherlands and the advanced production technologies used. The research further found that Dutch ware potato prices exhibit large variability compared to crops such as sugar that have rigid price regulations.

Contracts between potato growers and the downstream stages of the chain are widely used to manage price volatility in the Dutch potato sector (European Commission, 2007; Bunte et al., 2009). The contracts establish a minimum guaranteed price, which may be subject to price revisions within a certain price band (European Commission, 2007). Insurance contracts are also used to manage income risk. Perils covered under yield insurance contracts for arable crops include extreme precipitation, hail, storm and brownrot (Ogurtsov et al., 2009; Meuwissen et al., 2013). Although futures markets could have been a solution to manage potato price volatility, the use of this instrument among Dutch potato farmers is very limited. The futures markets for potatoes and hogs that operated in the Amsterdam exchange ceased to operate in June 2006 because of a lack of market liquidity (European Commission, 2007; Melyukhina, 2011). Futures contracts for ware potato are currently traded in the European Energy Exchange (EEX) in Leipzig, Germany.

\subsection{Method}

The following steps were taken to calculate the revenue insurance premium rates for Dutch ware potato farms. First, farms were categorised according to their expected yields and yield variances. The Just-Pope (1978) production function provides the theoretical basis needed to compute the expected yields and yield variances. Next, premium rates were computed for each category of farms. The theoretical framework underlying the Just-Pope production function is presented in section 3.1. This is followed by the empirical frameworks to estimate the Just-Pope production function (section 3.2.1), to categorise the farms (section 3.2.2) and to calculate the premium rates for each category of farms (section 3.2.3).

\subsubsection{Theoretical framework - Just-Pope production function}

The Just-Pope production function is specified as

$Y_{i t}=f\left(X_{i t}\right)+\varepsilon_{i t} \sqrt{h\left(X_{i t}\right)}$,

where $Y_{i t}$ is the output of farm $i$ at time $t, f\left(X_{i t}\right)$ is expected output, which can take any functional form, $X_{i t}$ are the inputs used by farm $i$ at time $t$, and $\varepsilon_{i t} \sqrt{h\left(X_{i t}\right)}$ is the stochastic part of the output. Specifying $\varepsilon_{i t} \sqrt{h\left(X_{i t}\right)}=u_{i t}$, the output variance is given as

$\operatorname{var}\left(Y_{i t}\right)=\operatorname{var}\left(u_{i t}\right)=E\left(u_{i t}^{2}\right)=E\left(\varepsilon_{i t}^{2}{\sqrt{h\left(X_{i t}\right)}}^{2}\right)=\sigma_{\varepsilon}^{2} h\left(X_{i t}\right)=h\left(X_{i t}\right)$.

In equation (2), the variance of the stochastic term $\varepsilon_{i t}$ is given by $\sigma_{\varepsilon}^{2}=1$ and its mean by $E\left(\varepsilon_{i t}\right)=0$. The output variance as a function of inputs is given by $h\left(X_{i t}\right)$, where $h$ can take any functional form. 
The Just-Pope production function allows the effects of inputs on expected output to differ from the effects of inputs on output variance (Gardebroek et al., 2010), that is $\frac{\partial f\left(X_{i t}\right)}{\partial X_{i t}} \neq \frac{\partial h\left(X_{i t}\right)}{\partial X_{i t}}$.

\subsubsection{Empirical framework}

a. Estimation of a Just-Pope production function

A quadratic specification was chosen to estimate equation (1). A quadratic specification enables the inclusion of inputs with zero values, unlike the translog or the log-linear specification. Moreover, unlike the linear specification, the quadratic specification has a theoretical underpinning because it can capture possible non-linear relationships between inputs and output levels (i.e. output levels may start decreasing if input level applications exceed a certain threshold). The quadratic specification of equation (1) is given by

$Y_{i t}=\alpha+\sum_{k=1}^{5} \alpha_{k} X_{k i t}+\sum_{k=1}^{5} \sum_{j=1}^{5} \alpha_{k j} X_{k i t} X_{j i t}+\theta_{1} t_{i t}+\theta_{2} t_{i t}^{2}+\sum_{k=1}^{5} \varphi_{k} t_{i t} X_{k i t}+u_{i t}$.

Equation (3) was estimated using fixed-effect estimation to capture the effects of unobserved farmspecific characteristics that affect output, such as soil quality and management. In equation (3), $Y_{i t}$ is the ware potato output of farm $i$ observed in year $t, \alpha_{k}$ are coefficients that indicate the effects of inputs on the output of farm $i$ at time $t$, and $X_{k i t}$ (or $X_{j i t}$ ) indicate the inputs used by each farm. Based on previous econometric studies of arable farms (e.g. Gardebroek et al (2010) and Tiedmann and Latacz-Lohmann (2013)), five inputs were included in the analysis, i.e. seedling $(k=1)$, protection $(k=2)$, energy $(k=3)$, fertiliser $(k=4)$ and ware potato land area $(k=5)$. All five inputs used in the estimation of equation (3) were used only for potato production. The time trend is given by $t$ and reflects technological changes. The coefficients $\alpha_{k j}$ indicate the effects of the interactions between inputs, and $\varphi_{k}$ indicate the interactions between inputs and the time trend. Production theory states that output is increasing in inputs.

A translog specification was used to model the output variance $h\left(X_{i t}\right)$. The translog specification of $h\left(X_{i t}\right)$ in equation (2) is given by

$$
\ln \left|u_{i t}\right|=\beta+\sum_{k=1}^{6} \beta_{k} \ln X_{k i t}+\sum_{k=1}^{6} \sum_{j=1}^{6} \beta_{k j} \ln X_{k i t} \ln X_{j i t}+\sum_{p=1}^{10} \gamma_{p} D_{p i t}
$$

A fixed-effect approach was not used to estimate equation (4), in order to be able to investigate the effect of farm location on output variance. This was of interest because geographical locations generally form the basis to construct farm insurance pools. The effects of location-specific factors, such as weather conditions and soil quality, were captured by including location dummies. The translog specification provides positive values for $\left|u_{i t}\right|$, which were used to categorise farms based on yield variances. In equation (4), the location dummies are given by $D_{p i t}$, with $D_{p i t}=1$ for location $p$ and 0 otherwise. Eleven provinces were included: Drenthe, Flevoland, Friesland, Gelderland, Groningen, Limburg, Noord-Brabant, Noord-Holland, Overijssel, Zeeland and Zuid-Holland. ZuidHolland was used as a reference. The effect of each location is given by $\gamma_{p}$. The effects of crop diversification, $\ln X_{6 i t}$ (i.e. $k=6$ ), were also included in the variance equation. Diversification is measured by the Herfindahl-Hirschman index. The inputs, $X_{k i t}$ for $k=1,2,3,4,5$, are as defined in 
equation (3). Crop diversification was expected to have an increasing effect on output variance because farms that diversify may take more risky production decisions due to the opportunity to compensate output losses in one crop by gains from another crop.

\section{b. Farm categorisation}

The first step to categorise farms was to calculate each farm's predicted expected output (i.e. $\hat{Y}_{i t}$ ) and predicted output variance (i.e. $\operatorname{ln|u_{tt}|}$ ) using the coefficients estimated in equations (3) and (4). The predicted absolute values of the residuals were retrieved by taking the exponential of the predicted output variance (i.e. $\left.\exp \left(\widehat{\ln \left|u_{l t}\right|} \mid\right)=\left|\hat{u}_{i t}\right|\right)$. Next, the predicted expected outputs $\left(\hat{Y}_{i t}\right)$ were divided by potato land area to obtain the expected yields, denoted as $\hat{y}_{i t}^{e}=\frac{\hat{Y}_{i t}}{X_{5 i t}}$. The predicted absolute values of the residuals $\left(\left|\hat{u}_{i t}\right|\right)$ were also divided by potato land area and then by expected yield to obtain the ratio of yield variance to expected yield. This ratio is denoted as $\hat{y}_{i t}^{v a r}=\frac{\frac{\left|\hat{u}_{i t}\right|}{x_{5 i t}}}{\hat{y}_{i t}^{e}}$. Since the ratio is a relative measure of variance, it enables the comparison of farms based on their yield variances. In the remainder of this chapter, this ratio is referred to as the relative variance.

Premium rate simulations were conducted for a reference year $T$. Four categories of farms were identified: farms with high expected yield, low expected yield, high relative variance and low relative variance. The conditions for categorising a farm in each of the four categories are given by:

If $\hat{y}_{i T}^{e}>\hat{y}_{T}^{e}$, then farm i was categorised as a high expected yield farm;

If $\hat{y}_{i T}^{e} \leq \hat{y}_{T}^{e}$, then farm i was categorised as a low expected yield farm;

If $\hat{y}_{i}^{\text {var }}>\hat{y}^{\text {var }}$, then farm i was categorised as a farm with a high relative variance; and

If $\hat{y}_{i}^{\text {var }} \leq \hat{y}^{\text {var }}$, then farm $\mathrm{i}$ was categorised as a farm with a low relative variance.

In conditions (5) and (6), $\hat{y}_{i T}^{e}$ indicates the expected yield of farm $i$ in year $T$ and $\hat{y}_{T}^{e}$ indicates the average of the expected yields of all farms in year $T$. In conditions (7) and (8), $\hat{y}_{i}^{\text {var }}$ indicates the relative variance of farm $i$ averaged over $t$ (i.e. average of $\hat{y}_{i t}^{v a r}$ over $t$ ) and $\hat{y}^{v a r}$ indicates the relative variance averaged over $i$ and $t$ (i.e. average of $\hat{y}_{i t}^{\text {var }}$ over $i$ and $t$ ). Note that the relative yields of a farm for all the years (and not only for year $T$ ) were used to categorise farms based on their relative yields.

\section{c. Premium rate calculations per category}

Premium rates were calculated for a reference year $T$ for each of the four categories defined in equations (5) to (8). For comparison, an average premium rate for all farms was also calculated. Prior to simulating the premium rates, the realised yields for the reference year $T$ and the realised log price returns were calculated as 
$\tilde{y}_{i T}=\hat{y}_{i T}^{e} \times\left(1+\frac{\frac{u_{i t}}{X_{5 i t}}}{\hat{y}_{i t}^{e}}\right)$ and

$\tilde{r}_{t}=\log \left(\frac{F_{H, t}}{F_{P, t}}\right)$

In equation (9), $\tilde{y}_{i T}$ is the realised yield for farm $i$ for year $T, \hat{y}_{i T}^{e}$ is the expected yield in year $T$, and $\hat{y}_{i t}^{e}$ is the expected yield in year $t$. This is given by $\hat{y}_{i t}^{e}=\frac{\hat{Y}_{i t}}{X_{5 i t}}$, where $\hat{Y}_{i t}$ is predicted by equation (3). Note that $\frac{\frac{u_{i t}}{X_{5 i t}}}{\hat{y}_{i t}^{e}}$ is used in equation (9) instead of $\hat{y}_{i t}^{v a r}$, where $u_{i t}$ is the actual residual derived from equation (3). This was because $\hat{y}_{i t}^{\text {var }}$ does not distinguish between positive and negative residuals; this distinction was needed to generate the realised yields. In equation $(10), \tilde{r}_{t}$ is the log price return in year $t, F_{H, t}$ is the price of a futures contract expiring in the harvest month of year $t$, and $F_{P, t}$ is the planting price of a futures contract expiring in the harvest month of year $t$.

The dependence structure of realised yields $\left(\tilde{y}_{i T}\right)$ and $\log$ price returns $\left(\tilde{r}_{t}\right)$ was represented by a copula. An m-dimensional copula given by $C\left(F_{1}\left(x_{1}\right), F_{2}\left(x_{1}\right), \ldots, F_{m}\left(x_{m}\right)\right)$ is defined as any multivariate distribution function in the unit hypercube $[0 ; 1]^{m}$ with uniform $U[0 ; 1]$ marginal distributions (Zhu et al., 2008; Goodwin and Hungerford, 2014; Ahmed and Serra, 2015). The marginal distributions of $x_{1}, x_{2}, \ldots, x_{m}$ are given by $F_{1}\left(x_{1}\right), F_{2}\left(x_{2}\right), \ldots, F_{m}\left(x_{m}\right)$ respectively, where $x$ can refer to any variables for which the dependence structure is of interest (i.e. realised yields $\left(\tilde{y}_{i T}\right)$ and $\log$ price returns $\left(\tilde{r}_{t}\right)$ in this chapter). According to Sklar's (1959) theorem, every joint distribution $F\left(x_{1}, x_{2}, \ldots, x_{m}\right)$ with marginal distribution functions $F_{1}, F_{2}, \ldots, F_{m}$ can be written as

$F\left(x_{1}, x_{2}, \ldots, x_{m}\right)=C\left(F_{1}\left(x_{1}\right), F_{2}\left(x_{1}\right), \ldots, F_{m}\left(x_{m}\right) ; \theta\right)$,

where $\theta$ is a vector of dependence parameters of the copula that measure the dependence between the marginals (Zhu et al, 2008).

The vector of dependence parameters $\theta$ was estimated in two steps. In a first step, the marginal distributions of the $\log$ returns and the realised yields were determined. Following Goodwin and Hungerford (2014), rank based empirical distributions were used to represent the marginal distributions. To generate the empirical distribution, each data series was first ranked from the smallest to the largest value across time. Then the following equation was used to generate the empirical distribution of each variable:

$\widehat{F}_{m, t}\left(x_{m, t}\right)=\frac{1}{N} \sum_{t=1}^{N} 1\left\{x_{m} \leq x_{m, t}\right\}$

where $\widehat{F}_{m, t}\left(x_{m, t}\right)$ is the empirical marginal distribution of $x_{m}$ (i.e. $\log$ price returns or realised yields), $N$ is the total number of years, and $1\left\{x_{m} \leq x_{m, t}\right\}$ is the indicator function, with $1\left\{x_{m} \leq x_{m, t}\right\}$ is 1 if $x_{m} \leq x_{m, t}$ and 0 otherwise.

In the second step, the vector of copula parameters $\theta$ was estimated by fitting a copula to the underlying marginal distributions obtained in equation (12). A Gaussian and a t copula were selected because they allow for possible negative correlations between prices and realised yields. Furthermore, the $t$ copula allows for tail dependence between prices and realised yields whereas the Gaussian copula does not. 
Following Goodwin and Hungerford (2014), a distribution of premium rates was obtained by first randomly drawing (with replacement) two farms from the farms available in a category (e.g. farms with high expected yields). Then either a Gaussian or t copula was fitted to the marginal distributions of the realised yields $\left(\tilde{y}_{i T}\right)$ of the selected two farms and the log price returns $\left(\tilde{r}_{t}\right)$ (i.e. a threedimensional copula). From the fitted copulas, 500 realised log price returns and 500 realised yields were simulated for each farm for year $T$ by assuming a normal distribution for both log price returns and realised yields. The simulated realised yields for year $T$ are denoted by $\check{y}_{i T}$ and the simulated futures prices at harvest for year $T$ are given by

$\check{F}_{H, T}=\exp \left(\check{r}_{t}\right) * F_{P, T}$.

In equation (13), $\breve{F}_{H, T}$ is the simulated harvest price for year $T, \check{r}_{t}$ denotes the simulated log price return, and $F_{P, T}$ is the observed planting price of a futures contract expiring in the harvest month of year $T$. The premium rates for the two randomly selected farms were calculated as

$$
\begin{aligned}
& P R_{1, T}=\frac{E\left[\left(\lambda \hat{y}_{1 T}^{e} \times F_{P, T}-\breve{y}_{1 T} \times \breve{F}_{H, T}\right) I\left(\check{y}_{1 T} \times \breve{F}_{H, T} \leq \lambda \hat{y}_{1 T}^{e} \times F_{P, T}\right)\right]}{\lambda \hat{y}_{1 T}^{e} \times F_{P, T}} \text { and } \\
& P R_{2, T}=\frac{E\left[\left(\lambda \hat{y}_{2 T}^{e} \times F_{P, T}-\check{y}_{2 T} \times \breve{F}_{H, T}\right) I\left(\check{y}_{2 T} \times \breve{F}_{H, T} \leq \lambda \hat{y}_{2 T}^{e} \times F_{P, T}\right)\right]}{\lambda \hat{y}_{2 T}^{e} \times F_{P, T}},
\end{aligned}
$$

where $P R_{1, T}$ is the premium rate for farm 1, $\hat{y}_{1 T}^{e}$ is farm 1's guaranteed yield and also the farm's expected yield for year $T, \lambda$ is the coverage rate (assumed at $75 \%$ ), $F_{P, T}$ is the guaranteed price, $\breve{y}_{1 T}$ is the simulated yield of farm 1 , and $I$ is an indicator equal to 1 if $\breve{y}_{1 T} \times \breve{F}_{H, T} \leq \lambda \hat{y}_{1 T}^{e} \times F_{P, T}$ and 0 otherwise. Similarly, $P R_{2, T}$ is the revenue insurance premium rate for farm 2, $\hat{y}_{2 T}^{e}$ is farm 2's guaranteed yield, which is equal to the farm's expected yield for year $T$, and $\check{y}_{2 T}$ is the simulated yield of farm 2. Note that the premium rates are pure premiums and do not account for transaction costs.

The loss costs and loss probabilities for the two randomly selected farms are given by

$$
\begin{aligned}
L C_{1, T} & =E\left[\left[\left(\lambda \hat{y}_{1 T}^{e} \times F_{P, T}-\check{y}_{1 T} \times \breve{F}_{H, T}\right) I\left(\check{y}_{1 T} \times \breve{F}_{H, T} \leq \lambda \hat{y}_{1 T}^{e} \times F_{P, T}\right)\right],\right. \\
L C_{2, T} & =E\left[\left(\lambda \hat{y}_{2 T}^{e} \times F_{P, T}-\check{y}_{2 T} \times \breve{F}_{H, T}\right) I\left(\check{y}_{2 T} \times \breve{F}_{H, T} \leq \lambda \hat{y}_{2 T}^{e} \times F_{P, T}\right)\right], \\
L P_{1, T} & =E\left(I\left(\check{y}_{1 T} \times \breve{F}_{H, T} \leq \lambda \hat{y}_{1 T}^{e} \times F_{P, T}\right)\right) \text { and } \\
L P_{2, T} & =E\left(I\left(\check{y}_{2 T} \times \breve{F}_{H, T} \leq \lambda \hat{y}_{2 T}^{e} \times F_{P, T}\right)\right) .
\end{aligned}
$$

In the above equations, $L C_{1, T}$ is the loss cost for farm 1 for year $T, L C_{2, T}$ is the loss cost for farm 2, $L P_{1, T}$ is the loss probability for farm 1 for year $T$ and $L P_{2, T}$ is the loss probability for farm 2.

The premium rates, loss costs and loss probabilities defined in equations (14) to (19) were calculated for 5000 draws of two farms. This provided a distribution of premium rates, loss costs and loss probabilities for the first category of farms. The entire process was then repeated for the remaining three categories of farms and also for all of the farms without any categorisation.

To describe the heterogeneity of farms within a category, the mean, median, 2.5 th percentile and 97.5th percentile of the simulated premium rates (i.e. 5000 pairs of $P R_{1, T}$ and $P R_{2, T}$ ) were determined. Then, the loss costs and the loss probabilities were determined for the farms with premium rates equal to the 2.5th and 97.5th percentiles and the medians of the simulated premium rates. For each draw of farms, the AIC, BIC and log likelihood were calculated for the fitted three-dimensional Gaussian and $\mathrm{t}$ 
copulas. The number of times each copula resulted in the lowest AIC and BIC and the highest log likelihood were then counted. The copula that performs best on these three measures (i.e. has the highest counts) better represents the data, and is therefore the preferred copula (Goodwin and Hungerford, 2014).

\subsection{Data}

Balanced panel data from 56 specialised Dutch arable farms for the period 2010-2014 were obtained from the Dutch Farm Accountancy Data Network (FADN). The data set consisted of ware potato output, ware potato land area, and expenditure on seedling, protection (e.g. herbicides and pesticides), fertilisers and energy materials (e.g. fuel) used for ware potato production. Producer price indexes (base year 2010) were obtained from Eurostat for Dutch potato seed, plant protection products and pesticides, fertiliser and soil improvers, and energy and lubricants. These price indexes were used to deflate the costs of seedling, protection, fertiliser and energy materials used for ware potato production. The panel data also included the province of each farm (i.e. Drenthe, Flevoland, Friesland, Gelderland, Groningen, Limburg, Noord-Brabant, Noord-Holland, Overijssel, Zeeland, Zuid-Holland) and the land area per farm of flower bulbs, vegetables, horticulture, wheat, barley, seed potato, starch potato, sugar beet and seed onions. The land areas under each crop and the ware potato land areas were used to calculate the Hirfindhal-Hirshman index (HHI), which measures each farm's degree of crop diversification.

The ware potato output, seedling, protection, energy and fertiliser data were rescaled by dividing each item by 100000 . The ware potato land area data was rescaled by dividing the values by 10 . In addition to the above FADN data, planting (April) and harvest (November) prices of a November contract of European processing potatoes traded in the European Energy Exchange (EEX) were obtained from the website barchart.com for the period 2010-2014. Table 6.1 presents the descriptive statistics of the data used in this chapter.

Table 6.1 - Description of data

\begin{tabular}{llll}
\hline Variables $^{1}$ & Units & Symbols & Mean \\
\hline Ware potato output $^{2}$ & $100000 \mathrm{~kg}$ & $Y_{i t}$ & 14.114 \\
Seedling $^{2}$ & $€ / 100000$ & $X_{1 i t}$ & 0.225 \\
Protection $^{2}$ & $€ / 100000$ & $X_{2 i t}$ & 0.176 \\
Energy $^{2}$ & $€ / 100000$ & $X_{3 i t}$ & 0.002 \\
Fertiliser $^{2}$ & $€ / 100000$ & $X_{4 i t}$ & 0.081 \\
Ware potato land area $^{2}$ & Hectares/10 & $X_{5 i t}$ & 2.703 \\
Crop diversification $_{\text {April futures price }}$ & Herfindhal-Hirschman index & $X_{6 i t}$ & 0.318 \\
November futures price & $€ /$ ton & $F_{P, t}$ & 109.458 \\
\hline Number of farms & & $F_{H, t}$ & 127.600 \\
\hline
\end{tabular}

${ }^{1}$ All inputs are used only for ware potato production. ${ }^{2}$ Deflated expenditures, with 2010 as base year. 


\subsection{Results and discussion}

\subsubsection{Farm categorisation}

The estimated coefficients of the Just-Pope production function presented in equations (3) and (4) are reported in Table A-1 and A-2 of the Appendix. The estimated coefficients cannot be interpreted directly because both the expected output and output variance equations of the Just-Pope production function are not linear in inputs. Therefore, the marginal effects of each input were calculated for both equations and presented in Table 6.2 (expected output) and Table 6.3 (output variance). The marginal effects are the first derivatives of each equation with respect to each input and were evaluated at the mean values of the inputs. Although not all of the marginal effects reported in Table 6.2 were statistically significant, the positive signs indicate that all production inputs had output-increasing effects. Only protection (i.e. herbicides and pesticides) and land area had a statistically significant effect on expected output. The results can be compared with those of Gardebroek et al (2010), who estimated a Just-Pope production function using panel data from Dutch organic and conventional arable farms for the period 1990 to 1999. Similar to this chapter, they found that protection and land area had a statistically significant and positive effect on the expected output of conventional farms. Furthermore, they also found that all inputs, except for fertilisers, had an output-increasing effect. Fertilisers had a significant and negative effect on the expected output of conventional farms, which the authors attributed to over-fertilisation of land.

Table 6.2 - Marginal effects of inputs on expected output

\begin{tabular}{lll}
\hline Variable & Marginal effect & Probability \\
\hline Seedling & 0.856 & 0.787 \\
Protection & $11.711^{* *}$ & 0.010 \\
Energy & 42.374 & 0.513 \\
Fertiliser & 0.278 & 0.969 \\
Ware potato land area & $4.055^{* *}$ & 0.000 \\
\hline
\end{tabular}

$* *$ indicates significant values at the $5 \%$ level of significance.

The results in Table 6.3 indicate that the marginal effects of inputs on output variance can differ from the marginal effects on expected output. For instance, while seedling had a positive and nonsignificant effect on expected output, the effect on output variance was negative and statistically significant. The negative effect indicates that improved seedling technologies reduce output fluctuations. This result is similar to that of Tiedmann and Latacz-Lohman (2013), who estimated a quadratic expected output equation and a linear output variance equation, using panel data from German organic and conventional arable farms for the period 1999 to 2007. Table 6.3 shows that land area had a positive and significant effect on output variance; this result is again similar to that of Tiedmann and Latacz-Lohman (2013) for conventional farms. This is an indication that larger farms are less able to react quickly to unfavourable weather conditions at harvest or planting times (Tiedmann and Latacz-Lohman, 2013). Although Gardebroek et al. (2010) also found a positive effect of land area on the output variance of conventional farms, the effect was not statistically significant. The location of a farm was included in the output variance equation. Table 6.3 shows that the location of farms can affect output variance. The differing effects of farm location on output variance indicate variation in soil types and weather conditions across farms. 
Table 6.3 - Marginal effects of inputs on output variance

\begin{tabular}{lll}
\hline Variable & Marginal effect & Probability \\
\hline Seedling & $-0.624 * *$ & 0.023 \\
Protection & 0.353 & 0.240 \\
Fertiliser & -0.321 & 0.144 \\
Ware potato land area & $0.830^{* *}$ & 0.037 \\
HHI (Herfindhal-Hirshman Index) & -0.131 & 0.679 \\
Drenthe & -0.455 & 0.355 \\
Flevoland & $-0.714 * *$ & 0.010 \\
Friesland & -0.386 & 0.525 \\
Gelderland & $-3.071^{*}$ & 0.092 \\
Groningen & $-0.908^{* *}$ & 0.026 \\
Limburg & 0.393 & 0.398 \\
Noord-Brabant & -0.398 & 0.233 \\
Noord-Holland & -0.103 & 0.762 \\
Zeeland & 0.417 & 0.529 \\
Zuid-Holland & -0.037 & 0.879 \\
\hline *and **indicate significant values at the 5\% and $10 \%$ levels of significance, respectively.
\end{tabular}

Overall, these findings support Goodwin's (1994) suggestion that observable characteristics, such as input use, should be used to properly determine the expected output and output variance of individual farms. The results in Table 6.2 and 6.3 indicate that input use does explain changes in expected output and output variance and can therefore be used by insurance companies to calculate premiums. Knowledge of expected output and output variance enables insurers to categorise farms accordingly and calculate premium rates commensurate with expected output and risk.

\subsubsection{Premium rates, loss costs and loss probabilities per category}

The distributions of loss costs, premium rates and loss probabilities for each category of farms are reported in Table 6.4 for the Gaussian Copula and in Table 6.5 for the $t$ copula. The variation in the loss costs, premium rates and loss probabilities reported in both Table 6.4 and 6.5 shows that farms were very heterogeneous, both within and across the four categories of farms. For example, the category-specific loss costs differed by at least $€ 1000$ between farms with premium rates equal to the 2.5th percentile and farms with premium rates equal to the $97.5^{\text {th }}$ percentile of the simulated premium rates. This variation indicates that calculating a single average premium rate for all farms can lead to the problem of adverse selection. This is further illustrated by comparing the average premium rate with the category-specific rates (see for instance the mean premium rate in the last column of Table 6.4). For instance, charging a premium rate of $26.3 \%$ on guaranteed revenue per hectare underestimates the riskiness of farms in the high relative variance category (which should instead be charged a rate equal to $33.1 \%$ ) and overestimates the riskiness of farms in the low relative variance category (which should be charged a rate equal to $24 \%$ ).

Both Table 6.4 and 6.5 show that farms with a high expected yield had higher loss costs, premium rates and loss probabilities than farms with a low expected yield. Similarly, farms with a high relative variance had higher loss costs, premium rates and loss probabilities than farms with a low relative variance. These results were consistent for all the moments of the distributions of loss costs, premium rates and loss probabilities (i.e. 2.5 th and 97.5 th percentiles, means and medians), except for the 2.5 th 
percentile of loss costs, premium rates and loss probabilities for farms in the low relative variance category. A further check was conducted to see if the farms with high expected yield were the same farms as those with high relative variance. The results are reported in the last two rows of Table 6.4 and 6.5, and show that 11 of the 17 farms with high relative variance also had high expected yield. Similarly, 32 of the 39 farms with low relative variance also had low expected output. This finding contradicts the finding of Skees and Reed (1986), that farms with a higher expected yield should be charged a lower premium than farms with a lower expected yield because the former have a lower relative risk. A possible explanation for the difference in results is the method used to measure expected yields and yield variances. Whereas Skees and Reed (1986) calculated expected yields and variances using actual yield data, this chapter used predictions from the Just-Pope function.

Table 6.4 - Simulated premium rates, loss costs and loss probabilities using a Gaussian copula

\begin{tabular}{|c|c|c|c|c|c|}
\hline & \multicolumn{2}{|c|}{ Expected yield } & \multicolumn{2}{|c|}{ Relative variance ${ }^{2}$} & \multirow[t]{2}{*}{ Overall } \\
\hline & High & Low & High & Low & \\
\hline \multicolumn{6}{|l|}{ Loss cost $^{1}$} \\
\hline 2.5th percentile & 1234.801 & 243.623 & 433.8991 & 748.106 & 700 \\
\hline Median & 2014.491 & 952.443 & 1883.194 & 1088.561 & 1222.208 \\
\hline 97.5th percentile & 3951.712 & 1508.218 & 3928.19 & 1677.565 & 2993.409 \\
\hline Mean & 2019.589 & 979.465 & 1984.987 & 1119.002 & 1363.167 \\
\hline \multicolumn{6}{|l|}{ Premium rate } \\
\hline 2.5th percentile & 0.234 & 0.067 & 0.121 & 0.181 & 0.171 \\
\hline Median & 0.311 & 0.217 & 0.332 & 0.238 & 0.254 \\
\hline 97.5th percentile & 0.499 & 0.326 & 0.496 & 0.318 & 0.439 \\
\hline Mean & 0.321 & 0.222 & 0.331 & 0.240 & 0.263 \\
\hline \multicolumn{6}{|l|}{ Loss probability } \\
\hline 2.5th percentile & 0.485 & 0.180 & 0.265 & 0.403 & 0.388 \\
\hline Median & 0.588 & 0.474 & 0.597 & 0.484 & 0.515 \\
\hline 97.5th percentile & 0.791 & 0.632 & 0.767 & 0.597 & 0.746 \\
\hline Mean & 0.596 & 0.481 & 0.587 & 0.489 & 0.522 \\
\hline Number of farms & 19 & 37 & 17 & 39 & 56 \\
\hline $\begin{array}{l}\text { Number of farms in high } \\
\text { expected yield and high } \\
\text { relative variance categories }\end{array}$ & 11 & & 11 & & \\
\hline $\begin{array}{l}\text { Number of farms in low } \\
\text { expected yield and low } \\
\text { relative variance categories }\end{array}$ & & 32 & & 32 & \\
\hline
\end{tabular}

A comparison of Table 6.4 and 6.5 shows that, although loss costs per category differed between the Gaussian and the $t$ copula, the premium rates and the loss probabilities were almost the same. This indicates that not much tail dependence is captured by the $t$ copula. That is, the dependence between Dutch ware potato prices and yields is not state-dependent (for example, the negative dependence between prices and yields does not get stronger in times of extremely low yields). A close examination of the loss costs obtained with the t copula showed no clear pattern in the differences between the loss costs calculated with the Gaussian and the t copula. If negative dependence occurred in the tails of the distribution (i.e. both extremely low prices and extremely low yields will not occur at the same time), then the loss costs, loss probabilities and premium rates from the $t$ copula would be expected to be lower than those from the Gaussian copula. The results in Table 6.5 show, however, that it is unclear 
whether there is positive or negative dependence in the tails of the joint distribution of Dutch ware potato prices and yields. These results contrast with those of Goodwin and Hungerford (2014), who found that the Gaussian copula overpriced risk compared to the $t$ copula. They used US corn and soya county-level yield and price data for the period 1960-2012. The difference in results may be because county-level yield data are more negatively correlated in the tails of the price and yield distributions than farm-level data. For instance, an extremely low yield for an individual farm may not necessarily result in extremely high prices, whereas this is more likely if a geographically aggregated yield is used.

The number of times each copula resulted in the highest log likelihood, the lowest AIC and the lowest BIC values were counted to see which copula better describes the price and yield data. The results, shown in Table 6.6, indicate that the Gaussian copula best represented the joint dependence between Dutch potato prices and yields. Our results contrast with those of Zhu et al. (2008), who calculated premium rates for a whole farm revenue insurance contract and found that the $t$ copula provided a better fit than the Gaussian copula. They used US corn and soya county-level yield and price data for the period 1960 to 2007. Our results indicate that the dependence between Dutch ware potato prices and individual farm yields is not state dependent and can therefore be simply captured by a Gaussian copula.

The premium rates obtained in this chapter (approximately $25 \%$ on average) are much higher than the premium rates found in other literature. For instance, using a t copula, Ahmed and Serra (2015) found premium rates of $1.4 \%$ for apples and $5.2 \%$ for oranges in Spain, for a coverage rate of $75 \%$. Also using a $t$ copula and a coverage rate of $75 \%$, Goodwin and Hungerford (2014) found an average premium rate of $0.3 \%$ for corn and $0.1 \%$ for soybean. In this chapter, the average premium rate estimated using a t copula (and Gaussian) at a 75\% coverage rate was approximately $25 \%$ on guaranteed revenue per hectare. The difference between the results of this chapter and those of previous literature is likely caused by the different types of data used. In this chapter, farm-level yield data are used whereas the cited studies used geographically aggregated yield data. Aggregating yield data can smooth out differences in yields across farms and therefore mask the heterogeneity of yield risk across farms. That is, the variation of an individual farm's yield over time can be much higher than the variation of an aggregated yield over time.

A check of the correlation between log price returns and realised yields for each farm revealed that, although correlations were negative for most of the farms (i.e. 43 farms), positive correlations were also observed (i.e. 13 farms) (detailed results can be obtained upon request from the authors). Of the 43 farms with negative yield-log price return correlations, 41 had a negative correlation less than 0.5 in absolute value. Using FADN panel data from 97 Dutch arable farms for the period 2002-2007, Melyukhina (2011) showed that Dutch ware potato yields and prices were positively correlated. Although the data used in this chapter cover the period 2010-2014, the rather weak negative correlation between prices and yields found in this chapter, coupled with the finding of Melyukhina (2011), suggests that Dutch potato farmers are not benefiting from a natural hedge between prices and yields. This may also explain why the premium rates found in this chapter are much higher than those found in previous literature. The high premium rates reported in this chapter also show that aggregated yields may be more negatively correlated with prices than farm-level yields. The results suggest that the use of yield data aggregated over a geographical area may underestimate each farm's likelihood of revenue loss and result in undervalued premium rates. 
Table 6.5 - Simulated premium rates, loss costs and loss probabilities using a t Copula

\begin{tabular}{|c|c|c|c|c|c|}
\hline & \multicolumn{2}{|c|}{ Expected yield } & \multicolumn{2}{|c|}{ Relative variance $^{2}$} & \multirow[t]{2}{*}{ Overall } \\
\hline & High & Low & High & Low & \\
\hline \multicolumn{6}{|l|}{ Loss cost } \\
\hline 2.5th percentile & 1275.278 & 201.068 & 452.011 & 822.758 & 830.100 \\
\hline Median & 1989.328 & 969.766 & 1810.151 & 1095.181 & 1184.075 \\
\hline 97.5th percentile & 3925.914 & 1488.354 & 3859.542 & 1706.908 & 2949.324 \\
\hline Mean & 2020.649 & 980.971 & 1971.532 & 1116.963 & 1364.947 \\
\hline \multicolumn{6}{|l|}{ Premium rate } \\
\hline 2.5th percentile & 0.234 & 0.07 & 0.106 & 0.182 & 0.173 \\
\hline Median & 0.311 & 0.222 & 0.329 & 0.238 & 0.254 \\
\hline 97.5th percentile & 0.498 & 0.326 & 0.498 & 0.319 & 0.442 \\
\hline Mean & 0.321 & 0.223 & 0.328 & 0.240 & 0.264 \\
\hline \multicolumn{6}{|l|}{ Loss probability } \\
\hline 2.5th percentile & 0.504 & 0.174 & 0.267 & 0.422 & 0.428 \\
\hline Median & 0.584 & 0.477 & 0.597 & 0.489 & 0.511 \\
\hline 97.5th percentile & 0.789 & 0.632 & 0.762 & 0.586 & 0.766 \\
\hline Mean & 0.596 & 0.481 & 0.593 & 0.487 & 0.523 \\
\hline Number of farms & 19 & 37 & 17 & 39 & 56 \\
\hline $\begin{array}{l}\text { Number of farm in high } \\
\text { expected yield and high relative } \\
\text { variance categories }\end{array}$ & 11 & & 11 & & 11 \\
\hline $\begin{array}{l}\text { Number of farm in low } \\
\text { expected yield and low relative } \\
\text { variance categories }\end{array}$ & & 32 & & 32 & \\
\hline
\end{tabular}

Table 6.6 -Fit of the Gaussian and t copulas

\begin{tabular}{lllllllllll}
\hline & \multicolumn{3}{c}{ Expected yield } & \multicolumn{3}{c}{ Relative variance $^{3}$} & \multirow{2}{*}{ Overall $^{3}$} \\
\cline { 2 - 8 } & High & & Low & & High & \multicolumn{3}{c}{ Low } & & \\
\hline Criteria $^{1}$ & $\mathrm{G}^{2}$ & $\mathrm{~T}$ & $\mathrm{G}$ & $\mathrm{T}$ & $\mathrm{G}$ & $\mathrm{T}$ & $\mathrm{G}$ & $\mathrm{T}$ & $\mathrm{G}$ & $\mathrm{T}$ \\
LLF & 1155 & 1122 & 1678 & 433 & 1315 & 1096 & 1589 & 505 & 1412 & 674 \\
AIC & 2221 & 56 & 2039 & 72 & 2378 & 33 & 2020 & 74 & 2024 & 62 \\
BIC & 2221 & 56 & 2039 & 72 & 2378 & 33 & 2020 & 74 & 2024 & 62 \\
\hline
\end{tabular}

${ }^{1}$ The reported numbers are the number of times each type of copula resulted in the highest log likelihood (LLF), and the lowest AIC (Akaike information criteria) and BIC (Schwartz information criteria).

${ }^{2} \mathrm{G}$ : Gaussian copula, T: t copula

${ }^{3}$ The ratio of yield variance to expected yield.

\subsection{Conclusion}

The income of EU farmers has become increasingly volatile because of increased volatility in both prices and yields. Although insurance schemes to protect farmers from income drops caused by decreases in both prices and yields are not currently available in the EU, such schemes have policy support within the CAP. This chapter calculated premium rates for a revenue insurance contract for 
four categories of farms in the Dutch ware potato sector. In a first step, a Just-Pope production function was estimated to predict each farm's expected yields and yield variances. Next, these predictions were used to group farms into four categories (i.e. high expected yield, low expected yield, high relative variance and low relative variance). Finally, premium rates were calculated for each farm category by modelling the joint dependence of prices and yields using a Gaussian and t copula. The analysis used balanced panel data on ware potato output and inputs from 56 specialised Dutch arable farms and prices of ware potato futures contracts traded in the European Energy Exchange, for the period 2010 to 2014.

An average premium rate of approximately $25 \%$ on guaranteed revenue per hectare was found for the Dutch ware potato sector. The Gaussian copula better represented the dependence between Dutch ware potato prices and yields than the t copula. This indicates that the dependence between Dutch potato prices and yields is not state-dependent. For both types of copula, the simulated premium rates varied across the four categories of farms. For the Gaussian copula, for instance, mean premium rates for the high expected yield category, low expected yield category, high relative variance, and low relative variance category were $32.1 \%, 22.2 \%, 33.1 \%$ and $24.0 \%$ on guaranteed revenue per hectare, respectively. In particular, the results show that farms with a high expected yield or a high relative variance should pay the highest premium rate compared to farms in the other two categories. The differences in premium rates within and across categories of farms indicate that farms are heterogeneous in loss costs and loss likelihoods, and therefore charging the same average premium rate to all Dutch ware potato farms can lead to adverse selection.

The relatively high premium rates for the Dutch ware potato sector indicate that a natural price-yield hedging opportunity is not available to Dutch potato farmers. Revenue insurance contracts can be offered through mutual funds, which currently have policy support within the CAP 2012-2020. Although Article 39 of the EU regulation No. 1305/2013 on rural development defines income as the total income of the farmer (European Commission, 2016a), the design and implementation of revenue insurance schemes may be less challenging than whole-farm income insurance schemes. This is because the revenue of farmers (i.e. price multiplied by yields) can be more objectively assessed based on farmers' production history and futures prices than the total income of a farmer, which can be subject to misreporting by farmers.

The results also have business implications. Revenue insurance schemes provide an opportunity for farmers to substitute the use of futures markets with revenue insurance contracts that are based on futures prices. Farmers have often argued that they find the use of futures markets to be cumbersome. The findings further show the need to consider the risk heterogeneity of farms when calculating premium rates. This can be done by categorising farms into risk groups and calculating premium rates per group. Insurance companies can use a farm's input use, which is observable, to predict a farm's expected yields and variances, which can in turn be used to categorise farms into groups. 


\section{References}

Ahmed, O. and Serra, T. (2015). Economic analysis of the introduction of agricultural revenue insurance contracts in Spain using statistical copulas. Agricultural Economics, 46 (1), 69-79.

Assefa, T.T., Meuwissen, M.P.M. and Oude Lansink, A.G.J.M. (2016). Price volatility perceptions, management strategies, and policy options in EU food supply chains. In Garrido, A., Brummer, B., M'Barek, R., Meuwissen, M.P.M. and Morales-Opazo, C. (Eds.), Agricultural Markets Instability. Revisiting the recent food crisis (pp. 178-192). New York, NY: Routledge.

Bielza, M., Stroblmair, J. and Gallego, J. (2007a). Agriculural risk management in Europe. Paper prepared for presentation at the 101st EAAE Seminar on management of climate risks in agriculture, Berlin, Germany.

Bielza, M., Garrido, A. and , Sumpsi, J.M. (2007b). Finding optimal price risk management instruments: the case of the Spanish potato sector. Agricultural Economics, 36 (1), 67-78.

Botzen, W. J. W., van den Bergh, J. C. J. M. and Bouwer, L.M. (2010). Climate change and increased risk for the insurance sector: a global perspective and an assessment for the Netherlands. Natural Hazards, 52 (3), 577-598.

Bunte, F., Bolhuis, J., de Bont, C., Jukema, G. and Kuiper, E. (2009). Pricing of food products [Memorandum 09 074]. The Hague: LEI Wageningen UR.

EEX. https://www.eex.com/en/ .

El Benni, N., Finger, R., Meuwissen, M.P.M. (2016). Potential effects of the Income Stabilization Tool (IST) in Swiss agriculture. European Review of Agricultural Economics, 43 (3), 475-502.

European Commission (2007). The potato sector in the European Union. Retrieved from http://ec.europa.eu/agriculture/publi/reports/fruitveg/potato/sec533_en.pdf .

European Commission (2016a). The Common Agricultural Policy after 2013. Retrieved from http://ec.europa.eu/agriculture/cap-post-2013/legislation/index_en.htm .

European Commission (2016b). Sugar. Retrieved from http://ec.europa.eu/agriculture/sugar/index_en.htm .

Eurostat. http://ec.europa.eu/eurostat/web/agriculture/data/main-tables .

FADN. http://ec.europa.eu/agriculture/rica/database/database_en.cfm .

Gardebroek, C., Chavez, M.D. and Oude Lansink, A. (2010). Analysing production technology and risk in organic and conventional Dutch arable farming using panel data. Journal of Agricultural Economics, 61 (1), 60-75.

Glauber, J.W. (2004). Crop insurance reconsidered. American Journal of Agricultural Economics, 86(5), 1179-1195.

Goodwin, B.K. (1994). Premium rate determination in the federal crop insurance program: What do averages have to say about risk? Journal of Agricultural and Resource Economics, 19(2), 382-395. 
Goodwin, B.K. (2001). Problems with market insurance in agriculture. American Journal of Agricultural Economics, 83(3), 643-649.

Goodwin, B.K. and Hungerford, A. (2014). Copula-based models of systemic risk in U.S. agriculture: Implications for crop insurance and reinsurance contracts. American Journal of Agricultural Economics, 97(3), 879-896.

Ghosh, S., Woodard, J.D. and Vedenov, D. (2011). Efficient estimation of copula mixture models: An application to the rating of crop revenue insurance. Selected Paper prepared for presentation at the Agricultural and Applied Economics Association's 2011 AAEA and NAREA Joint Annual Meeting, Pittsburgh, Pennsylvania.

Just, R. and Pope, R. (1978). Stochastic specification of production functions and economics implications. Journal of Econometrics, 7 (1), 67-86.

Langeveld, J.W.A., Verhagen, A., van Asseldonk, M. and Metselaar, K. (2003). Coping with increasing extremes in agriculture: an exploration for the Netherlands. Paper prepared for the XIVth Global Warming Conference, Boston, USA.

Melyukhina, O. (2011). Risk management in Agriculture in The Netherlands (OECD Food, Agriculture and Fisheries Papers No. 41). OECD Publishing.

Meuwissen, M.P.M., Huirne, R.B.M. and Skees, J.R. (2003). Income insurance in European agriculture. Euro Choices, 2(1), 12-17.

Meuwissen, M.P.M., Van Asseldonk, M.A.P.M. and Huirne, R.B.M. (eds), 2008. Income stabilisation in European agriculture; design and economic impact of risk management tools., Wageningen: Wageningen Academic Publishers.

Meuwissen, M.P.M., Van Asseldonk, M., Peitola, K., Hardaker, B. and Huirne, R. (2011). Income insurance as a risk management tool after 2013 CAP reforms. Paper prepared for presentation at the EAAE 2011 congress on change and uncertainty, challenges for agriculture, food and natural ressouorces, Zurich, Switzerland.

Meuwissen, M.P.M., Assefa, T.T. and van Asseldonk, M.A.P.M. (2013). Supporting insurance in European agriculture: Experience of mutuals in the Netherlands. Eurochoices, 12(3), 10-16.

Ogurtsov, V.A., Van Asseldonk, M.A.P.M. and Huirne, R.B.M. (2007). Insurance decisions by Dutch dairy and arable farmers. Journal of farm management, 13(2), 95-106.

Ogurtsov, V.A., van Asseldonk, M.A.P.M. and Huirne, R.B.M. (2009). Purchase of catastrophe insurance by Dutch dairy and arable farmers. Review of Agricultural Economics, 31(1), 143-162.

Perez-Blanco, D., Mysiak, J., Gutiérrez-Martín, C. and de Salvo, M. (2014). What role for income stabilisation insurance in EU agriculture? (Report No. RP0242). The case of the Regione Emilia Romagna in Italy. Retrieved from CMCC website: http://www.cmcc.it/publications/rp0242-whatrole-for-income-stabilisation-insurance-in-eu-agriculture-the-case-of-the-regione-emilia-romagna-initaly.

Severini, S. and Cortignani, R. (2011). Modeling farmer participation to a revenue insurance scheme by means of positive mathematical programming. Paper prepared for presentation at the EAAE 2011 
congress on change and uncertainty challenges for agriculture, food and natural resources, Zurich, Switzerland.

Skees, J.R. and Reed, M.R. (1986). Rate making for farm-level crop insurance: Implications for adverse selection. American Journal of Agricultural Economics, 68 (3), 653-659.

Sklar, A. (1959). Distribution functions in n dimensions and their margins. Statistics Publications, University of Paris, 8, 229-231.

Tejeda, H.A. and Goodwin, B.K. (2008). Modelling crop prices through a Burr distribution and analysis of correlation between crop prices and yields using a Copula method. Selected Paper prepared for presentation at the American Agricultural Economics Association Annual Meeting, Orlando, Forida, USA.

Tiedemann, T. and Latacz-Lohmann, U. (2013). Production risk and technical efficiency in organic and conventional agriculture - The case of arable farms in Germany. Journal of Agricultural Economics, 64 (1), 73-96.

Zhu, Y., Ghosh, S.K. and Goodwin, B.K. (2008). Modeling dependence in the design of whole farm insurance contract. Selected paper prepared for presentation at the American agricultural economics association annual meeting Orlando, Florida, USA. 


\section{Appendix}

Table A-1 - Expected output equation of the Just-Pope production function

\begin{tabular}{|c|c|c|c|}
\hline Variable & Parameter & Coefficient & Probability \\
\hline Seedling & $\alpha_{1}$ & 0.155 & 0.975 \\
\hline Protection & $\alpha_{2}$ & $22.332 * *$ & 0.011 \\
\hline Energy & $\alpha_{3}$ & 13.091 & 0.906 \\
\hline Fertiliser & $\alpha_{4}$ & -2.528 & 0.854 \\
\hline Total area & $\alpha_{5}$ & $3.536 * *$ & 0.000 \\
\hline Seedling $^{2}$ & $\alpha_{11}$ & -25.727 & 0.272 \\
\hline Protection & $\alpha_{22}$ & 3.287 & 0.941 \\
\hline Energy $^{2}$ & $\alpha_{33}$ & -1928.89 & 0.103 \\
\hline Fertiliser $^{2}$ & $\alpha_{44}$ & 52.359 & 0.528 \\
\hline Total area ${ }^{2}$ & $\alpha_{55}$ & $0.232 * *$ & 0.026 \\
\hline Seedling $\mathrm{x}$ protection & $\alpha_{12}$ & $132.56^{* *}$ & 0.016 \\
\hline Seedling $x$ energy & $\alpha_{13}$ & $1517.474 * *$ & 0.000 \\
\hline Seedling $\mathrm{x}$ fertiliser & $\alpha_{14}$ & -41.779 & 0.672 \\
\hline Total area $\mathrm{x}$ seedling & $\alpha_{15}$ & -1.535 & 0.409 \\
\hline Protection $\mathrm{x}$ energy & $\alpha_{23}$ & -187.737 & 0.689 \\
\hline Protection $\mathrm{x}$ fertiliser & $\alpha_{24}$ & $-180.467 * *$ & 0.038 \\
\hline Total area $\mathrm{x}$ protection & $\alpha_{25}$ & $-8.466 * *$ & 0.008 \\
\hline Energy $\mathrm{x}$ fertiliser & $\alpha_{34}$ & $2667.589^{*}$ & 0.067 \\
\hline Total area $\mathrm{x}$ energy & $\alpha_{35}$ & $-183.567 * *$ & 0.000 \\
\hline Total area $\mathrm{x}$ fertiliser & $\alpha_{45}$ & 9.948 & 0.238 \\
\hline Trend & $\theta_{1}$ & 0.328 & 0.317 \\
\hline Trend $^{2}$ & $\theta_{2}$ & -0.060 & 0.225 \\
\hline Seedling $\mathrm{x}$ trend & $\varphi_{1}$ & $-2.356^{*}$ & 0.068 \\
\hline Protection $\mathrm{x}$ trend & $\varphi_{2}$ & -1.202 & 0.534 \\
\hline Energy $\mathrm{x}$ trend & $\varphi_{3}$ & 2.724 & 0.944 \\
\hline Fertiliser $\mathrm{x}$ trend & $\varphi_{4}$ & 0.768 & 0.793 \\
\hline Area $x$ trend & $\begin{array}{l}\varphi_{4} \\
\varphi_{5}\end{array}$ & 0.239 & 0.133 \\
\hline Constant & $\alpha$ & 1.336 & 0.238 \\
\hline Overall $\mathrm{R}^{2}$ & & 0.957 & \\
\hline Within $\mathrm{R}^{2}$ & & 0.922 & \\
\hline Overall $\mathrm{R}^{2}$ & & 0.915 & \\
\hline
\end{tabular}

*indicates significant values at the $5 \%$ level and ** at the $10 \%$ level. 
Table A-2 - Output variance equation of the Just-Pope production function

\begin{tabular}{|c|c|c|c|}
\hline Variable & Parameter & Coefficient & Probability \\
\hline Seedling & $\beta_{1}$ & $-6.596^{*}$ & 0.051 \\
\hline Protection & $\beta_{2}$ & 1.126 & 0.642 \\
\hline Fertiliser & $\beta_{4}$ & 3.531 & 0.129 \\
\hline Total area & $\beta_{5}$ & 0.329 & 0.943 \\
\hline $\begin{array}{l}\text { HHI (Herfindhal- } \\
\text { Hirshman index) }\end{array}$ & $\beta_{6}$ & -0.294 & 0.934 \\
\hline Seedling $^{2}$ & $\beta_{11}$ & -0.342 & 0.555 \\
\hline Protection $^{2}$ & $\beta_{22}$ & -0.216 & 0.709 \\
\hline Fertiliser $^{2}$ & $\beta_{44}$ & -0.244 & 0.305 \\
\hline Total $_{\text {area }}{ }^{2}$ & $\beta_{55}$ & 0.557 & 0.511 \\
\hline $\mathrm{HHI}^{2}$ & $\beta_{66}$ & 0.042 & 0.967 \\
\hline Seedling $\mathrm{x}$ protection & $\beta_{12}$ & -1.304 & 0.112 \\
\hline Seedling $\mathrm{x}$ fertiliser & $\beta_{14}$ & 0.662 & 0.319 \\
\hline Total area $\mathrm{x}$ seedling & $\beta_{15}$ & 1.657 & 0.123 \\
\hline Seedling x HHI & $\beta_{16}$ & $-2.326^{* *}$ & 0.020 \\
\hline Protection $\mathrm{x}$ fertiliser & $\beta_{24}$ & $1.009^{*}$ & 0.058 \\
\hline Total area $\mathrm{x}$ protection & $\beta_{25}$ & 0.353 & 0.695 \\
\hline Protection x HHI & $\beta_{26}$ & 1.245 & 0.192 \\
\hline Total area $\mathrm{x}$ fertiliser & & $-1.629 * *$ & 0.021 \\
\hline & $\beta_{45}$ & & \\
\hline Fertiliser x HHI & $\beta_{46}$ & 0.705 & 0.265 \\
\hline Area x HHI & $\beta_{56}$ & 0.831 & 0.455 \\
\hline Drenthe & $\gamma_{1}$ & -0.455 & 0.355 \\
\hline Flevoland & $\gamma_{2}$ & $-0.714 * *$ & 0.010 \\
\hline Friesland & $\gamma_{3}$ & -0.386 & 0.525 \\
\hline Gelderland & $\gamma_{4}$ & $-3.071^{*}$ & 0.092 \\
\hline Groningen & $\gamma_{5}$ & $-0.908 * *$ & 0.026 \\
\hline Limburg & $\gamma_{6}$ & 0.393 & 0.398 \\
\hline Noord-Brabant & $\gamma_{7}$ & -0.398 & 0.233 \\
\hline Noord-Holland & $\gamma_{8}$ & -0.103 & 0.762 \\
\hline Zeeland & $\gamma_{9}$ & 0.417 & 0.529 \\
\hline Zuid-Holland & $\gamma_{10}$ & -0.037 & 0.879 \\
\hline Constant & $\beta$ & -0.037 & 0.879 \\
\hline Overall $\mathrm{R}^{2}$ & & 0.367 & \\
\hline
\end{tabular}

*indicates significant values at the 5\% level and ** at the $10 \%$ level. 
Chapter 7

\section{General discussion}




\subsection{Introduction}

The food crisis of 2006/2007 has sparked considerable research and policy interest in the volatility of food and agricultural commodity prices. Although a decade has passed since the crisis, the agricultural sector of the European Union (EU) is still susceptible to price volatility owing to the reduced government market interventions and increased liberalization of the sector (Meuwissen et al., 2011; Severeni and Cortignani, 2011). Market interconnectedness along food supply chains assures that price volatility originating at one stage of the chain is transmitted along the chain thereby exposing all chain actors to risk and uncertainty. If left unmanaged, price volatility can have harmful impacts on investment, production and other business decisions of food chain actors (Tangermann, 2011; Taya, 2012).

The general objective of this thesis was to examine the transmission and management of food price volatility in food supply chains. Chapter 2 reviewed the literature and identified gaps in the literature. Chapter 3 investigated empirically and theoretically the impact of market power on price volatility transmission in the German fresh pork supply chain. Price transmission and price volatility transmission were investigated by estimating a vector error correction model (VECM) and ordinary least square (OLS) regressions. The conjectural variation approach was used to measure market power. Chapter 4 explored through interviews the perceptions and management of price volatility by 42 chain actors in $6 \mathrm{EU}$ food supply chains (i.e. Spanish tomatoes, German pork, Dutch tomatoes, Bulgarian wheat, French wheat and Dutch cheese). Chapter 5 presented a method to evaluate the effectiveness of price volatility management strategies along food supply chains. The method was illustrated with strategies identified in Chapter 4 for the Spanish tomato and French wheat chains. Chapter 6 calculated premium rates of an agricultural revenue insurance contract, a price volatility management strategy which has yet to be implemented in European agriculture. Data for the Dutch ware potato sector is used for the analysis. The chapter calculated premium rates for homogenous groups of farms categorized based on their expected yields and yield variances. Expected yields and variances were predicted based on the estimation of a Just-Pope production functions. In the simulations of premium rates, copulas were used to model the dependence between yields and prices.

The remainder of this chapter first synthesizes and reflects on the results (Section 7.2) and the methods used in this thesis (Section 7.3). Section 7.4 reflects on the data used in this thesis. This is followed by Section 7.5 which provides the business implications and Section 7.6 the policy implications of this thesis. Section 7.7 ends the chapter with the main conclusions of the thesis.

\subsection{Synthesis of results}

This thesis addressed two key issues, which are the transmission of price volatility in food supply chains and the management of price volatility by food supply chain actors. A synthesis of the results related to each issue and the relationship between the two issues are discussed below.

\section{Price volatility transmission}

The agricultural economics literature has often been concerned with the transmission of price levels than with the transmission of price volatility (Chapter 2). A possible reason could be the implicit assumption that the transmission of price levels implies the transmission of price volatility and vice versa. The definitional distinction between the two types of transmissions has not always been highlighted in the previous literature. Chapter 2 addressed this gap by defining price level transmission 
and price volatility transmission as the transmission of predictable and non-predictable price changes in the chain, respectively. The chapter further argued that the transmission of price levels may not necessarily entail the transmission of price volatility in the chain, and vice versa. In the previous literature, the studies of Natcher and Weaver (1999) and Serra (2011) support this argument. This thesis also provided further evidence supporting this argument. In Chapter 3, it was found that the slaughterhouses transmitted predictable short-term farm price changes while not transmitting unpredictable farm price changes (i.e. farm price shocks). Such results imply that a chain actor may have a competitive pressure to respond to predictable price changes. On the other hand, chain actors may expect competitors not to respond to unpredictable price changes as these can be perceived as temporary.

The issue of asymmetric price transmission has considerable importance in the literature on price level transmissions. The literature often found that margin-squeezing increases in input prices (or decreases in output prices) will be transmitted faster and/or more completely than the corresponding marginstretching price changes (Meyer and Von-Cramon Taubadel, 2004). Studies that investigated asymmetric transmission of unpredictable price changes were also identified in the review of Chapter 2. For instance, Zheng et al (2008) find that retail prices respond more to positive farm price shocks than to negative farm price shocks. Asymmetric price volatility transmission was not however empirically investigated in this thesis (i.e. in Chapter 3). This can be considered as a limitation of the chapter as more insight could have been obtained on the pricing behaviour of actors in the German pork chain. The analysis of asymmetric price volatility transmission can be left as an issue for future research.

Although Chapter 3 did not investigate asymmetries in the sign of price shock transmission (i.e. traditional definition of asymmetry - transmission of negative versus positive shocks), it showed that price shock transmission can be asymmetric in the direction of causality. Asymmetry in the direction of causality implies here that input price shocks are transmitted while output price shocks are not, or vice versa. In Chapter 3, it was found that although consumer price shocks transmitted upstream in the chain, farm price shocks were not transmitted downstream in the chain. These results cannot however be generalized to all food supply chains as evidenced in the review of Chapter 2. While some studies find price volatility transmit from the retail stage to upstream stages in the chain (e.g. Apergis and Rezitis, 2003; Khiyavi et al., 2011), others find that causality runs from the farm to the retail stage (e.g. Zheng et al., 2008; Uchezuba et al., 2010). The degree of price volatility transmission in the food supply chain is therefore chain-specific.

The degree of price volatility transmission in the chain is determined among other by the degree of market power of food chain actors (Chapter 3). Although the literature on price volatility transmission acknowledges that market power has an effect on volatility transmission, it did not provide any empirical or theoretical evidence for such an effect (Chapter 2). Chapter 3 filled this literature gap by investigating price volatility transmission in the German pork chain. In Chapter 3, it was found that retailers use market power to transmit consumer price shocks to upstream stages in the chain while preventing the transmission of farm price shocks. These results are in line with Zheng et al. (2008), Uchezuba et al. (2010), Serra (2011), Alexandri (2011) and Rezitis (2012) who also suggest that retailers use market power to keep consumer prices irresponsive to price shocks in upstream stages of the chain. The above studies do not, nevertheless, provide any empirical or theoretical evidence for their claim. 


\section{Price volatility management strategies}

Although price volatility may have negative consequences for businesses, price volatility may not necessarily result in the implementation of price volatility management strategies by food chain actors (Chapter 4, Chapter 5). Price volatility defined as the deviation of prices from expected levels is perceived as price risk and therefore results in the implementation of strategies if the deviation exceeds a threshold level, if it is caused by shocks in demand and/or supply (i.e. and not speculation), if margins are not stable and if the deviation persists for a certain period of time (Chapter 4). The threshold price deviation triggering strategies depends in turn on the cost of the strategy, the chain actor's risk attitude, the price volatility the chain actor would face if a strategy is implemented and the volume traded (Chapter 5). The above findings highlight that, price volatility is only one aspect of price risk. That is, in contrast to price volatility, price risk depends on more factors than the deviation of prices from expected levels (i.e. the size of the deviation, the persistence of the deviation, the stability in margins and the cause of deviation).

Chain actors use a wide set of strategies to manage the risk from price volatility (Chapter 4). The current literature on agricultural risk management strategies focuses on only a few types of strategies. These include hedging in derivative markets, forward contracts, and diversification (for instance in Martin 1995, Meuwissen et al. 2001, Hall et al. 2003, Bergfjord 2009). Although a long list of strategies was identified in Chapter 4, this list is not exhaustive as this thesis could have explored an even more diverse set of strategies if a wider sample of chains and chain actors had been considered. For instance, one type of strategy not indicated in Chapter 4 is the use of revenue insurance contracts to manage price risk. Chapter 6 argues that revenue insurance can be a useful tool to manage income volatility arising as the result of both price and yield volatility. This is particularly true if the opportunity of a natural hedge between prices and yields is limited (Chapter 6). A possible reason why revenue insurance was not indicated as a price volatility management strategy by the farmers interviewed in Chapter 4 could be because revenue insurance schemes do not exist yet in the investigated food markets (i.e. German pig, Dutch milk, Dutch tomatoes, Spanish tomatoes, French wheat and Bulgarian wheat).

The degree of market power in the food supply chain does not only have an effect on price volatility transmission in the chain but also on price volatility management strategies used in the chain. In fact, a two-way relationship can be identified between the degree of market power and price volatility management strategies in the chain. In Chapter 3, it was found that retailers used market power to hinder the transmission of farm price shocks while they transmitted consumer price shocks to slaughterhouses. It can be argued that retailers' market power permits them to use a strategy in which they hinder the transmission of farm price shocks to keep consumer prices stable. On the other hand, the transmission of consumer price shocks to the slaughterhouse stage can be considered as a strategy that retailers use to protect their own margins from being squeezed or unstable as a result of consumer price shocks. Some price volatility management strategies increase the market power of the chain actors that implement them (Chapter 4). Example of such strategies are mergers among wholesalers to gain more market power and secure a higher output price (Dutch tomatoes) and producing and trading improved quality products (Spanish tomatoes, Bulgarian wheat) (Chapter 4). The relationship between market power and price volatility management strategies is a reminder that price volatility is not only managed through traditional instruments such forward contracts and derivative markets as often suggested in previous literature, but that it can also be managed by way of altering market power relations in the chain (Chapter 4). 


\section{Relation between price volatility transmission and price volatility management strategies}

Results of this thesis highlight the two-way relationship between price volatility transmission and the management of price volatility by food chain actors. A number of strategies identified in Chapter 4 can have an effect on the degree of price volatility transmission. The strategy of producing and trading premium products can enable chain actors to easily transmit their input price shocks to their customers as these are believed to be less sensitive to changes in the prices of premium products compared to those of standard products (Chapter 4). Forward contracts that fix prices only when price changes remain within a certain price band (e.g. in the Dutch cheese chain) permit one to transmit a price shock if the size of shock exceeds a certain level. Some of the studies in Chapter 2 also argued that contracts can have an effect on price volatility transmissions in the chain (for instance, Khan and Helmers, 1997; Apergis and Rezitis, 2003; and Khiyavi et al., 2012). As indicated in Chapter 2, no studies have been conducted to date on the effect of strategies on price volatility transmission in the chain. In Chapter 5, although the effect of strategies on price volatility was investigated per stage of the food supply chain, the effect of a strategy in one stage of the chain on the price volatility in another stage of the chain was not investigated. This can be an avenue for future research.

Price volatility transmission can also affect the choice of strategies (Chapter 4). For instance, in the Dutch cheese chain, a strategy that cheese processors use is to avoid long-term price fixing sales contracts and opt for shorter sales contracts (Chapter 4). This is because of the difficulty to transmit sudden shocks in milk prices by adjusting cheese prices. The choice for contracts with flexible sales prices also arises as a result of the difficulty to transmit milk price shocks to cheese prices. Overall, the results above indicate that the mechanism and extent of price volatility transmission in the chain cannot fully be understood if one has limited knowledge on the price volatility management strategies in the chain (and vice versa).

\subsection{Methodological approaches}

This section first reflects on the measurements of price volatility and the degree of market power in the chain used in this thesis. It then presents a reflection on methodological issues related to the identification, effectiveness and pricing of price volatility management strategies.

\section{Measurement of price volatility}

A commonality across the chapters of this thesis is that price volatility is defined as the deviation of observed prices from expected prices. This definition is also in line with the literature (Brümmer et al., 2013; Huchet-Bourdon, 2011; FAO et al., 2011). Nevertheless, the methods used to measure expected prices and price volatility differ across chapters. The methods for measuring expected prices and price volatility are discussed in more detail below. Table 7.1 summarizes the measures of expected prices and price volatility used in the different chapters.

\section{Expected prices}

Three specifications of expected prices are used in this thesis. Chapter 3 measured expected prices using the multivariate time-series model called vector error correction model (VECM). Chapter 5 used a linear trend model to measure expected prices. In Chapter 6 , the futures price at planting time is used as the harvest time expected price. A commonality across the three measures is that expected prices vary over time and that they are based on information about past prices. A difference in the 
measures is that in Chapter 3 and 5, expected prices are model based while expected prices in Chapter 6 they are not.

The modelling of expected prices should account for long-term trends, seasonality and cycles to avoid mistaking changes in expected prices for volatility ${ }^{2}$ (Brümmer et al., 2013). While the measurement of expected prices in Chapter 3 accounts for long-term trends and seasonal effects, it does not account for cycles due to the short-time span considered (i.e. 2000-2011). The fact that Chapter 5 only accounts for trends can be considered a limitation of the chapter. A line of improvement in the measurements of expected prices is the harmonization of the measurements used in Chapter 3 and 5. More specifically, a VECM accounting for long-term trends, seasonality and price linkages in the chain could have provided a better measure of expected prices in Chapter 5 compared to accounting only for a trend in the prices. The model specification used in Chapter 3 (VECM) provides a richer information about expected prices than the one used in Chapter 5 as it also accounts for market linkages across stages of the food supply chain. Although the VECM is widely applied in the price volatility transmission literature (Chapter 2), the literature does not provide a theoretical underpinning for the empirical modelling of price linkages in the chain. This literature gap is addressed in Chapter 3 by modelling the long-term price linkages in the food chain using the framework of Sexton and Zhang (2001) and Verreth et al. (2015).

The difference in measures of expected prices across the chapters is justified in light of the differences in research focuses. While Chapter 3 and 5 focus on prices along the chain, Chapter 6 is focuses only on the farm stage. The fact that futures prices are only available for agricultural commodities (i.e. at farm level) makes it impossible to use futures prices along the chain. Therefore, expected prices along the chain should be generated using spot prices at various stages of the chain. Although expected prices could have been generated using time-series models in Chapter 6 (e.g. as in Ahmed and Serra, 2015), the availability of futures price data for the Dutch ware potato sector and the superiority of futures prices over spot prices in terms of quality (Brümmer et al., 2013) makes futures prices a better measure of expected prices. Besides, futures markets are argued to provide objective reference prices for the rating of agricultural insurance schemes (Meuwissen et al., 2011).

\section{Price volatility}

An assumption underlying the definition of price volatility as the deviation of prices from expected prices is that price volatility is unobserved and should be inferred from the models used to determine expected prices (see discussion above). Price deviations (i.e. difference between observed prices and expected prices) form the basis for price volatility modelling. The literature offers alternative ways to model price volatility depending on the objective at hand. If the objective is to understand past price volatility (i.e. ex-post volatility), parametric models (i.e. based on model parameters) such as generalized conditional heteroskedasticity models $(\mathrm{GARCH})$ and non-parametric measures such as "realized volatility" (i.e. based on squares of daily price returns) are suitable (Brümmer et al., 2013). On the other hand, if the objective is to determine the expectations of market participants about future price volatility (i.e. ex-ante volatility), then the concept of implied volatility is relevant (Brümmer et al., 2013). The term implied arises from the fact that volatility is inferred from the prices of derivative contracts such as options (Badarji et al., 2011).

\footnotetext{
${ }^{2}$ The economics literature defines four types of prices expectations: naive, adaptive, quasi-rational, and rational. Expected prices generated using predicted values from time-series models characterize quasi-rational expectations (Chavas, 1999).
} 
In Chapter 3, price volatility is measured using an OLS regression. In the price volatility transmission literature, multivariate GARCH (MGARCH) models are typically used to model price volatility transmissions in the chain (Chapter 2). A limitation of such models is that they lack a theoretical basis underlying price volatility linkages in the chain. Chapter 3 addressed this limitation by using Thille's (2006) framework to model price volatility transmission in such a way that the effects of market power in the chain are also incorporated. Following Thille's (2006) framework, the estimated volatility model was an ordinary least square regression in which the squares of the observed monthly price changes was the dependent variable (measuring price volatility) while the squares of the residuals (i.e. deviations from the expected price model - VECM) were the independent variables that proxied the variances in the farm and consumer price shocks. This is in contrast to MGARCH models which base price volatility measurement only on the squares of the residuals from the VECM (or another expected price model).

Unlike Chapter 3, in Chapter 5 the residuals from the linear trend model were not further modelled. Instead, four measures of price volatility were estimated, i.e. the coefficient of variation, the skewness, the kurtosis, the 5th percentile and the 95th percentile of the price residuals. Unlike the approach followed in Chapter 3, the approach in Chapter 5 assumes that price volatility is not-time varying. This is because the four volatility measures are calculated over the whole sample period. Since the objective in Chapter 5 was to compare price volatility when strategies are implemented by chain actors and when they are not, such comparison is easier when price volatility is measured over the whole sample period than for each time period (i.e. monthly and weekly). Price volatility was not measured in Chapter 6. Nevertheless, the stochastic nature of prices was captured in the premium rate simulations through the distribution of log-price returns (i.e. ratio of planting and harvest futures prices).

In Chapter 4, price volatility was defined as the percentage deviation of prices from their expected levels. The interview results showed that chain actors perceived price deviations from expected levels as volatility only when the percentage deviations exceed a certain threshold (i.e. 10-15\%). This introduces the concept of threshold and excess price deviations with the latter being the amount of price deviation above the threshold level. Chapter 4 further introduces the concept of persistence of price volatility which is defined as the time period during which observed prices remain above or below expected levels. The concepts of threshold price deviation and persistence of deviation highlight the complexity underlying the measurement of price volatility. Dissecting price volatility into its various components can contribute to a better measurement of price volatility. Figure 7.1 illustrates the various components of prices that one needs to consider to improve price volatility measurements. These components are expected prices, threshold price deviations, excess price deviations, total price deviations (excess plus threshold deviations) and persistence of total price deviations. The Figure decomposes the deviation of prices at time $t$ into its threshold and excess components. The persistence of deviation measures the time duration between time $t$ (i.e. when prices deviate from their expected levels) until they return back to their expected levels (i.e. time $t+1$ ). 
Table 7.1- Methods for measuring expected prices, price deviations and price volatility

\begin{tabular}{|c|c|c|}
\hline Chapters & Expected prices & Price volatility \\
\hline $\begin{array}{l}3 \text { - Market power and price } \\
\text { volatility transmission }\end{array}$ & $\begin{array}{l}\text { Vector error correction } \\
\text { model (VECM) on prices }\end{array}$ & $\begin{array}{l}\text { Square of the monthly price } \\
\text { changes }\end{array}$ \\
\hline 5 - Effectiveness of strategies & $\begin{array}{l}\text { Linear trend equation on } \\
\text { prices }\end{array}$ & $\begin{aligned} & \text { Price residuals': } \\
&- \text { Coefficient of variation } \\
&- \text { Skewness } \\
&- \text { Kurtosis } \\
&- 5^{\text {th }} \text { percentile } \\
&- 95^{\text {th }} \text { percentile }\end{aligned}$ \\
\hline 6 - Revenue insurance & $\begin{array}{l}\text { Planting price of a futures } \\
\text { contract expiring at harvest }\end{array}$ & $\mathrm{NA}^{1}$ \\
\hline
\end{tabular}

${ }^{\mathrm{I}}$ Not applicable because price volatility was not measured in Chapter 6.

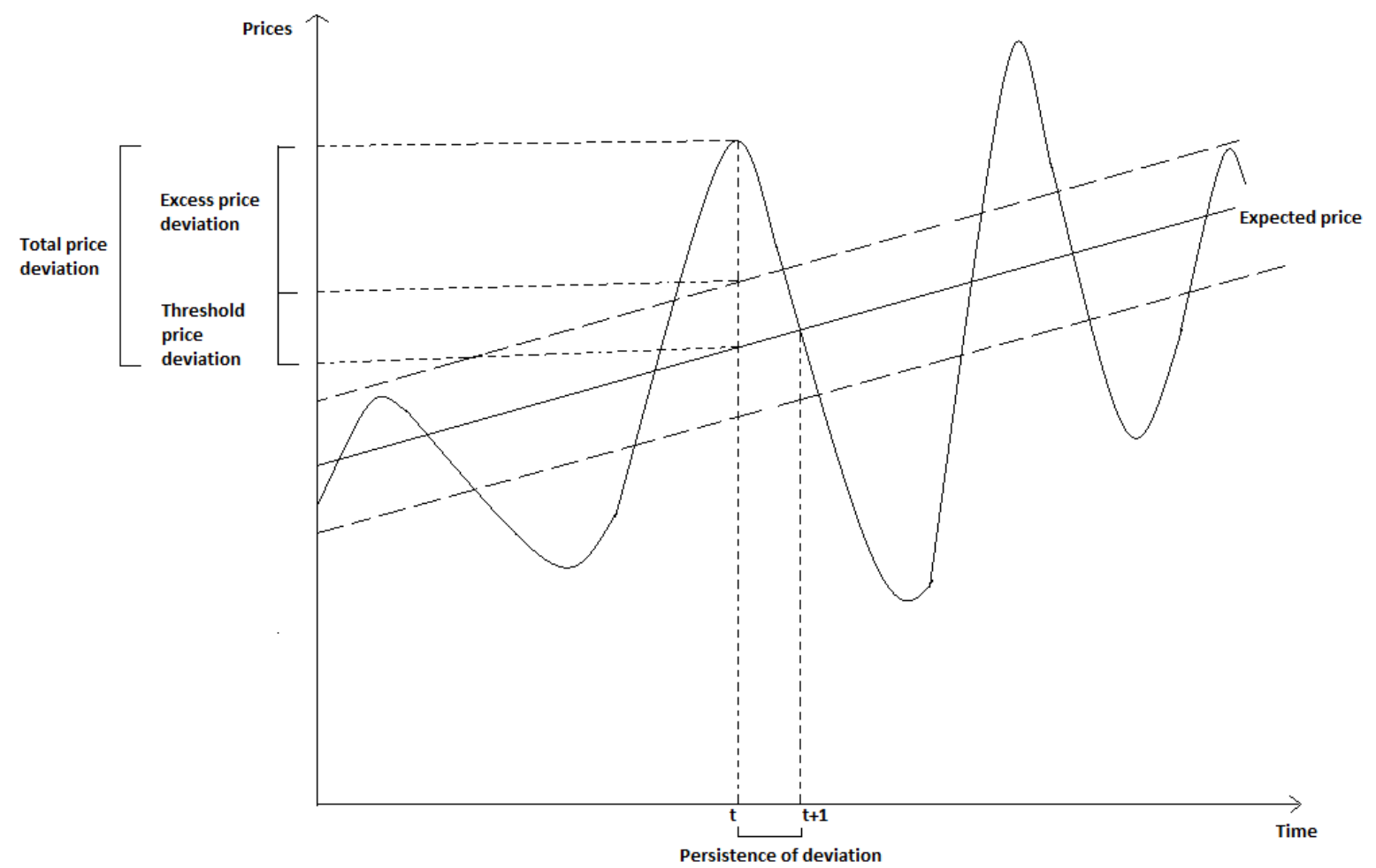

Figure 7.1 - Components of price volatility

\section{Modelling market power}

The literature distinguishes four approaches for measuring market power. These are industry case studies, the structure-conduct-performance paradigm (SCP), the New Empirical Industrial Organization (NEIO) approaches and time-series models (e.g. asymmetric transmission models) (Digal and Ahmadi-Esfahani, 2002). Unlike the SCP paradigm and time-series models, NEIO approaches have theoretical foundations (Digal and Ahmadi-Esfahani, 2002). The conjectural 
variation approach, which is one of the NEIO approaches, is used in Chapter 3 to measure the degree of market power. Although the conjectural variation approach has theoretical foundations, it is also sensitive to simplifying modelling assumptions. For instance, the assumptions made in Chapter 3 about firms' technology (i.e. constant marginal marketing and processing costs of retailers and processors) and the functional forms of demand and supply functions (i.e. linear) can affect estimation results. For instance, assuming a quadratic marketing and processing cost function would not permit to measure marginal costs through a constant term in the error-correction term of the VECM.

Another weakness of the conjectural variation approach relates to the empirical estimation of the market power parameter (Digal and Ahmadi-Esfahani, 2002). In Chapter 3 for instance, it was not possible to distinguish the parameter measuring the oligopsony power exercised by the slaughterhouses on farmers from that measuring the oligopsony power exercised by the retailers on slaughterhouses when estimating the VECM. Therefore, only one parameter for oligopsony power in the chain could be estimated. A similar challenge was faced in the OLS equations used to related market power with price volatility transmission. The OLS coefficient on the variable measuring consumer price shocks is a combination of the oligopoly and oligopsony power parameters of the retailer towards consumers and slaughterhouses, respectively, and of the oligopsony power parameter of the slaughterhouse towards farmers. Therefore, the effect of the retailer's oligopoly power on consumer price shock transmission cannot be identified in a straight forward manner from the effects of other market power parameters.

Despite its limitations, it can be argued that the conjectural variation approach can be a better measure of market power compared to measuring market power through measures of market structure (e.g. concentration ratios, Herfindhal-Hirschman index) used in the SCP paradigm. This is because the conjectural variation approach models firm conduct (i.e. degree of market competitiveness) in contrast to measures of market concentration which do not convey such information (Lee, 2007). Although the SCP paradigm asserts that market structure determines and therefore proxies market conduct, causality can also run the other way around (Lee, 2007).

\section{Identification, effectiveness and pricing of price volatility management strategies}

In this thesis, price volatility management strategies were identified (Chapter 4) and their effectiveness was evaluated (Chapter 5). In Chapter 6, a price volatility management strategy (i.e. revenue insurance) was priced (i.e. premium rates were calculated). Chapter 4 used an exploratory and openended approach to identify price volatility management strategies used by chain actors to manage the risk from price volatility. The previous literature on agricultural risk management (i.e. which focuses on the farm stage) generally uses a survey approach whereby farmers are asked to rate their preferences of a pre-specified list of strategies using Likert scales (e.g. Patrick et al., 1985; Wilson and Armstrong, 1987; Martin, 1996; Knutson et al., 1998; Meuwissen et al., 2001; Hall et al., 2003; Greinier et al., 2009; Bergfjord, 2009). Using structured types of questionnaires limits the opportunity to identify a wider set of strategies that farmers might have used to manage price risk. In this regard, the open-ended approach followed in this thesis is commendable. A limitation of the approach followed in Chapter 4 is the small sample size used and therefore the lack of the generalizability of the results to a wider sample size. To be able to generalize the wide set of strategies identified in Chapter 4 to a wider sample size, the identified strategies could be pre-specified in a structured type of questionnaire and their relevance be rated by chain actors through a large-scale survey. Therefore, the open-ended approach followed in Chapter 4 could be supported with the more structured approach followed in previous literature. 
A method for evaluating the effectiveness of price volatility management strategies in reducing price volatility was presented in Chapter 5 . The method was then illustrated using strategies used in the Spanish tomato and French wheat chains. An advantage of the presented method is that different stages of the chains are considered (i.e. farm, wholesale and processing). In addition, strategies that involve both the adjustment of prices (e.g. forward contracts) and the timing of sale (e.g. waiting a week before selling tomatoes) were considered. This is in contrast to the previous literature which mainly focuses on the farm stage and on strategies that involve the adjustment of prices (e.g. Neyhard et al., 2013; Manfredo et al., 2003). A challenge in the method presented in Chapter 5 is the parameterization of the strategies as this involves making numerous assumptions about the strategies. For instance, determining the prices a chain actor would face if he/she uses a forward contract involves making assumptions on how the contract price is set. This in turn can affect the effectiveness of the considered forward contract to reduce price volatility. For instance, while the selling forward contracts of Spanish tomato wholesalers perform similarly than the base scenario (i.e. no strategies), those entered by French wheat processors result in prices that are more positively skewed and with a higher kurtosis than the base scenario. Future research can check the sensitivity of results to alternative parameterization of strategies.

A price volatility management strategy not indicated in the interviews of Chapter 4 is agricultural revenue insurance. Premium rates of a hypothetical revenue insurance contract were calculated in Chapter 6. The findings in Chapter 6 showed that premium rates of a revenue insurance contract for the Dutch ware potato sector were much higher than the rates calculated in other studies (e.g. Goodwin and Hungerford, 2014; Ahmed and Serra, 2015). The premium rates could be much lower if a coverage rate lower than $75 \%$ had been used. Future research could investigate the sensitivity of premiums rates to alternative coverage rates. Premium rates can also be lower if a whole-farm revenue insurance (i.e. insuring total revenue from multiple crops) was considered instead of a revenue insurance contract only for ware potatoes. Zhu et al. (2008) for instance have shown that the negative dependence between the revenues of several crops results in a lower premium rate compared to a onecrop contract. Whole-farm insurance contracts can be feasible for arable farms as these generally operate on a rotational plan, thus planting multiple crops. Future research can therefore evaluate premium rates of a whole-farm revenue insurance contract for Dutch arable farms.

\subsection{Data issues}

An important issue in price volatility analyses is the frequency of price data used in the analysis (i.e. whether the data is daily, weekly, monthly, etc.) because the extent to which prices vary over time depends on the time frequency considered. In Chapter 3, monthly pork price data was used to investigate price volatility transmission in the German pork chain. In Chapter 4, however, it was shown that prices in the German pork chain are, in practise, set on a weekly basis. Therefore, the use of weekly data at the different stages of the chain would have captured more dynamics in price and price volatility transmission in the chain. Since using monthly average prices smooths price changes that occur weekly, the price volatility transmitted from one chain stage to another can be lower than when measured on a weekly basis. Although high frequency price data was available at the farm stage, data were not available for the rest of the chain. If weekly prices had been used in Chapter 3, there would have been a possibility of detecting a transmission of farm price shocks to the slaughterhouses, for instance. The use of high frequency price data was however less necessary in Chapter 6. In Chapter 6 , the monthly averages of the daily futures prices at time of planting (i.e. month of April) and the monthly averages of the daily futures prices at time of harvest (i.e. month of November) were used. 
Using monthly averages of daily prices can better reflect the planting and harvest months' prices than using prices on a specific day of the planting and harvest months (e.g. last trading day of April and November). Since daily futures prices can highly fluctuate, using a price on a specific day of the month may not represent prices for the whole month.

Another issue relates to whether the used price data reflects the price of a specific food product or a basket of food products. In Chapter 3 for instance, the pork meat data used were averages of the prices of different pork cuts. Therefore, possible differences in price and price volatility transmission for different pork cuts could not be identified. Based on the findings from Chapter 4, it is expected that the retail sector better transmits input price shocks in case of premium pork cuts than it transmits input price shocks related to non-premium pork cuts. This is because consumers of premium products are expected to be less sensitive to price changes (Chapter 4). The analyses conducted in Chapter 3 therefore may have smoothed out any differences in transmission that may exist across different pork cuts.

In time-series price analysis, the length of the time-series is also of importance. In Chapter 3, the relatively short time span of the data (2000-2011) available for the chapter can be considered as a limitation. The fact that periods with lower price volatility from 2011 onwards were not considered in the analysis may be limiting as price and price volatility transmission can change over time. Considering the period post 2011 would have permitted to analyse changes in price shock transmissions by slaughterhouses and retailers in the pre- and post-2011 periods. Serra (2011) for instance has shown that retailers better transmit farm price volatility during low volatility periods than during high volatility periods. The time span of the prices and yields data used in case of Chapter 6 is also limited (only 5 years from 2010 to 2014). The limited time span in Chapter 6 may, nevertheless, be acceptable as 5 years (or more) historical data is used in practise to assess farmers' income losses in insurance programs in the EU (see Bielza et al., 2007).

\subsection{Business implications}

This thesis suggests that, in the food supply chain, farmers and particularly those who produce nonstorable products are chain actors that are the most vulnerable actors to price volatility. Farmers generally produce undifferentiated products, have limited ability to adjust supply to price signals and are much larger in number than actors downstream in the food supply chain. As also shown in Chapter 4 , farmers' strategies fall in the 'survival' category meaning that their strategies are mostly limited to minimizing losses in times of adverse price shocks as opposed to the 'adaptive' strategies used by the rest of the chain. The latter type of strategies aimed at keeping margins stable in spite of adverse price shocks. Farmers producing non-storable products such as tomatoes and pigs are pressured to sell products even in times of large drops in prices (Chapter 4) and therefore have a limited flexibility that producers of storable products have (e.g. wheat producers). Solutions that allow farmers to earn a fair price even in times of volatile prices are therefore needed for farmers of non-storable products. Solutions can include product value addition through better variety selection, focusing on niche markets and further processing of produce. These strategies were argued by the chain actors interviewed in Chapter 4 to yield stable and high prices for their produces.

This thesis showed that price volatility can transmit in the food supply chain. This indicates that chain actors can use information about price developments in other stages of the chain to predict price developments in their own market. For instance in Chapter 3, it was found that consumer price shocks 
were transmitted by retailers to the slaughterhouse stage. This implies that slaughterhouses can use information about price developments in the consumer market to make strategic decisions. As an example, one of the sources of consumer price shocks in the meat market is news of animal food scares (Van Asseldonk et al., 2000; Serra, 2011). If slaughterhouses are aware that price drops in the consumer markets caused by the news will also result in a drop in their own prices, they can plan for a flexible pig sourcing strategy that allows them to easily reduce the number of pigs sourced if an animal food scare should occur.

Previous studies on price risk management strategies of actors downstream to the farm stage argue that forward contracts are preferred instruments to cope with price volatility (for instance in Heyder et al., 2010). The finding in Chapter 4 showed, however, that price-fixing contracts may not be attractive means to cope with price risk particularly if one is not able to secure such a contract for both inputs and outputs. The limited use of price-fixing contracts by food chain actors has implications for credit institutions that make loans conditional on chain actors' engagement in forward contract agreements with clients. It indicates that credit institutions should provide chain actors the flexibility to engage in contracts that do not fix prices. The limited preference for price fixing contracts arises from the difficulty of predicting prices by the chain actors (Chapter 4). In this regard, the provision of accurate, timely and detailed price predictions by financial consultancy companies is necessary.

The results reported in Chapter 6 have implications for insurance companies. Chapter 6 argues that the problem of adverse selection can be countered by insurance companies by calculating premium rates that vary across risk categories of farms. Risk categories of farms can be formed by predicting farmer's expected yields and yield variances based on the farms' input uses. Categorization of farms into risk groups can prevent risky farms from being undercharged and non-risky farms from being overcharged.

\subsection{Policy implications}

Price volatility becomes an issue of concern and requires policy support when it induces risk averse behaviour and leads to inefficient investment decisions (FAO et al., 2011) and when it becomes a threat to food security (Hernandez et al., 2013). In the EU agriculture, market measures under the CAP have traditionally kept market prices at high and stable levels (Bardaji et al., 2016; Tangermann, 2011). Since world trade agreements require a more liberalized agricultural market, current EU market measures focus more on indirect measures such fixed area payments aimed at stabilizing farm income instead of measures with direct impact on prices (Bardaji et al., 2016). Supporting private price volatility management initiatives of food chain actors can also qualify as a measure with limited distorting effect on prices and trade. Findings of this thesis suggest that farmers need policy support more than actors in the rest of the chain. The strategies that farmers currently use to deal with price volatility suggest that farmers have limited control over prices that they receive (Chapter 4). Examples of such strategies are postponing the timing of sales by Spanish tomato and German pig farmers and avoiding major investments and substituting expensive ingredients by Dutch dairy farmers (Chapter 4).

One area of policy support is the provision of farm extension services related to the use of futures contracts. In the case of German pig farmers for instance, although a futures market for pigs exist, farmers are reluctant to hedge because of the limited liquidity of these markets. Educating farmers on the benefits and mechanisms of trading in such markets can increase the liquidity of the markets and 
encourage farmers to hedge. Providing policy incentives to encourage farmers to join farmer producer organizations or cooperatives can be another area of policy support. Farmers who are member of these organizations can mobilize the financial capability needed to add value to their products through further processing and to concentrate supply and therefore build countervailing power vis-a-vis the downstream stages of the chain. A stronger market power in turn enables better negotiation of trade terms including prices during times of adverse price movements.

Extension services related to agricultural revenue insurance schemes are another area of policy support. The case of the Dutch ware potato sector investigated in Chapter 6 showed that revenue insurance premium rates for this sector are relatively high compared to those obtained for other sectors in other studies (e.g. in Ahmed and Serra, 2015). This shows that the opportunity for a natural hedge between prices and yields is limited in the Dutch ware potato sector. This highlights the need to take up a revenue insurance contract to cope with both price and yield risk. Since price and yield risks are systemic in nature, the provision of reinsurance by governments can also be another area of policy support to encourage private insurers to offer revenue insurance contracts to farmers.

The concept of excessive price volatility (or excess price deviation from expected levels) introduced earlier in this chapter is relevant when defining market interventions such as the management of food storage (i.e. keeping and release of stocks) to ensure food security. If properly defined, the level of excessive volatility can signal policy makers of when such policy interventions should take place. It may however be necessary to distinguish between excess volatility that needs a strategic action of food chain actors from the excess volatility that requires policy interventions, with the latter type being beyond the capability of chain actors to cope with.

The policy relevance of defining excess price volatility is well acknowledged in the literature (Badarji et al., 2011; FAO et al., 2011). It is argued that policy interventions are justified only when price volatility exceeds a certain threshold. Chapter 4 showed that even food chain actors implement coping strategies when price volatility (i.e. price deviation from an expected level) exceeds a certain threshold. It may therefore be necessary to distinguish the level of excess price volatility that can be coped with by food chain actors from the level of excess price volatility that needs policy intervention as these two levels may differ.

\subsection{Main conclusions}

The objective of this thesis was to investigate the transmission of price volatility and its management by food supply chains. The main conclusions are as follows:

- A largely ignored aspect in the agricultural economics literature is the effect of contextual factors such as the degree of market power and pricing strategies used in food supply chains on the degree of price volatility transmission (Chapter 2).

- German pork retailers use their market power to reduce the transmission of upstream (i.e. farm, slaughterhouse) price shocks to consumers (Chapter 3).

- Deviations of prices by more than 10 to $15 \%$ from expected levels are perceived as price volatility by food chain actors (Chapter 4 ).

- Strategies used by food chain actors to manage the risk from price volatility include not only traditional strategies such as future and forward contracts but also strategies such as 
the production of premium products, vertical and horizontal collaborations and strategies that involve the enhancement of productivity and cost efficiency (Chapter 4).

- While the selling forward contracts used by Spanish tomato wholesalers perform similar to the base scenario (i.e. no strategies) on all volatility measures, those used by French wheat processors result in prices that are more positively skewed and with a higher kurtosis than the base scenario (Chapter 5).

- The premium rate charged on guaranteed revenue per hectare to farms with a high expected yield (a high yield variance to expected yield ratio) are approximately $22 \%$ (34\% ) higher than the average premium rate calculated if all farms were in one pool. (Chapter 6).

- The market power of a chain actor increases if certain price volatility management strategies (e.g. merger among wholesalers) are implemented while the opportunity to implement some strategies (e.g. transmitting price shocks) increases if a chain actor has some degree of market power (Chapter 3 and 4).

- The extent of price volatility transmission in a food supply chain is the outcome of the degree of market power exercised and the price volatility management strategies implemented by food supply chain actors (Chapter 2, 3 and 4). 


\section{References}

Ahmed, O. and Serra, T. (2015). Economic analysis of the introduction of agricultural revenue insurance contracts in Spain using statistical copulas, Agricultural Economics, 46 (1), 69-79.

Alexandri, C. (2011). Analysis of price transmission along the agri-food chains in Romania. Agricultural Economics and Rural Development, 8(2), 171-189.

Apergis, N., and Rezitis, A. (2003). Agricultural price volatility spillover effects: The case of Greece. European Review of Agricultural Economics, 30(3), 389-406.

Bardaji, M., Garrido, A., Blanco, I., Felis, A., Sumpsi, J.M., Garcia-Azcarate, T., Enjolras, G. and Capitanio, F. (2016). State of play of risk management tools implemented by Member States during the period 2014-2020: National and European frameworks. Retrieved from http://www.europarl.europa.eu/RegData/etudes/STUD/2016/573415/IPOL_STU(2016)573415_EN.pd $\underline{\mathrm{f}}$.

Bergfjord, O.J. (2009). Risk perception and risk management in Norwegian aquaculture. Journal of Risk Research, 12 (1), 91-104.

Bielza, M., Stroblmair, J. and Gallego, J. (2007). Agriculural risk management in Europe. Paper prepared for presentation at the 101st EAAE Seminar on management of climate risks in agriculture, Berlin, Germany.

Brümmer, B., Korn, O., Schlüßler, K. and Jamali Jaghdani, T. and Saucedo, A (2013). Volatility in the after crisis period - A literature review of recent empirical research (ULYSSES Working Paper 1).

Retrieved from http://www.fp7-

ulysses.eu/publications/ULYSSES\%20Working\%20Paper\%201_Volatility\%20in\%20the\%20after\%20 crisis\%20period $\% 20 \% \mathrm{E} 2 \% 80 \% 93 \% 20 \mathrm{~A} \% 20$ literature\%20review\%20of\%20recent $\% 20$ empirical\%20r esearch.pdf.

Chavas, J.P. (1999). On the economic rationality of market participants: The case of expectations in the U.S. pork market. Journal of Agricultural and Resource Economics, 24 (1), 19-37.

Digal, L.N. and Ahmadi-Esfahani, F.Z. (2002). Market power analysis in the retail food industry: a survey of methods. The Australian Journal of Agricultural and Resource Economics, 46 (4), 559-584.

FAO, IFAD, IMF, OECD, UNCTAD, WFP, the World Bank, the WTO, IFPRI and the UN HLTF (2011). Price volatility in food and agricultural markets: policy responses. Retrieved from http://www.oecd.org/dataoecd/40/34/48152638.pdf.

Goodwin, B.K. and Hungerford, A. (2014). Copula-Based Models of Systemic Risk in U.S. Agriculture: Implications for Crop Insurance and Reinsurance Contracts, American Journal of Agricultural Economics, 97(3), 879-896.

Greinier, R., Patterson, R., and Miller, O. (2009). Motivations, risk perceptions, and adoption of conservation practices by farmers. Agricultural systems, 99 (2), 86-104.

Hall, D.C., Knight, T.O., Coble, K.H., Baquet, A.E., and Patrick, G.F. (2003). Analysis of beef producers' risk management perceptions and desire for further risk management education. Review of Agricultural Economics, 25(2), 430-448. 
Hernandez, M.A., Ibarra, R., and Trupkin, D.R. (2013). How far do shocks move across borders? Examining volatility transmission in major agricultural futures markets. European Review of Agricultural Economics, 41(2), 1-25.

Heyder, M., Theuvsen, L., and Von Davier, Z. (2010). Strategies for coping with uncertainty: The adaptation of food chains to volatile markets. Journal on Chain and Network Sciences, 10(1), 17-25.

Huchet-Bourdon, M. (2011). Agricultural Commodity Price Volatility (OECD Working Papers No. 52). Retrieved from http://www.oecd-

ilibrary.org/docserver/download $/ 5 \mathrm{~kg} 0 \mathrm{t} 00 \mathrm{nrthc} . \mathrm{pdf}$ ?expires=1471440885\&id=id\&accname=guest\&che cksum=D24095030055E7E8CF2B15DD886839AD .

Just, R.E. and Pope, R.R. (1978). Stochastic specification of production functions and economic implications. Journal of econometrics, 7(1), 67-86.

Khan, M.A.,and Helmers,G.A.(1997).Causality, input price variability and structural changes in theU.S. livestock-meat industry. Paper submitted to the western agricultural economics association meeting, Reno, Nevada.

Khiyavi, P.K., Moghaddasi, R., Eskandarpur, B., and Mousavi, N. (2012). Spillover effects of agricultural products price volatilities in Iran. Journal of Basic and Applied Scientific Research, 2(8), 7906-7914.

Knutson, R.D., Smith, E.G., Anderson, D.P., and Richardson, J.W. (1998). Southern farmers' exposure to income risk under the 1996 farm bill. Journal of Agriculture and Applied Economics, 30(1), 35-46.

Lee, C. (2007). SCP, NEIO and beyond (Working Paper Series Vol. 2007-05). Retrieved from http://www.agi.or.jp/7publication/workingpp/wp2007/2007-05.pdf .

Manfredo, M., Richards and McDermott (2003). Risk management techniques for agricultural cooperatives: An empirical evaluation. Paper presented at the NCR-134 conference on applied commodity price analysis, forecasting, and market risk management, St. Louis, Missouri.

Martin, S. (1996). Risk management strategies in New Zealand agriculture and horticulture. Review of Marketing and Agricultural Economics, 64(1), 31-44.

Meyer, J., and von Cramon-Taubadel, S. (2004). Asymmetric price transmission: A survey. Journal of Agricultural Economics, 55(3), 581-611.

Meuwissen, M.P.M, Huirne, R.B.M., and Hardaker, J.B. (2001). Risk and risk management: An empirical analysis of Dutch livestock farmers. Livestock Production Science, 69 (1), 43-53.

Meuwissen, M.P.M., Van Asseldonk, M., Peitola, K., Hardaker, B. and Huirne, R. (2011). Income insurance as a risk management tool after 2013 CAP reforms? Paper prepared for presentation at the EAAE 2011 Congress on change and uncertainty, challenges for agriculture, food and natural resources, Zurich, Switzerland.

Natcher, W.C., and Weaver, R. (1999). The transmission of price volatility in the beef market: A multivariate approach. Paper selected for presentation at the American Agricultural Economics Association annual meeting, Nashville, Tennessee. 
Neyhard, J., Tauer, L. and Gloy, B. (2013). Analysis of price risk management strategies in dairy farming using whole-farm simulations. Journal of Agricultural and Applied economics, 42 (2), 313327.

Patrick, G.R., Wilson, P.N., Barry, P.J., Boggess, W.G., and Young, D.L. (1985). Risk perceptions and management responses: Producer-generated hypotheses for risk modelling. Southern Journal of Agricultural Economics, 17(2), 231-238.

Rezitis, A.N. (2012). Modelling and decomposing price volatility in the Greek meat market. International Journal of Computational Economics and Econometrics, 2(3-4), 1757-1189.

Serra, T. (2011). Food scares and price volatility: The case of the BSE in Spain. Food policy, 36(2), 179-185.

Severini, S. and Cortignani, R. (2011). Modeling farmer participation to a revenue insurance scheme by means of positive mathematical programming. Paper prepared for presentation at the EAAE 2011 congress on change and uncertainty challenges for agriculture, food and natural resources, Zurich, Switzerland.

Sexton, R.J. and Zhang, M. (2001). An assessment of the impact of food industry market power on U.S. consumers. Agribusiness, 17(1), 59-79.

Tangermann, S. (2011). Risk management in agriculture and the future of the EU's Common Agricultural Policy. Retrieved from http://ictsd.org/downloads/2011/12/risk-management-inagriculture-and-the-future-of-the-eus-common-agricultural-policy.pdf.

Taya, S. (2012). Stochastic model development and price volatility analysis ( OECD food, agricultural and fisheries working papers No. 57). OECD publishing.

Thille, H. (2006). Inventories, market structure, and price volatility. Journal of Economic Dynamics and Control, 30 (7), 1081-1104.

Uchezuba, I.D., Jooste, A., and Willemse, J. (2010). Measuring asymmetric price and volatility spillover in the

South African broiler market. Retrieved in June 2013 from http://ageconsearch.umn.edu/bitstream/96434/

2/179briol.pdf.

Van Asseldonk, M.A., Kuiper, W.E and Huirne, R.B. (2000). Classical swine fever epidemic and price volatility. Proceedings of the $9^{\text {th }}$ international symposium on veterinary epidemiology and economics, Breckenridge, Colorado, USA.

Verreth, D.M.I., Emvalomatis, G., Bunte, F., Kemp, R. and Oude Lansink, A.G.J.M. (2015). Price Transmission, International Trade, and Asymmetric Relationships in the Dutch Agri-Food Chain. Agribusiness, 31 (4), 521-542.

Wilson, P.N., Luginsland, T.R., and Armstrong, D.V. (1987). Risk perceptions and management responses of Arizona dairy producers. Dairy Science, 71 (2), 545-551.

Zheng, Y., Kinnucan, H.W., and Thompson, H. (2008). News and volatility of food prices. Applied Economics, 40(13),1629-1635. 
Zhu, Y., Ghosh, S.K. and Goodwin, B.K. (2008). Modelling dependence in the design of whole farm insurance contract. Selected paper prepared for presentation at the American agricultural economics association annual meeting, Orlando, Florida. 


\section{Summary}

The 2006-2011 period has been marked by increased volatility in food an agricultural commodity prices at a global level. Several factors contributed to the rise of price volatility. Demand booming factors such as economic growth, shifting dietary patterns in developing countries and growth of the biofuel industry, and supply slowing factors such as the weak transfer of market price signals to farmers are attributed to the rise in food price volatility. Prices in the EU agricultural market have traditionally been kept stable with market measures under the CAP such as border protection through import barriers, export subsidies, production quotas and intervention. Nevertheless, the mounting pressure of such market interventions on the EU budget and the increasing tensions with the EU's trading partners have led to CAP reforms that gradually shifted the policy from market interventions to decoupled single farm payments and opened up the EU to international markets. The liberalization of the EU market has in turn exposed EU farmers to price shocks in global agricultural markets. Although a decade has passed since the 2006/07 food crisis, the agricultural sector of the EU is still susceptible to price volatility owing to the increased liberalization of the sector. Market interconnectedness along food supply chains assures that price volatility originating at one stage of the chain is transmitted along the chain thereby exposing all chain actors to risk and uncertainty. If left unmanaged, price volatility can have harmful impacts on investment, production and other business decisions of food chain actors.

The overall objective of this thesis is to investigate the transmission and management of price volatility in food supply chains. Five sub-objectives follow from the main objective. These are to 1) review the existing price volatility transmission literature in food supply chains and identify the research gaps, 2) investigate the effect of market power on price volatility transmission in a food supply chain, 3) explore price volatility perceptions and management strategies of actors in food supply chains, 4) design a method for evaluating the effectiveness of price volatility management strategies in reducing the price volatility faced by food supply chain actors, and to 5) calculate premium rates of an agricultural revenue insurance contract by taking into account the risk heterogeneity of farms.

Chapter 2 reviews the previous literature on price volatility transmission in food supply chains. The review first illustrates the definitional and methodological differences between price transmission and price volatility transmission in food chains. The review then explores methods adopted to investigate price volatility transmission and the data used. It then identifies the research gaps in previous literature and suggests improvements for further research. One of the gaps identified in the reviewed literature is the lack of attention given to the effects of contextual factors on price volatility transmissions in food supply chains. Contextual factors include market power in the chain and pricing strategies (e.g. contracts) by chain actors. Although the reviewed literature acknowledges that such factors can have an effect on price volatility transmission in the chain, such effects are not investigated to date, neither theoretically nor empirically.

Chapter 3 addresses a gap identified in the previous literature by investigating the effect of market power both on price transmission and price volatility transmission in the German fresh pork chain. Theoretical models of price transmission and price volatility transmission are first developed to theoretically link both types of transmission with market power. Market power is measured using the conjectural variation approach. The theoretical models are then used to empirically estimate price transmission and price volatility transmission in the German fresh pork chain. A vector error correction model and least square regressions are used for the empirical estimations. Monthly farm, 
slaughterhouse and retail pork prices for the period 2000-2010 were used for the empirical application. Results show that retail market power limited both types of transmissions. Competition inducing policy measures coupled with measures that support price risk management initiatives of chain actors are encouraged to protect chain actors from possible squeezes in margins resulting from the nontransmission of predictable and non-predictable price changes.

Chapter 4 explores price volatility perceptions and management strategies of food chain actors by conducting interviews with forty-two actors in six EU food supply chains (i.e. Dutch cheese, Dutch tomatoes, Spanish tomatoes, French wheat, Bulgarian wheat and German pork). Price volatility perceptions are explored by asking chain actors on percentage price deviations from expected levels which they perceived as price volatility. Actors are then asked about the strategies they use to deal with price volatility. Results show that deviations of prices by more than 10 to $15 \%$ from expected levels were perceived as price volatility by a majority of the chain actors. Results further show that price volatility management strategies in EU food chains are diverse and well beyond traditional instruments such as futures and forward contracts

Chapter 5 outlines a method to evaluate the effectiveness of price volatility management in food supply chains. The presented method proposes a way to remove the effects of market power in the chain when evaluating the effectiveness of strategies in food supply chains. The method uses the percentage price deviations defined in Chapter 4 to define triggers of strategy implementation of food chain actors. Strategies identified in Chapter 4 for the Spanish tomato and French wheat farmers and wholesalers are used to illustrate the presented method. Weekly farm and wholesale tomato prices and monthly farm and wholesale wheat prices for the period January 2005 to December 2014 were used for the illustrations.

Chapter 6 calculates premium rates of a revenue insurance contract for Dutch ware potato farmers. Premium rates are calculated by categorizing farms based on their expected yields and yield variances. These two measures are used because they affect farmers' likelihood of losses and therefore determine farmers' risk levels. Farmers' categorization can in turn help to reduce the problem of adverse selection. Four categories were identified: Farms with high expected yields, low expected yields, high yield variance to expected yield ratios and low yield variance to expected yield ratios. Expected yields and yield variances are predicted by estimating a Just-Pope production function. To simulate the premium rates, the dependence between prices and yields is modelled using copulas. Results show that the Gaussian copula which best represented the dependencies between prices and yields results in premium rates of $32.1 \%, 22.2 \%, 33.1 \%$ and $24.0 \%$ on guaranteed revenue per hectare for the high expected yield, low expected yield, high yield variance to expected yield ratio and low yield variance to expected yield ratio categories, respectively. The difference in premium rates across categories of farms implies that charging the same average premium rate to all Dutch ware potato farms can lead to adverse selection.

Chapter 7 synthesizes the results and reflects on the data and methods used in the different chapters. The chapter synthesizes results related to two key issues addressed in this thesis. These are the transmission of price volatility in food supply chains and the management of price volatility by food supply chain actors. The relationship between these two key issues is also discussed. Results in Chapter 2 and 3 suggest that price volatility transmission may not necessarily imply the transmission of price levels in the chain, and vice versa. The results in Chapter 3 further suggested that the degree of retail market power reduces the transmission of farm price shocks while enhancing the transmission of consumer price shocks. Chapter 4 and 5 showed that price volatility does not necessarily result in the implementation of price volatility management strategies. That is, food chain actors perceive price 
volatility as risky and therefore implement coping strategies not simply because observed prices have deviated from their expected levels but also because the price deviation exceeds a certain threshold, persist for a certain period of time and are caused by factors other than speculation (Chapter 4). Furthermore, the implementation of a strategy depends on the cost of the strategy, the chain actor's risk attitude, the price volatility the chain actor would face if a strategy is implemented and the volume traded (Chapter 5). Whether margins remain stable also matters to decide on the implementation of a strategy (Chapter 4). A two-way relationship between strategies and the degree of market power is highlighted in Chapter 7. That is, the market power of a chain actor increases if certain price volatility management strategies are implemented (Chapter 4) while the opportunity to implement some strategies increases if a chain actor has some degree of market power (Chapter 3). A number of strategies identified in Chapter 4 can have an effect on the degree of price volatility transmission. Price volatility transmission can also affect the choice of strategies (Chapter 4). Based on the findings of this thesis, the following main conclusions can be drawn:

- A largely ignored aspect in the agricultural economics literature is the effect of contextual factors such as the degree of market power and pricing strategies used in food supply chains on the degree of price volatility transmission (Chapter 2).

- German pork retailers use their market power to reduce the transmission of upstream (i.e. farm, slaughterhouse) price shocks to consumers (Chapter 3 ).

- Deviations of prices by more than 10 to $15 \%$ from expected levels are perceived as price volatility by food chain actors (Chapter 4 ).

- Strategies used by food chain actors to manage the risk from price volatility include not only traditional strategies such as future and forward contracts but also strategies such as the production of premium products, vertical and horizontal collaborations and strategies that involve the enhancement of productivity and cost efficiency (Chapter 4).

- While the selling forward contracts used by Spanish tomato wholesalers perform similar to the base scenario (i.e. no strategies) on all volatility measures, those used by French wheat processors result in prices that are more positively skewed and with a higher kurtosis than the base scenario (Chapter 5).

- The premium rate charged on guaranteed revenue per hectare to farms with a high expected yield (a high yield variance to expected yield ratio) are approximatively $22 \%$ $(34 \%)$ higher than the average premium rate calculated if all farms were in one pool. (Chapter 6).

- The market power of a chain actor increases if certain price volatility management strategies are implemented (e.g. merger among wholesalers) while the opportunity to implement some strategies (e.g. transmitting price shocks) increases if a chain actor has some degree of market power (Chapter 3 and 4).

- The extent of price volatility transmission in a food supply chain is the outcome of the degree of market power exercised and the price volatility management strategies implemented by food supply chain actors (Chapter 2, 3 and 4). 


\section{Acknowledgements}

Finally, it's done! Doing a $\mathrm{PhD}$ has been a long journey in which I grew both on personal and academic levels. For this, several people deserve credit and should be acknowledged.

Alfons, thank you for being a great mentor to me! I have always admired how quickly you came up with solutions whenever I got stuck with econometric and other research related problems. Your solutions gave me great relief at least until I faced yet another challenge. Although sometimes I find myself resisting to suggestions that you make, these suggestions have always ended up in greatly improving my work. I would also like to thank you for believing in my potentials, a belief you expressed in one way or another.

Miranda, our journey together goes back even before the start of my $\mathrm{PhD}$. The day you told me that your project (ULYSSES) was granted funding and that you accepted me as your PhD student in the project was one of the happiest day of my life. I am extremely grateful for the great opportunity you gave me not only to advance my career but also to visit so many countries, a wish I had since childhood. Your way of mentoring has taught me to be an independent researcher and a researcher who is always cautious about the practical implications of research results. On a more personal level, I will never forget the laughs we had during our trips together to various ULYSSES meetings. Miranda, thank you for believing in me!

This thesis could not have been successfully completed without the guidance of Koos Gardebroek, Barry Goodwin, Alberto Garrido and other team members of ULYSSES. Koos, although your 'Dutch' (straight forward) comments scared me sometimes, they were in fact great motivators to work harder on my article. So, thank you for your bold comments. Barry, thank you for making time for me in your busy schedule. I greatly appreciate the hands-on approach you took to guide me through your R codes and your prompt responses to the questions I sent through emails. Alberto, thank you for your friendly approach during our ULYSSES meetings and your words of encouragement when commenting on our ULYSSES deliverables. I would like to thank the other team members of ULYSSES for your constructive comments during ULYSSES presentations and your collaboration in providing secondary data (Especially Kristina) as well as giving the necessary contact addresses when collecting primary data.

Thankfully, my $\mathrm{PhD}$ journey was not only about writing my thesis and journal articles but was also an opportunity to make new friends with whom I have spent memorable times. For this, the friends I made in the BEC group (Ngoc, Eliana, Frazen, Beshir, Laya, Lien, Nurul, Daniel, Dikky, Ewaldus, Simon, Wudu, Tariku, Monica, Juliet) should take the credit. Ngoc, a special thanks goes to you because you have been my closest and truest friend throughout my $\mathrm{PhD}$. We have supported each other through all the struggles that being a PhD student brought to us, and now that I think back, I think that my $\mathrm{PhD}$ journey would have been so much less enjoyable if you were not there. I particularly will not forget the tremendous amount of time we spent together shopping, both online and in stores (I wonder how much money we spent in the past four years). Eliana, thank you for being such a nice office mate. Chatting with you in between work times was always a stress reliever. Beshir, thank you for being both a friend and an advisor. Our heated econometric and economics related discussions have always given me ideas on how to improve my work. Laya, although our friendship is only a recent one, I now wish you had started your $\mathrm{PhD}$ much earlier so that we could have spent more 
memorable times together. Frazen, thank you for the bright face you show everyday showing me that one can keep smiling in spite of the stress that doing a $\mathrm{PhD}$ entails.

Being away from by beloved home country Ethiopia was not easy. But fortunately, I got to feel at home thanks to my dear Ethiopian friends at WUR (Banchi, Meknay, Alemtsehay Ferede, Kali, Mahi, Mahdi, Wossen, Saba, Yenenesh, Netsi, Engu, Eske, Abiy). Thank you for the great get-togethers we had on weekends. These have been a great boost of energy and motivation for the weekdays. Mekwanent, Beshir, Yalem, Belay, Abay, Abex, Worku, thank you for the enjoyable times we spent during afternoon coffee breaks. My two long-time dear friends Alemtsehay Jima and Ayni who always gave me their support although far away from WUR deserve my heartfelt thank you! Alemtsi, thank you for your friendship and your firm belief that I will have a successful career. Your belief kept me going throughout my $\mathrm{PhD}$ journey.

Although the following few lines of words cannot adequately describe the gratefulness I feel towards my parents (Kuku and Ababa) and my sister (Smoothie), I still would like to put forward the following words of my most heartfelt acknowledgements. Kukuye yemewedesh enate, thank you for being the most amazing mother I could ever wish for! I can say without the slightest doubt in my mind that, hadn't it been for your endless love and support, I would not have completed my PhD. Thank you for your endless love. Ababa, you are simply my role model. I learned to be a hardworking, a completely dedicated, committed, and responsible person from you. Thank you for your patient guidance and love. Smoothie, you simply spiced up my PhD journey. I sometimes even fear that I would be out of breath and die of laughter due to our little comic, imaginative world we created and your creative, quite intelligent jokes. Thank you for letting me escape from the not-so-fun $\mathrm{PhD}$ journey once in a while. I dedicate this thesis to my parents and my sister. 


\section{Curriculum Vitae}

Tsion Taye Assefa was born on October 2, 1985 in Addis Abeba, Ethiopia. In 2002, she finished high school in Lycee Guebre Mariam in Addis Abeba. In the same year, she joined Mekelle University where she did her Bachelor in Accounting and Finance. Once completing her Bachelor, she got a job as an assistant lecturer in Mekelle University. In 2008, she started her Masters in Finance and Investment in Mekelle University which she completed in 2010. In the same year, she started her second Msc in Wageningen University which she completed in 2012 with specialization in business economics.

In 2012, she started her PhD in the business economics group. She worked in the EU project entitled ULYSSES on food price volatility in food supply chains. During her PhD study, she took economics related courses, supervised the thesis and assisted in practicals of Msc students. She also was a visiting scholar in North Carolina State University in the USA for a period of 3 months (September November, 2016). 


\section{Education certificate}

Tsion Taye Assefa

Wageningen School of Social Sciences (WASS)

Completed Training and Supervision Plan

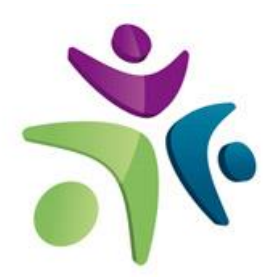

Wageningen School

of Social Sciences

\begin{tabular}{|c|c|c|c|}
\hline Name of the learning activity & Department/Institute & Year & ECTS* \\
\hline \multicolumn{4}{|l|}{ A) Project related competences } \\
\hline Advanced Micro Economics, ECH 32306 & Wageningen University & 2012 & 6 \\
\hline $\begin{array}{l}\text { Organization of the Agribusiness, } \\
\text { BEC } 31306\end{array}$ & Wageningen University & 2012 & 6 \\
\hline Decision science 2, ORL 30306 & Wageningen University & 2013 & 6 \\
\hline Advanced Econometrics, AEP 60306 & Wageningen University & 2013 & 6 \\
\hline \multicolumn{4}{|l|}{ B) General research related competences } \\
\hline Introduction course & WASS & 2012 & 1 \\
\hline $\mathrm{PhD}$ thesis proposal & $\mathrm{BEC}$ & 2012 & 6 \\
\hline $\begin{array}{l}\text { 'The impacts of food price volatility on the } \\
\text { sourcing and selling strategies of food and } \\
\text { agricultural companies in the European } \\
\text { Union' }\end{array}$ & $\begin{array}{l}\text { 140th EAAE Seminar, } \\
\text { Perugia, Italy }\end{array}$ & 2013 & 1 \\
\hline $\begin{array}{l}\text { 'Price volatility transmission in selected } \\
\text { European food supply chains' }\end{array}$ & $\begin{array}{l}\text { 133rd EAAE Seminar, } \\
\text { Chania, Greece }\end{array}$ & 2013 & 1 \\
\hline $\begin{array}{l}\text { 'Food scares and price volatility: the case } \\
\text { of German and Spanish pig chains' }\end{array}$ & $\begin{array}{l}29^{\text {th }} \text { Int. Conference of } \\
\text { agricultural economists } \\
\text {, Milan, Italy }\end{array}$ & 2015 & 1 \\
\hline $\begin{array}{l}\text { 'Does price volatility matter? An assessment } \\
\text { along EU food chains' }\end{array}$ & $\begin{array}{l}\text { 29th Int. Conference of } \\
\text { agricultural economists, } \\
\text { Milan, Italy }\end{array}$ & 2015 & 1 \\
\hline \multicolumn{4}{|c|}{ C) Career related competences/personal development } \\
\hline $\begin{array}{l}\text { Techniques for writing and presenting a } \\
\text { scientific paper }\end{array}$ & WGS & 2012 & 1.2 \\
\hline $\begin{array}{l}\text { The Empirics of Economic Organizations } \\
\text { in Agri-Food Systems }\end{array}$ & $\begin{array}{l}\text { University of Perugia, } \\
\text { Italy }\end{array}$ & 2013 & 1 \\
\hline $\begin{array}{l}\text { Teaching (Advanced Financial and } \\
\text { Business Management, Practicals) }\end{array}$ & BEC, WUR & $2013 / 2016$ & 1 \\
\hline $\begin{array}{l}\text { Bsc (1 student) and Msc (2 students) thesis } \\
\text { supervision }\end{array}$ & BEC, WUR & $2013 / 2014 / 2015$ & 2 \\
\hline Total & & & 40.2 \\
\hline
\end{tabular}

*One credit according to ECTS is on average equivalent to 28 hours of study load 